\title{
Recommandations pratiques pour le diagnostic et la prise en charge de la fibrose pulmonaire idiopathique - Actualisation 2017. Version longue
}

French practical guidelines for the diagnosis and management of idiopathic pulmonary fibrosis. 2017 update. Full-length update

\author{
V. Cottin ${ }^{\mathrm{a}, *, 1}$, B. Crestani ${ }^{\mathrm{b}}$, J. Cadranel $^{\mathrm{c}}$, \\ J.-F. Cordier ${ }^{a}$, S. Marchand-Adam ${ }^{d}$, G. Prévot ${ }^{e}$, \\ B. Wallaert ${ }^{f}$, E. Bergot ${ }^{\mathrm{g}}$, P. Camus ${ }^{\mathrm{h}}$, J.-C. Dalphin ${ }^{\mathrm{i}}$, \\ C. Dromer ${ }^{\mathrm{j}}, \mathrm{E}$. Gomez ${ }^{\mathrm{k}}$, D. Israel-Biet ${ }^{\text {, }}$, \\ S. Jouneau ${ }^{\mathrm{m}}$, R. Kessler ${ }^{\mathrm{n}}, \mathrm{C} .-\mathrm{H}$. Marquette ${ }^{\circ}$, \\ M. Reynaud-Gaubert ${ }^{p}, B$. Aguilaniu ${ }^{q}$, D. Bonnet ${ }^{r}$, \\ P. Carré ${ }^{\mathrm{s}}$, C. Danel $^{\mathrm{t}}$, J.-B. Faivre ${ }^{\mathrm{u}}$, G. Ferretti $^{\mathrm{v}}$, \\ N. Just ${ }^{w}$, F. Lebargy ${ }^{x}$, B. Philippe ${ }^{y}$, P. Terrioux ${ }^{z}$, \\ F. Thivolet-Béjui ${ }^{\mathrm{aa}}, \mathrm{B}$. Trumbic ${ }^{\mathrm{ab}}, \mathrm{D}$. Valeyre ${ }^{\mathrm{ac}}$
}

\footnotetext{
a Centre national de référence des maladies pulmonaires rares, pneumologie, hôpital Louis-Pradel, hospices civils de Lyon, université Claude-Bernard-Lyon 1, Lyon, France

b Service de pneumologie A, centre de compétences pour les maladies pulmonaires rares, $\mathrm{CHU}$ Bichat, université Paris Diderot, Paris, France

' Service de pneumologie et oncologie thoracique, centre de compétences pour les maladies pulmonaires rares, hôpital Tenon, université Pierre-et-Marie-Curie, Paris 6, GH-HUEP, Assistance publique-Hôpitaux de Paris, Paris, France

d Service de pneumologie, centre de compétences pour les maladies pulmonaires rares, CHU de Tours, Tours, France

e Service de pneumologie, centre de compétences pour les maladies pulmonaires rares, CHU Larrey, Toulouse, France
}

\footnotetext{
* Auteur correspondant.

Adresse e-mail : vincent.cottin@chu-lyon.fr (V. Cottin).

1 www.maladies-pulmonaires-rares.fr.
} 
f Service de pneumologie et immuno-allergologie, centre de compétences pour les maladies pulmonaires rares, hôpital Calmette, CHRU de Lille, Lille, France

' Service de pneumologie et oncologie thoracique, centre de compétences pour les maladies pulmonaires rares, $\mathrm{CHU}$ de Caen, Caen, France

h Service de pneumologie et oncologie thoracique, centre de compétences pour les maladies pulmonaires rares, CHU Dijon-Bourgogne, Dijon, France

i Service de pneumologie, allergologie et oncologie thoracique, centre de compétences pour les maladies pulmonaires rares, hôpital Jean-Minjoz, CHRU de Besançon, Besançon, France j Service de pneumologie, centre de compétences pour les maladies pulmonaires rares, hôpital Haut-Lévèque, CHU de Bordeaux, Bordeaux, France

${ }^{k}$ Département de pneumologie, centre de compétences pour les maladies pulmonaires rares, CHU de Nancy, Vandouvre-lès-Nancy, France

' Service de pneumologie, centre de compétences pour les maladies pulmonaires rares, hôpital européen Georges-Pompidou, université Paris-Descartes, Paris, France

$\mathrm{m}$ Service de pneumologie, centre de compétences pour les maladies pulmonaires rares, $\mathrm{CHU}$ de Rennes, IRSET UMR 1085, université de Rennes 1, Rennes, France

n Service de pneumologie, centre de compétences pour les maladies pulmonaires rares, hôpital civil, CHU de Strasbourg, Strasbourg, France

- Service de pneumologie, centre de compétences pour les maladies pulmonaires rares, CHU de Nice, FHU Oncoage, université Côte d'Azur, France

P Service de pneumologie, centre de compétence des maladies pulmonaires rares, CHU Nord, Marseille, France

q Université Grenoble-Alpes, Grenoble, France

r Service de pneumologie, centre hospitalier de la Côte-Basque, Bayonne, France

s Service de pneumologie, centre hospitalier, Carcassonne, France

t Département de pathologie, hôpital Bichat-Claude-Bernard, université Paris Diderot, Assistance publique-Hôpitaux de Paris, Paris 7, Paris, France

u Service d'imagerie thoracique, hôpital Calmette, CHRU de Lille, Lille, France

$\checkmark$ Clinique universitaire de radiologie et imagerie médicale, CHU Grenoble-Alpes, Grenoble, France

w Service de pneumologie, centre hospitalier Victor-Provo, Roubaix, France

x Service des maladies respiratoires, CHU Maison-Blanche, Reims, France

y Service de pneumologie, centre hospitalier René-Dubos, Pontoise, France

z Service de pneumologie, centre hospitalier de Meaux, Meaux, France

aa Service d'anatomie et cytologie pathologiques, hôpital Louis-Pradel, Lyon, France

ab Cap Evidence, Paris, France

ac Service de pneumologie, centre de compétences pour les maladies pulmonaires rares, hôpital Avicenne, CHU Paris-Seine-Saint-Denis, Bobigny, France

\section{Introduction}

La fibrose pulmonaire idiopathique (FPI) est la forme la plus fréquente de pneumopathie interstitielle diffuse (PID) idiopathique chronique chez l'adulte. Il s'agit d'une maladie fibroproliférative, irréversible, de cause inconnue, dont l'évolution est habituellement progressive, survenant principalement à partir de 60 ans et limitée aux poumons. Qualifiée de maladie orpheline notamment en raison de l'absence de traitement ayant fait la preuve formelle de son efficacité jusqu'à une période très récente, la FPI est une maladie rare dont la prévalence a été évaluée aux États-Unis entre 14 et 28/100 000 personnes [1], ce qui correspondrait à un minimum de 9000 patients en France et une incidence entre 6,8 et $9 / 100000$ par an [1,2], soit un minimum de 4400 nouveaux patients par an en France.

L'organisation du diagnostic et de la prise en charge de la FPI, en France, repose sur un Centre national de référence pour les maladies pulmonaires rares et des Centres régionaux de compétences dans le cadre du Plan national maladies rares.

Depuis la publication en 2011 de recommandations internationales sur le diagnostic et la prise en charge de la FPI [3], et la publication des précédentes recommandations françaises [4], de nouvelles données ont été publiées notamment sur l'efficacité et la tolérance de certains traitements proposés pour modifier l'évolution de la maladie ou utilisés à titre symptomatique. Le présent travail vise à proposer aux médecins un document synthétisant les données 


\begin{tabular}{ll} 
Tableau 1 & Liste des acronymes. \\
\hline CBP & Cancer bronchopulmonaire \\
CVF & Capacité vitale forcée \\
DLCo & Capacité de diffusion du monoxyde de carbone \\
ECMO & Oxygénothérapie extracorporelle par \\
& membrane \\
ECR & Essai contrôlé randomisé \\
EFR & Explorations fonctionnelles respiratoires \\
FPI & Fibrose pulmonaire idiopathique \\
HP & Hypertension pulmonaire \\
HR & Hazard ratio \\
IC 95 & Intervalle de confiance à 95 \% \\
LBA & Lavage broncho-alvéolaire \\
NAC & N-acétylcystéine \\
PHS & Pneumopathie d'hypersensibilité \\
PIC & Pneumopathie interstitielle commune \\
PID & Pneumopathie interstitielle diffuse \\
PINS & Pneumopathie interstitielle non spécifique \\
RGO & Reflux gastro-esophagien \\
SAOS & Syndrome d'apnées obstructives du sommeil \\
SEF & Syndrome d'emphysème et fibrose pulmonaires \\
& combinés \\
SPLF & Société de pneumologie de langue française \\
SSP & Survie sans progression \\
TM6 & Test de marche de six minutes \\
&
\end{tabular}

actuellement disponibles, et à définir en termes aussi clairs que possible et adaptés à la réalité de la pratique quotidienne les modalités de diagnostic et de prise en charge de la FPI.

La liste des acronymes utilisés de façon répétée dans ce texte figure dans le Tableau 1.

\section{Méthodes}

\section{Responsabilité des groupes}

Ce document rédigé par des spécialistes français de la FPI est une mise à jour des recommandations françaises sur le diagnostic et la prise en charge de la FPI publiées en 2013, fondée sur l'analyse critique de la littérature publiée ultérieurement dans ce domaine. Il résulte du travail d'un groupe de coordination, d'un groupe de rédaction, et d'un comité de lecture constitués à cette occasion.

Le document a été rédigé en respectant les règles d'élaboration des «Bonnes pratiques cliniques» selon la méthode des «Recommandations pour la pratique clinique » de la Haute Autorité de santé [5].

Le groupe de coordination a eu pour missions de soumettre le protocole d'élaboration et de validation auprès de la Société de pneumologie de langue française (SPLF) et de la Revue des maladies respiratoires (RMR), de réaliser une revue systématique et une synthèse de la littérature, de préparer une première version du document pour le groupe de rédaction, d'organiser et veiller au bon déroulement du protocole d'élaboration et de validation et de soumettre les recommandations validées par le groupe de rédaction et le comité de lecture à la SPLF et à la RMR pour publication.

Le groupe de rédaction a eu pour missions d'évaluer la première version du document élaborée par le groupe de coordination, d'apprécier à l'aide d'une échelle (« d'accord », «j'hésite », « pas d'accord »), d'identifier les points à retravailler, de proposer des suggestions sur la forme et sur le fond, et de valider le document à soumettre au comité de lecture.

Le comité de lecture, constitué de 2 pneumologues exerçant en CHU (à l'exclusion des centres de compétences), 3 pneumologues exerçant en centre hospitalier général, 2 pneumologues exerçant en secteur privé, 2 radiologues spécialisés et 2 anatomopathologistes spécialisés en pathologie thoracique, a eu pour mission d'apprécier à l'aide d'une échelle de 1 (désaccord total) à 9 (accord total) l'ensemble des thématiques abordées et des recommandations correspondantes dans le document soumis par le groupe de coordination. Le vote a été conduit par voie électronique, l'analyse des votes étant conduite de façon anonyme. Une proposition de recommandation figure dans le texte des recommandations soumis à l'avis du comité de lecture si elle a obtenu l'approbation d'au moins $80 \%$ des membres du groupe de rédaction. La cotation devait être fondée sur la synthèse des données publiées dans la littérature (jointe au questionnaire) et sur l'expérience du lecteur dans le domaine abordé. Les membres du comité de lecture pouvaient ne répondre qu'aux parties du questionnaire qui relevaient de leur compétence.

\section{Composition des groupes}

Groupe de coordination : V. Cottin (Lyon), J. Cadranel (Paris), J.-F. Cordier (Lyon), B. Crestani (Paris), S. MarchandAdam (Tours), G. Prévot (Toulouse), D. Valeyre (Bobigny), B. Wallaert (Lille).

Groupe de rédaction : élargi aux autres responsables des centres de compétences des maladies pulmonaires rares : V. Cottin (Lyon), J. Cadranel (Paris), J.-F. Cordier (Lyon), B. Crestani (Paris), S. Marchand-Adam (Tours), G. Prévot (Toulouse), D. Valeyre (Bobigny), B. Wallaert (Lille), E. Bergot (Caen), P. Camus (Dijon), C. Dromer (Bordeaux), J.-C. Dalphin (Besançon), E. Gomez (Nancy), D. Israel-Biet (Paris), S. Jouneau (Rennes), R. Kessler (Strasbourg), C.H. Marquette (Nice), M. Reynaud-Gaubert (Marseille).

Comité de lecture : élargi aux médecins ci-dessous :

Pneumologues libéraux :

- Dr Philippe Carré (Carcassonne) ;

- Dr Philippe Terrioux (Meaux).

Pneumologues de centres hospitaliers généraux :

- Dr Daniel Bonnet (Bayonne);

- Dr Nicolas Just (Roubaix) ;

- Dr Bruno Philippe (Pontoise).

Pneumologues de centres hospitaliers universitaires :

- Pr Bernard Aguilaniu (Grenoble) ;

- Pr François Lebargy (Reims).

Radiologues : 
- Pr Gilbert Ferretti (Grenoble) ;

- Dr Jean Baptiste Faivre (Lille).

(Anatomo)-pathologistes :

- Dr Claire Danel (Paris) ;

- Pr Françoise Thivolet-Béjui (Lyon).

Médecins généralistes :

- Dr Bertrand Legrand (Tourcoing).

Paramédicaux :

- Mme Catherine Paganon (Cadre infirmier).

Associations de patients :

- association Pierre Enjalran pour la fibrose pulmonaire idiopathique ;

- association lutte contre la fibrose pulmonaire.

Il est à noter que les représentants des médecins généralistes, des personnels paramédicaux et des associations de patients ont effectué une lecture du document pour information, remarques et suggestions éventuelles, mais n'ont pas participé aux votes, compte tenu de sa spécificité médicale et scientifique.

\section{Étapes d'établissement des recommandations}

Les différentes étapes de l'élaboration de ces recommandations ont été les suivantes :

- recueil des remarques et suggestions préliminaires des centres de compétences et de leurs correspondants pneumologues libéraux et hospitaliers ;

- rédaction d'une première version du document par le groupe de coordination ;

- lecture de la première version du document par le groupe de rédaction;

- réponses et version révisée par le groupe de coordination ;

- lecture et votes du comité de lecture ;

- réponses et version révisée par le groupe de coordination des questions de niveau de consensus insuffisant ;

- lecture et votes du comité de lecture ;

- réponses et version révisée par le groupe de coordination ;

- lecture par le conseil scientifique de la SPLF ;

- réponses et version révisée par le groupe de coordination ;

- soumission à la Revue des maladies respiratoires.

Le conseil scientifique de la SPLF a émis un avis sur la pertinence, la rédaction et l'applicabilité des recommandations.

Une recommandation figure dans le texte des recommandations si elle a obtenu l'approbation d'au moins $90 \%$ des membres du comité de lecture $(\geq 90 \%$ des réponses du comité de lecture dans l'intervalle [5-9]) (Annexe 1).

Les recommandations ont été formulées de la façon suivante :

- «il est recommandé de » signifie que la mesure devrait être appliquée chez la majorité des patients (exemple d'un traitement d'efficacité établie) ;

- « il est proposé de » signifie que la mesure peut être appliquée chez une partie des patients (exemple d'un traitement d'efficacité très vraisemblable) ;
- « il n'est pas recommandé de » signifie que la mesure ne doit pas être appliquée chez la majorité des patients (exemple d'un traitement inefficace);

- «il est recommandé de ne pas » signifie que la mesure ne doit pas être appliquée (exemple d'un traitement dont l'effet serait délétère).

La méthodologie des recommandations a été approuvée par le conseil scientifique de la SPLF le 27 octobre 2016. Le texte des recommandations a été approuvé par le conseil scientifique de la SPLF le 04 février 2017.

Un soutien logistique a été apporté par Opened Mind Health, à partir d'un don institutionnel des laboratoires Boehringer Ingelheim et Roche à parts égales. Les laboratoires n'avaient pas de rôle dans l'élaboration des recommandations.

Les déclarations de liens d'intérêts des experts des différents groupes sont annexées au présent document et publiées sous format électronique.

\section{Diagnostic}

La FPI débute majoritairement après l'âge de 60 ans avec une légère prédominance masculine [6-9]. Les signes cliniques de la FPI ne sont pas spécifiques et le diagnostic est souvent porté (trop) tardivement. Le tableau initial associe une dyspnée d'effort, d'installation progressive et une toux non productive ; les râles crépitants secs bilatéraux (reproduisant le bruit du « velcro ", râles velcro) sont quasiment constants et précoces [3,10-13]. Un hippocratisme digital est présent dans près de $50 \%$ des cas. Un amaigrissement ou une altération de l'état général sont plus rares. La cyanose et les signes d'insuffisance ventriculaire droite ne s'observent qu'à un stade avancé. La maladie évolue en l'absence de traitement vers l'insuffisance respiratoire chronique restrictive et le décès. Une hypertension pulmonaire (HP) précapillaire est souvent présente à un stade avancé, notamment en cas d'emphysème associé. La présence d'un aspect de pneumopathie interstitielle commune (PIC ; ou usual interstitial pneumonia [UIP] selon la terminologie anglo-américaine), radiologique et/ou histopathologique, est indispensable pour que le diagnostic de FPI puisse être porté.

\section{Critères radiologiques et histopathologiques de diagnostic positif}

La FPI est une PID fibrosante de cause inconnue, associée à un aspect radiologique (Tableau 2) et/ou histopathologique (Tableau 3) de PIC [3].

En l'absence de biopsie pulmonaire, le diagnostic peut être retenu en présence d'une PID idiopathique (en l'absence de manifestation extrarespiratoire associée et de contexte étiologique), si le scanner thoracique de haute résolution montre un aspect de PIC certaine (Fig. 1). Lorsqu'une biopsie pulmonaire est réalisée, le diagnostic de FPI est retenu selon une combinaison de l'aspect du scanner thoracique et de la biopsie pulmonaire montrant un aspect de PIC (Tableau 4). 
Tableau 2 Diagnostic de la fibrose pulmonaire idiopathique : critères tomodensitométriques de pneumopathie interstitielle commune.

\begin{tabular}{|c|c|c|}
\hline \multicolumn{2}{|c|}{ Présence de critères de l'aspect de PIC } & \multirow{2}{*}{$\begin{array}{l}\text { Signes tomodensitométriques incompatibles avec un aspect de } \\
\text { PIC ( } 1 \text { au moins de ces signes) }\end{array}$} \\
\hline PIC certaine ( 4 critères) & PIC possible ( 3 critères) & \\
\hline $\begin{array}{l}\text { Prédominance sous } \\
\text { pleurale basale }\end{array}$ & $\begin{array}{l}\text { Prédominance sous } \\
\text { pleurale basale }\end{array}$ & $\begin{array}{l}\text { Prédominance aux sommets ou à la partie moyenne des poumons } \\
\text { Prédominance péribronchovasculaire }\end{array}$ \\
\hline Réticulations & Réticulations & Opacités en verre dépoli plus étendues que les réticulations \\
\hline $\begin{array}{l}\text { Rayon de miel avec ou } \\
\text { sans bronchectasies de } \\
\text { traction }\end{array}$ & & $\begin{array}{l}\text { Micronodules profus (bilatéraux, prédominant dans les lobes } \\
\text { supérieurs) }\end{array}$ \\
\hline \multirow{3}{*}{$\begin{array}{l}\text { Absence de signes } \\
\text { incompatibles avec } \\
\text { aspect de PIC (voir } \\
\text { ci-contre) }\end{array}$} & $\begin{array}{l}\text { Absence de signes } \\
\text { incompatibles avec }\end{array}$ & $\begin{array}{l}\text { Kystes non contigus (multiples, bilatéraux, à distance des zones } \\
\text { de rayon de miel) }\end{array}$ \\
\hline & $\begin{array}{l}\text { aspect de PIC (voir } \\
\text { ci-contre) }\end{array}$ & $\begin{array}{l}\text { Atténuation diffuse en mosaïque/trappage aérique (bilatéral, } \\
\text { dans } 3 \text { lobes ou plus) }\end{array}$ \\
\hline & & Condensation segmentaire ou lobaire \\
\hline
\end{tabular}

D’après Raghu et al. [3].

PIC : pneumopathie interstitielle commune.

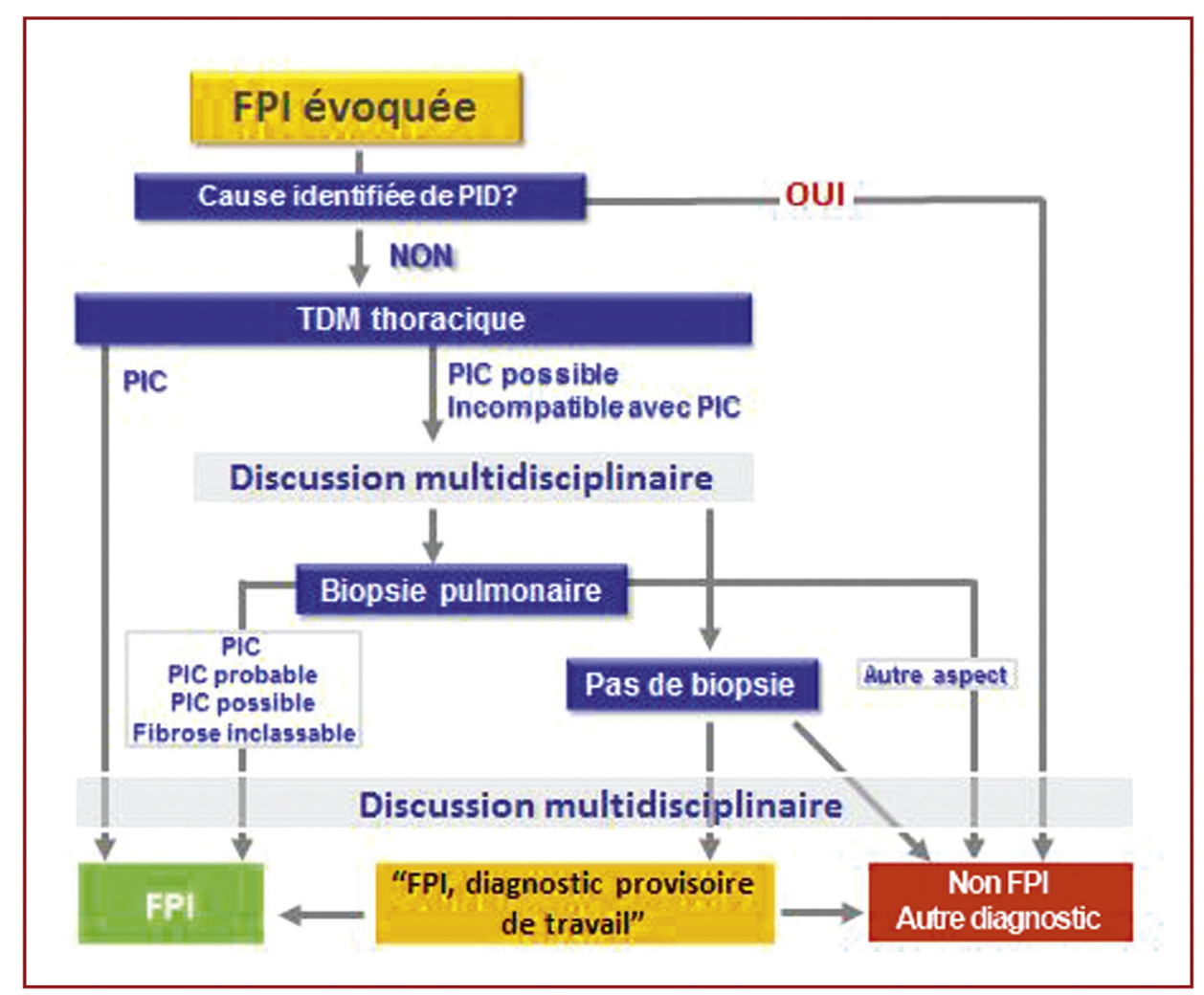

Figure 1. Algorithme diagnostique de la fibrose pulmonaire idiopathique. FPI : fibrose pulmonaire idiopathique ; PIC : pneumopathie interstitielle commune ; PID : pneumopathie interstitielle diffuse ; TDM : tomodensitométrie ; diagnostic provisoire de travail : voir paragraphe 3.8.2.

Dans tous les cas, l'exclusion des autres formes de PID est nécessaire pour retenir le diagnostic de FPI, en particulier celles qui sont liées à une exposition environnementale, notamment professionnelle, un médicament ou une maladie systémique, en particulier une connectivite.

Il est à noter que la reproductibilité de l'identification de l'aspect en rayon de miel, même par des radiologues experts des PID, est faible [14]. De même, la reproductibilité entre radiologues pour identifier un aspect de PIC est modérée [15]. Dans certains cas, le scanner thoracique montre un aspect de PIC possible et il n'est pas réalisé de biopsie pulmonaire (biopsie contre-indiquée ou dont le risque est important, biopsie non proposée pour des raisons diverses, refus du patient) ; il n'est alors pas possible de 
Tableau 3 Diagnostic de la fibrose pulmonaire idiopathique : critères histopathologiques de pneumopathie interstitielle commune.

\begin{tabular}{|c|c|c|c|}
\hline $\begin{array}{l}\text { PIC certaine (présence } \\
\text { de } 4 \text { critères) }\end{array}$ & $\begin{array}{l}\text { PIC probable (présence } \\
\text { de } 3 \text { critères, ou rayon } \\
\text { de miel seul) }\end{array}$ & $\begin{array}{l}\text { PIC possible (présence } \\
\text { de } 3 \text { critères) }\end{array}$ & $\begin{array}{l}\text { Anomalies excluant le } \\
\text { diagnostic de PIC (au } \\
\text { moins } 1 \text { des } 6 \text { critères } \\
\text { ci-dessous) }\end{array}$ \\
\hline $\begin{array}{l}\text { Fibrose } \\
\text { marquée/remodelage } \\
\text { architectural, à } \\
\text { prédominance sous- } \\
\text { pleurale/paraseptale } \pm \text { rayon } \\
\text { de miel }\end{array}$ & $\begin{array}{l}\text { Fibrose } \\
\text { marquée/remodelage } \\
\text { architectural, à } \\
\text { prédominance sous- } \\
\text { pleurale/paraseptale } \pm \text { rayon } \\
\text { de miel }\end{array}$ & $\begin{array}{l}\text { Fibrose } \\
\text { parenchymateuse } \\
\text { disséminée }^{c} \text { ou diffuse, } \\
\text { avec ou sans } \\
\text { inflammation } \\
\text { interstitielle }\end{array}$ & $\begin{array}{l}\text { Membranes hyalines }^{a} \\
\text { Pneumopathie } \\
\text { organisée }^{a, b} \\
\text { Granulomes } \\
\text { Infiltration } \\
\text { inflammatoire }\end{array}$ \\
\hline $\begin{array}{l}\text { Atteinte disséminée }{ }^{c} \\
\text { du parenchyme par la } \\
\text { fibrose }\end{array}$ & $\begin{array}{l}\text { Absence soit d'atteinte } \\
\text { disséminée }^{c} \text { du } \\
\text { parenchyme par la } \\
\text { fibrose, soit de foyers } \\
\text { fibroblastiques (mais } \\
\text { pas absence des } \\
2 \text { critères) }\end{array}$ & $\begin{array}{l}\text { Absence d'autre critère } \\
\text { de PIC }\end{array}$ & $\begin{array}{l}\text { interstitielle marquée à } \\
\text { distance du rayon de } \\
\text { miel } \\
\text { Anomalies } \\
\text { prédominantes } \\
\text { centrées sur les voies } \\
\text { aériennes }\end{array}$ \\
\hline $\begin{array}{l}\text { Présence de foyers } \\
\text { fibroblastiques }\end{array}$ & $\begin{array}{l}\text { Absence de signes } \\
\text { suggérant un autre } \\
\text { diagnostic (cf. } \\
\text { ci-contre) }\end{array}$ & & $\begin{array}{l}\text { Autres signes suggérant } \\
\text { un autre diagnostic }\end{array}$ \\
\hline $\begin{array}{l}\text { Absence de signes } \\
\text { suggérant un autre } \\
\text { diagnostic (cf. } \\
\text { ci-contre) }\end{array}$ & $\begin{array}{l}\text { ou } \\
\text { Rayon de miel seul }\end{array}$ & $\begin{array}{l}\text { Absence de signes } \\
\text { suggérant un autre } \\
\text { diagnostic (cf. } \\
\text { ci-contre) }\end{array}$ & \\
\hline
\end{tabular}

D’après Raghu et al. [3].

PIC : pneumopathie interstitielle commune.

a Peuvent être présentes en cas d'exacerbation aiguë de fibrose pulmonaire idiopathique.

b Un granulome isolé ou occasionnel ou une composante légère de pneumopathie organisée peuvent rarement être présents au sein d'une biopsie montrant par ailleurs un aspect de PIC certaine.

c Atteinte disséminée (ou éparse, patchy) : alternance de territoires de fibrose et de territoires préservés traduisant l'hétérogénéité spatiale des lésions.

${ }^{d}$ Cette situation représente habituellement du poumon avec fibrose évoluée, où du rayon de miel a été prélevé et où un aspect de PIC peut être présent dans d'autres territoires. Ces zones donnent en général lieu à un rayon de miel évident au scanner thoracique ; il est préférable de prélever des territoires à distance de ces zones repérées en préopératoire au scanner.

Tableau 4 Fibrose pulmonaire idiopathique : diagnostic de synthèse (après exclusion d'une cause de fibrose).

\begin{tabular}{lllllll}
\hline \multicolumn{5}{c}{ Aspect histopathologique } \\
\cline { 2 - 6 } & PIC & PIC probable & PIC possible & Fibrose inclassable & Non PIC & Biopsie non faite $^{\text {a }}$ \\
\hline $\begin{array}{llllll}\text { Aspect radiologique } \\
\text { PIC }\end{array}$ & FPI & FPI & FPI & FPI & Non FPI & FPI \\
PIC possible & FPI & FPI & FPI probable & FPI probable & Non FPI & Selon discussion \\
Non PIC & FPI possible & Non FPI & Non FPI & Non FPI & Non FPI & Selon discussion \\
& & & & & multidisciplinaire
\end{tabular}

FPI : fibrose pulmonaire idiopathique ; PIC : pneumopathie interstitielle commune.

a Catégorie non présente dans les recommandations internationales et proposée par le groupe de coordination.

b Une FPI est relativement fréquente.

c Une FPI n'est pas exclue. 


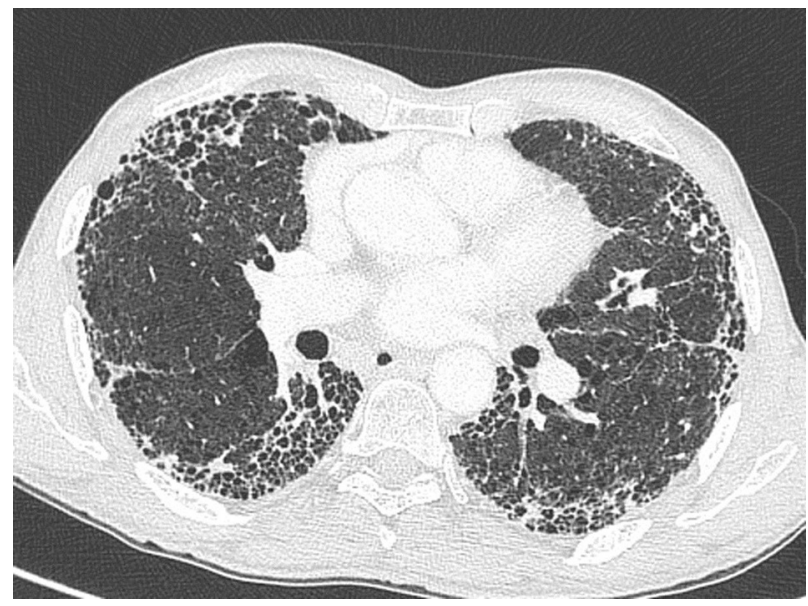

Figure 2. Aspect tomodensitométrique de pneumopathie interstitielle commune, comportant des opacités réticulaires de prédominance basale et sous-pleurale, un aspect en rayon de miel, des bronchectasies par traction, en l'absence de signe incompatible avec ce diagnostic (homme, fumeur, 68 ans).

porter le diagnostic de FPI selon les recommandations internationales [3].

Certains auteurs suggèrent qu'un aspect de PIC possible dans un contexte compatible avec une FPI pourrait être suffisant pour poser le diagnostic de FPI en l'absence de biopsie pulmonaire. Néanmoins, cet argument repose sur une étude méthodologiquement faible (analyse post-hoc d'un essai thérapeutique de patients sélectionnés pour une suspicion de FPI) [16] et sur l'analyse post-hoc du sous-groupe de patients inclus dans les études Inpulsis ${ }^{\odot}$, qui ne présentaient pas de rayon de miel sur le scanner et n'avaient pas eu de biopsie pulmonaire chirurgicale [17]. Ce dernier travail montre que ces patients ont un déclin de la fonction respiratoire (capacité vitale forcée [CVF]) comparable à celui des patients ayant du rayon de miel ou ayant eu une biopsie pulmonaire chirurgicale.

\section{Scanner thoracique sans biopsie pulmonaire}

Le scanner thoracique de haute résolution est indispensable au diagnostic de FPI. Il permet d'apprécier au mieux la topographie des lésions. La méthode de réalisation de cet examen est indiquée dans le Tableau 5. Dans environ $50 \%$ des cas, le scanner $[3,18]$ montre un aspect caractéristique réalisant un aspect de PIC (Fig. 2), permettant de porter le diagnostic de FPI si l'analyse est réalisée par une équipe pneumologique et radiologique expérimentée dans le domaine des PID et dans un contexte compatible. Dans les autres cas, l'imagerie n'est pas caractéristique (Fig. 3) et le diagnostic ne peut pas être affirmé en l'absence de biopsie pulmonaire. Parfois le scanner montre des aspects incompatibles avec une PIC (Fig. 4). Les critères de PIC certaine ou possible au scanner sont indiqués dans le Tableau 2. Un aspect en rayon de miel est nécessaire pour retenir un aspect de PIC certaine au scanner thoracique.

Des critères de diagnostic radiologique de «PIC probable » ont été proposés afin de limiter le nombre de patients relevant en théorie d'une biopsie pulmonaire
Tableau 5 Méthode de réalisation du scanner thoracique de haute résolution.

\section{Nécessaire}

Patient en décubitus ; puis, patient en procubitus si des opacités liées à la gravito-dépendance gênent l'analyse en décubitus ; ou procubitus d'emblée Sans injection de produit de contraste

Coupes en apnée inspiratoire

Coupes axiales contiguës (ou non) reconstruites à $\leq 2 \mathrm{~cm}$ d'intervalle

Épaisseur de coupe $\leq 2 \mathrm{~mm}$

Champ de reconstruction focalisé sur les poumons Acquisition respectant les normes européennes d'irradiation (en évitant l'ultra-basse dose pour le diagnostic)

Lecture des images reconstruites avec un « filtre dur » et une fenêtre parenchymateuse

Archivage des acquisitions en coupes fines sur CD, DVD, ou serveur pour relecture ultérieure

Optionnel

Reconstructions en minimal intensity projection (minIP) en épaisseur de 5 à $8 \mathrm{~mm}$ dans le plan sagittal ${ }^{a}$ Images en procubitus si des opacités liées à la gravito-dépendance gênent l'analyse en décubitus Coupes en expiration pour exclure un piégeage aérique lobulaire ${ }^{\mathrm{b}}$

Reconstructions coronales et sagittales, si on dispose d'acquisitions volumiques

a Afin de différencier les bronchiolectasies de traction du rayon de miel.

b L'acquisition en expiration n'est pas systématique, est d'indication discutée, mais est parfois utile en cas de suspicion de pneumopathie d'hypersensibilité. La présence d'au moins 5 lobules avec piégeage aérique au sein d'au moins 3 lobes pulmonaires est considérée comme significative.

\section{Recommandation 1}

Il est recommandé de considérer qu'un aspect tomodensitométrique de pneumopathie interstitielle commune certaine, incluant notamment un aspect en rayon de miel (Tableau 2), est suffisant pour établir le diagnostic de FPI, après élimination des autres causes de pneumopathie interstitielle commune (formes secondaires).

$[19,20]$, mais ces critères nécessitent d'être validés, notamment en termes d'impact sur les décisions de prise en charge.

\section{Place de la biopsie pulmonaire chirurgicale}

Le diagnostic de FPI peut être porté en présence d'une présentation radiologique de PIC et/ou d'un aspect histopathologique de PIC (Tableau 3) et dans un contexte idiopathique. Lorsque l'aspect radiologique n'est pas celui de PIC certaine, le diagnostic de FPI n'est certain que 


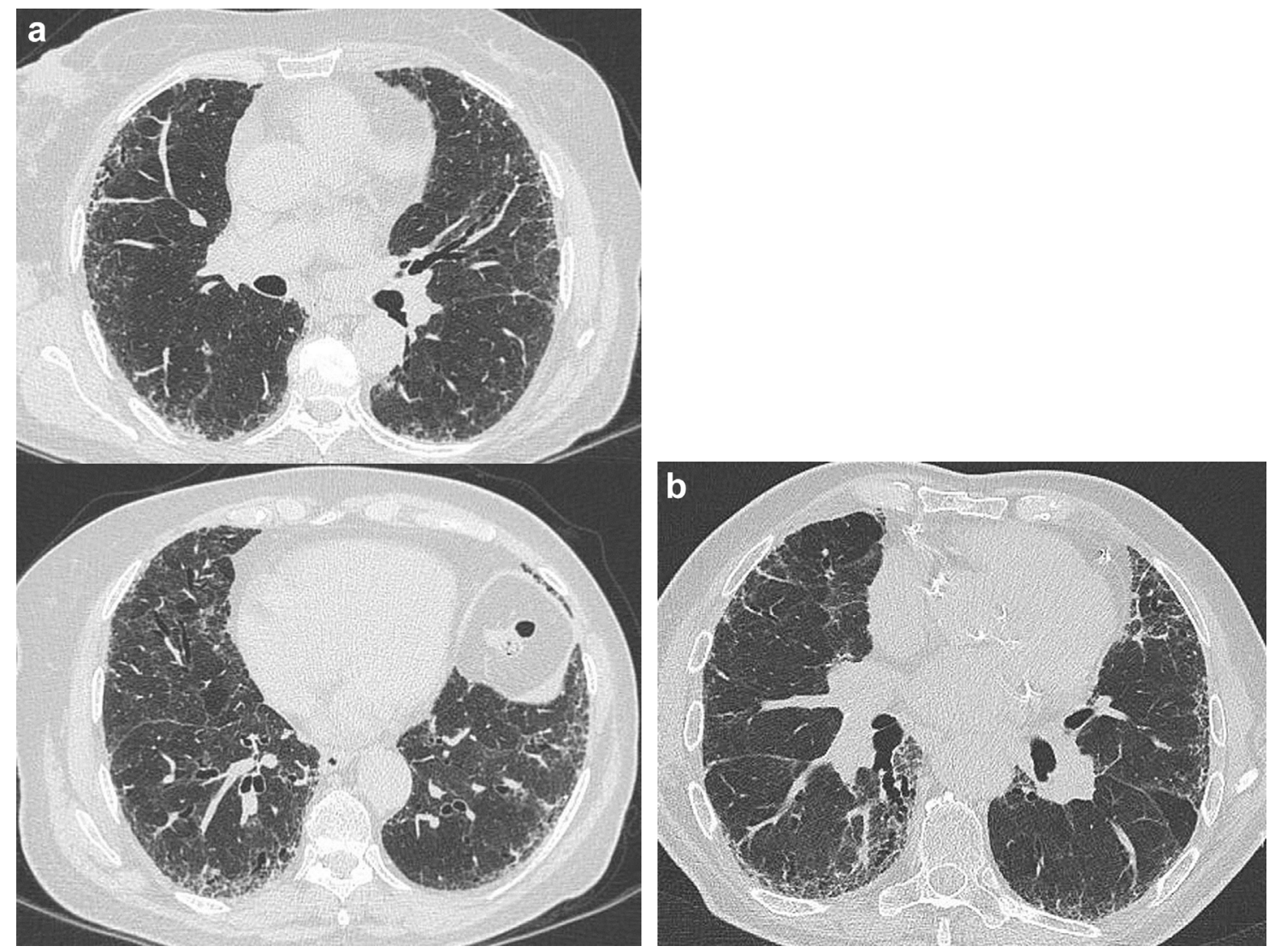

Figure 3. Aspect tomodensitométrique de pneumopathie interstitielle commune possible, comportant des opacités réticulaires de prédominance basale et sous-pleurale, des bronchectasies par traction, en l'absence de signe incompatible avec ce diagnostic, mais sans aspect en rayon de miel ( $a$ : homme de 71 ans ; $b$ : homme de 79 ans).

si la biopsie pulmonaire met en évidence un aspect histopathologique de PIC selon une combinaison de l'aspect radiologique et de l'aspect histopathologique (Tableau 4) [3]. La décision de proposer une biopsie pulmonaire vidéochirurgicale est laissée à l'appréciation des cliniciens à l'issue de la discussion multidisciplinaire (Tableau 6), en tenant compte notamment de l'évaluation du risque éventuel de la biopsie $[21,22]$, de l'âge, de l'existence de comorbidités, du stade, des explorations fonctionnelles respiratoires (EFR), de l'évolutivité de la pneumopathie interstitielle, et des conséquences thérapeutiques éventuelles.

Le risque iatrogène est faible si la maladie est peu évoluée (par exemple, CVF > $70 \%$ et capacité de diffusion du monoxyde de carbone [DLco] $>40 \%$ ) et si elle n'est pas en cours d'accélération ; en revanche, la biopsie comporte un risque plus élevé si elle est réalisée en urgence, à un âge plus élevé (par exemple âge physiologique > 75 ans) et en présence de comorbidités [21]. La biopsie pulmonaire doit être réalisée et analysée par une équipe expérimentée (pneumologue, chirurgien thoracique, anatomopathologiste). Les sites de la biopsie (au moins deux dans deux lobes différents) sont discutés au préalable avec le chirurgien. La biopsie peut confirmer le diagnostic de PIC ou mettre en évidence d'autres aspects, par exemple de pneumopathie interstitielle non spécifique ou de pneumopathie d'hypersensibilité. La biopsie permet aussi de réaliser une analyse minéralogique.

Dans certains cas, le scanner montre seulement un aspect de PIC possible et il n'est pas réalisé de biopsie pulmonaire vidéochirurgicale (biopsie contre-indiquée ou dont le risque est important, biopsie non proposée, refus du patient) ; il n'est alors pas possible de porter formellement le diagnostic de FPI selon les recommandations internationales [3].

\section{Cryobiopsies}

La technique relativement récente de cryobiopsie est réalisée sous anesthésie générale, de préférence par bronchoscopie rigide et à l'aide d'une cryosonde flexible [23]. Son rendement diagnostique est meilleur que celui des biopsies transbronchiques (74\% à $98 \%$ ) [24] grâce à l'obtention de fragments biopsiques plus volumineux, comportant moins d'artefacts. En revanche, elle pourrait être associée à un taux supérieur de complications (hémorragies, pneumothorax) [25]. Même si elle est encore peu diffusée en pratique, la cryobiopsie pratiquée par des centres entraînés semble être une alternative possible à la biopsie chirurgicale, car elle est moins invasive (par exemple, pas de ventilation sur poumon unique) [26-28]. Une étude a exploré la place de la cryobiopsie dans l'algorithme diagnostique et a suggéré un 
Tableau 6 Indication et technique de la biopsie pulmonaire en cas de suspicion de fibrose pulmonaire idiopathique.

\begin{tabular}{|c|c|}
\hline Indication & $\begin{array}{l}\text { Absence d'image tomodensitométrique } \\
\text { permettant le diagnostic de FPI }\end{array}$ \\
\hline Lieu & $\begin{array}{l}\text { Centre chirurgical ayant une activité de } \\
\text { biopsie pulmonaire vidéo-chirurgicale } \\
\text { pour pneumopathies interstitielles } \\
\text { diffuses et anatomopathologiste } \\
\text { expérimenté dans la prise en charge des } \\
\text { pneumopathies interstitielles diffuses }\end{array}$ \\
\hline Technique & $\begin{array}{l}\text { Vidéochirurgie si possible (biopsies } \\
\text { transbronchiques exclues) }\end{array}$ \\
\hline Prélèvements & $\begin{array}{l}\text { Profonds, au niveau de plusieurs lobes }{ }^{c} \text {, } \\
\text { en évitant les pointes de la lingula et du } \\
\text { lobe moyen, ainsi que les territoires } \\
\text { sièges de destruction sévère en rayon de } \\
\text { miel }\end{array}$ \\
\hline \multicolumn{2}{|c|}{$\begin{array}{l}\text { FPI : fibrose pulmonaire idiopathique. } \\
\text { a Indication théorique à confronter lors d'une discussion multi- } \\
\text { disciplinaire avec le risque de la biopsie, l'âge, les comorbidités } \\
\text { éventuelles, et à discuter avec le patient. Une cause de fibrose } \\
\text { doit avoir été écartée. } \\
\text { b Pour obtenir une biopsie de taille suffisante. } \\
\text { c Les lésions peuvent différer selon les lobes. }\end{array}$} \\
\hline
\end{tabular}

apport diagnostique comparable à celui de la biopsie pulmonaire chirurgicale pour obtenir un consensus diagnostique en discussion multidisciplinaire [29].

\section{Diagnostic différentiel}

Le diagnostic positif de la FPI nécessite l'exclusion des autres formes de PID [30]. Celles-ci comprennent principalement les pneumopathies interstitielles:

- de cause connue : antigène inhalé responsable de pneumopathie d'hypersensibilité (PHS) (voir http://maladies-pulmonaires-rares. $\mathrm{fr} /{ }^{2}$ pour une liste non exhaustive des agents en cause), médicaments (voir www.pneumotox.com), agent minéral responsable de pneumoconiose (notamment silice, amiante), cancer primitif ou secondaire, œdème pulmonaire lésionnel ou hémodynamique ;

- de cause inconnue mais survenant dans un contexte défini :

- connectivite ou autre maladie systémique, en particulier polyarthrite rhumatoïde et sclérodermie systémique,

- sarcoïdose,

- PID bien définie comme une lymphangioléiomyomatose, une granulomatose pulmonaire à cellules de Langerhans ou une pneumopathie chronique idiopathique à éosinophiles.

Ces affections sont évoquées sur les données de l'interrogatoire, de l'examen clinique, et de l'imagerie,

2 http://maladies-pulmonaires-rares.fr/ckfinder/userfiles/files / documents-telecharger/RPA/RPA\%20causes\%20PHS\%202010.pdf.

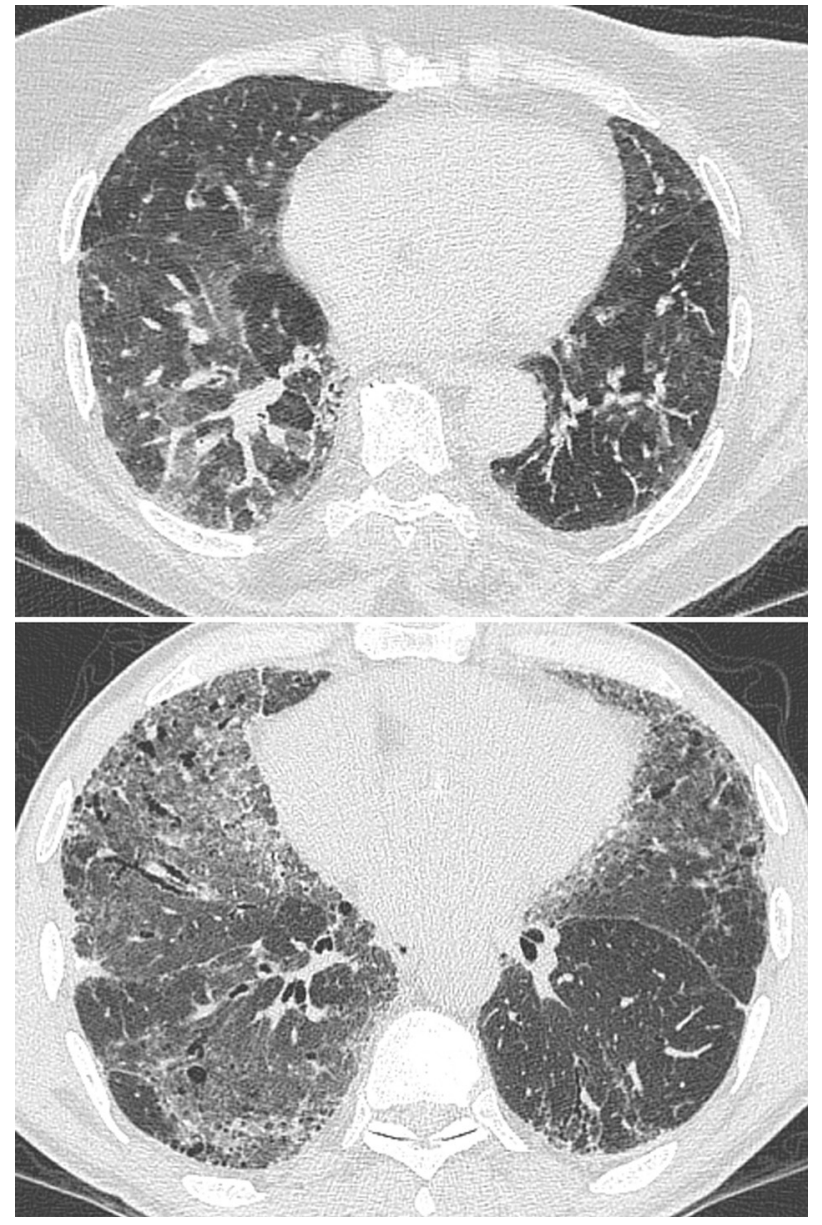

Figure 4. Exemples d'aspects tomodensitométriques non compatibles avec une pneumopathie interstitielle commune. Haut : hyperdensité en verre dépoli réalisant un aspect en mosaïque et micronodules centrolobulaires au cours d'une pneumopathie d'hypersensibilité aviaire ; bas : hyperdensité en verre dépoli, réticulation intralobulaire de répartition diffuse et bronchectasies par traction, au cours d'une pneumopathie interstitielle non spécifique idiopathique.

\section{Recommandation 2}

Il est recommandé d'envisager une biopsie pulmonaire chez les patients pour lesquels le diagnostic de FPI est suspecté, en l'absence d'un aspect de pneumopathie interstitielle commune certaine sur le scanner thoracique. La décision de proposer une biopsie est prise dans le cadre d'une discussion multidisciplinaire après évaluation du risque opératoire, en tenant compte de l'évaluation du risque de la biopsie, notamment selon l'âge, le retentissement fonctionnel de la maladie, l'existence de comorbidités et l'évolutivité de la pneumopathie interstitielle. La biopsie pulmonaire est habituellement réalisée par méthode vidéochirurgicale ; la place des cryobiopsies est en cours d'évaluation.

et posent généralement peu de difficultés de diagnostic différentiel avec la FPI, à l'exception de l'asbestose pulmonaire, et des formes chroniques fibrosantes de PHS 
(notamment aviaires), dont la présentation radiologique est parfois comparable à celle de la FPI. Les pneumopathies environnementales sont donc essentielles à rechercher. Selon une étude, l'enquête environnementale approfondie et la relecture des biopsies permettent parfois de requalifier un diagnostic initial de FPI en forme chronique de PHS [31]. Une évaluation par un conseiller en environnement peut être demandée. Il faut interroger le patient sur son cursus professionnel et orienter en cas de doute vers une consultation spécialisée en pathologies professionnelles. Des questionnaires et listes standardisés sont utiles pour identifier une cause professionnelle (amiante) ou une exposition à un antigène organique (cf. site Internet : http://maladies-pulmonaires-rares. $\mathrm{fr} /{ }^{3}$ ). Un aspect de PIC certaine au scanner ne préjuge pas du caractère idiopathique ou secondaire de la pneumopathie infiltrante. Dans certains cas, les formes chroniques de PHS peuvent prendre un aspect de PIC indiscernable de celui d'une FPI. La présence sur le scanner de zones d'hypo-atténuation (voire de mosaïque) et de micronodules centrolobulaires, et l'absence de prédominance aux bases sont alors des éléments d'orientation en faveur de la PHS [32].

Les causes infectieuses (Mycoplasma pneumoniae, virus, Pneumocystis jiroveci) sont plutôt responsables de PID aiguës. Les causes médicamenteuses sont assez rarement en cause dans les PIC [33]. L'identification éventuelle d'une cause de PID chronique exclut le diagnostic de FPI. Une fois les causes de PID exclues, on admet le diagnostic de PID idiopathique et il est alors important de distinguer la FPI des autres PID idiopathiques sur les données de l'imagerie et, si elle est disponible, de l'histopathologie.

En pratique, le diagnostic différentiel de la FPI se pose surtout avec la pneumopathie interstitielle non spécifique (PINS) dans sa forme fibrosante, les autres PID idiopathiques, les PHS chroniques, les PID avec connectivite fruste, et les formes inclassables de PID idiopathique.

\section{Recommandation 3}

Chez un patient chez lequel une FPI est suspectée, il est recommandé de rechercher des arguments en faveur d'une cause déterminée de pneumopathie interstitielle diffuse, en particulier une exposition à des médicaments, à un antigène inhalé, à des particules minérales, ou une connectivite.

\section{Explorations biologiques}

Une PID réalisant un aspect radiologique et/ou histopathologique compatible avec une PIC [34] peut être la manifestation clinique inaugurale d'une connectivite [35]. Lorsqu'un diagnostic de FPI est suspecté, l'existence de signes extrarespiratoires et d'auto-anticorps évocateurs d'une connectivite sont à rechercher d'autant plus s'il s'agit d'une femme et/ou d'un sujet âgé de moins de 50 ans.

\footnotetext{
3 http://maladies-pulmonaires-rares.fr/ckfinder/userfiles/files / documents-telecharger/RPA/RPA\%20causes\%20PHS\%202010.pdf.
}

Les examens proposés sont les suivants : anticorps antinucléaires, anticorps antipeptides cycliques citrullinés et facteur rhumatoïde. En fonction de l'orientation clinique, ou s'il existe des anticorps antinucléaires, l'analyse peut être élargie, par exemple, vers la recherche d'anticorps et de biomarqueurs associés au syndrome de Gougerot-Sjögren (anti-SSA, anti-SSB), à la sclérodermie systémique (anticentromères, antitopoisomérase), aux myopathies inflammatoires (anticorps anti-Mi-2, antiU3RNP, anti-ARNt-synthétases, créatine phosphokinase par exemple). L'existence d'un auto-anticorps sans manifestation extrarespiratoire est possible au cours de la $\mathrm{FPI}$, comme dans la population générale (anticorps antinucléaires, facteur rhumatoïde notamment). Les anticorps anti-ARNt-synthétase comportent les anticorps anti-histidylARNt-synthétase (Jo1), anti-alanyl-ARNt-synthétase (PL12), anti-threonyl-ARNt-synthétase (PL7) et sept autres anticorps plus rares [36]. Les anticorps anti-synthétase et les autres anticorps des myosites (anti-MDA5, -NXP2, -TIF1 $\gamma$, $\mathrm{Ku}$, etc.) sont souvent non détectés par les techniques de dépistage en immunofluorescence et doivent être recherchés systématiquement, si la présentation radioclinique est compatible (sujet jeune, signes cliniques, biologiques ou électromyographiques de dermatomyosite et installation aiguë ou subaiguë). L'apparition au cours de l'évolution de signes, symptômes ou anomalies sérologiques évocateurs d'une connectivite peut conduire à remettre en cause le diagnostic de FPI. Des anticorps anticytoplasme des polynucléaires neutrophiles (ANCA) sont souvent recherchés du fait de l'association possible de la FPI avec une vascularite à ANCA (polyangéite microscopique) [37]. Dans une série coréenne, 6,6 \% des patients présentant une FPI avaient également des ANCA [38]. Dans une série japonaise de 111 patients ayant une $\mathrm{FPI}, 4$ ont développé une polyangéite microscopique avec des ANCA antimyéloperoxydase [39].

Les explorations biologiques comportent également des éléments destinés à détecter un syndrome inflammatoire ou une atteinte extrarespiratoire : numération formule sanguine, protéine C-réactive, créatininémie, transaminases, $\gamma$-glutamyltransférase et phosphatases alcalines. La recherche de précipitines (Annexe 2 ) est justifiée s'il existe une exposition à des antigènes organiques ou une suspicion de PHS. La recherche d'agents infectieux notamment par lavage bronchoalvéolaire (cf. ci-après) est justifiée en cas de doute pour une infection. La recherche d'une pathologie lymphoproliférative (électrophorèse et immunoélectrophorèse des protéines, immunofixation urinaire, cryoglobulinémie) est justifiée en cas de présentation faisant suspecter une PID autre qu'une FPI.

En ce qui concerne le diagnostic et l'évaluation de la fibrose pulmonaire, plusieurs biomarqueurs sont en cours d'évaluation (par exemple, KL-6 [Krebs von den Lungen-6], MMP7 [matrix metalloproteinase-7], analyse génomique sur cellules mononuclées circulantes) mais aucun n'est recommandé pour l'instant $[40,41]$. Parmi ces biomarqueurs, les produits de dégradation du collagène sont particulièrement prometteurs pour évaluer l'évolutivité de la maladie et, peut-être, prédire une réponse au traitement [42]. 


\section{Recommandation 4}

Il est recommandé de rechercher des signes biologiques de connectivite lorsqu'un diagnostic de FPI est suspecté.

\section{Recommandation 5}

Il est proposé de réaliser des explorations biologiques lorsqu'un diagnostic de FPI est suspecté, comportant : numération formule sanguine, protéine C-réactive, créatininémie, transaminases, $\gamma$ glutamyltransférase, phosphatases alcalines, créatine phosphokinase et électrophorèse des protéines sanguines, anticorps antinucléaires, anticorps antipeptides cycliques citrullinés, facteur rhumatoïde, anticorps anticytoplasme des neutrophiles et selon l'orientation clinique ou en cas de détection d'anticorps antinucléaires, anticorps spécifiques du syndrome de Gougerot-Sjögren (anti-SSA, anti-SSB), de la sclérodermie systémique (anticentromères, anti-topoisomérase-1, anti-U3RNP), anticorps antisynthétases et anticorps rares associés aux myosites, et une recherche de précipitines orientée par la clinique.

\section{Lavage broncho-alvéolaire}

La technique du lavage broncho-alvéolaire (LBA) doit suivre les recommandations internationales [43]. Il faut notamment respecter les contre-indications et éviter de pratiquer le LBA si l'état respiratoire du sujet ne le permet pas. L'examen montre au cours de la FPI une hypercellularité avec augmentation des polynucléaires neutrophiles (>3\%), voire des polynucléaires éosinophiles ( $>1 \%$, mais habituellement inférieurs au taux des neutrophiles). Un profil lymphocytaire (>30\%) fait évoquer un autre diagnostic que celui de FPI : sarcoïdose, PHS, PINS, connectivite, pneumopathie médicamenteuse ou radique, maladie lymphoproliférative, pneumopathie organisée $[43,44]$.

L'apport diagnostique du LBA est surtout important lorsque la présentation radiologique n'est pas de PIC certaine, si une PHS chronique est envisagée [3], ou en cas d'exposition à l'amiante pour une étude minéralogique.

\section{Recommandation 6}

Il est proposé de réaliser un LBA en cas de pneumopathie interstitielle diffuse chronique. Lorsqu'un diagnostic de FPI est suspecté, le LBA est surtout utile si l'aspect radiologique n'est pas celui d'une pneumopathie interstitielle commune certaine.

\section{Enquête génétique}

La question des fibroses pulmonaires familiales/génétiques a fait l'objet d'une revue générale en 2015 par Borie et al.
[45] : les paragraphes suivants sont issus de cette revue, dont ils résument les points-clés.

\section{Fibroses pulmonaires familiales}

On parle de fibrose pulmonaire familiale quand il existe au moins deux cas de fibrose pulmonaire dans une même famille [46], mais toute PID, de cause connue ou inconnue, peut être familiale et s'associer à une maladie génétique. Entre $2 \%$ et $20 \%$ des FPI sont familiales et la transmission semble suivre un mode autosomique dominant [46]. Au sein d'une famille atteinte, les PID sont plus fréquentes chez les hommes, les fumeurs et les personnes plus âgées.

Au scanner, les PID familiales se manifestent le plus souvent par un aspect de PIC, plus rarement de PINS ou de pneumopathie organisée [47]. Au plan histopathologique, les aspects habituellement retrouvés sont ceux des PIC, mais il existe des formes inclassables ou des aspects de PINS, de PHS ou de pneumopathie organisée [47]. Le profil évolutif des fibroses pulmonaires familiales est comparable à celui des formes sporadiques $[48,49]$.

Les principaux gènes incriminés dans la survenue des fibroses pulmonaires génétiques sont rappelés au Tableau 7. Aucun facteur génétique constamment associé aux FPI sporadiques n'a été identifié.

\section{Mutations du complexe télomérase}

Le complexe télomérase catalyse l'addition de séquences répétées d'ADN au niveau des télomères, protégeant ainsi les chromosomes du raccourcissement lors des mitoses. Il comporte plusieurs protéines, dont la transcriptase inverse de la télomérase (TERT). Les mutations du gène TERT sont les plus fréquemment retrouvées dans les fibroses familiales ; ces mutations induisent des atteintes extrarespiratoires diverses [50], cutanéomuqueuses (dyskératose congénitale avec dystrophie unguéale, hyperpigmentation cutanée localisée et leucoplasie orale), hématologiques (aplasie médullaire, myélodysplasie, leucémie aiguë, anémie d'origine centrale), hépatiques (cirrhose), ainsi que des déficits immunitaires cellulaires et humoraux, des rétinopathies exsudatives et une atteinte neurologique centrale. En cas de mutation du gène TERT, la survenue d'une PID dépend de l'âge : inexistante avant 40 ans, elle survient chez plus de $60 \%$ des patients mutés après 60 ans [51]. Des mutations portant sur d'autres composants du complexe télomérase ou interagissant avec lui ont été décrites en association avec une fibrose pulmonaire (RTEL1, PARN, RAF1, DKC1, TINF2) ou avec des manifestations cutanées, hématologiques, neurologiques ou gastro-intestinales sans fibrose pulmonaire (RTEL1, NOP10, NHP2, CTC1). Certains emphysèmes familiaux sont également en rapport avec des mutations du complexe télomérase.

La mutation de TERT ou TR s'accompagne d'une diminution de la longueur des télomères, mais la mesure de cette longueur ne permet pas le diagnostic de la mutation. Le raccourcissement des télomères survient physiologiquement avec l'âge [52], en cas d'exposition au tabac ou aux pesticides et au cours de nombreuses maladies chroniques. Au cours des FPI sporadiques, on peut observer des télomères courts sans mutation de TERT ni de TR [52].

Il n'existe pas de traitement spécifique de ces fibroses. En cas de transplantation pulmonaire, il existe un risque 
Tableau 7 Principaux gènes associés aux fibroses pulmonaires.

\begin{tabular}{|c|c|c|c|c|}
\hline Gène & Fonction & Maladies associées & Transmission & Variation \\
\hline $\begin{array}{l}\text { TERT, TR, RTEL1, } \\
\text { PARN, NAF1, } \\
\text { TINF2/DKC1 }\end{array}$ & Télomérase & $\begin{array}{l}\text { Dyskératose } \\
\text { congénitale, } \\
\text { téloméropathie }\end{array}$ & $\begin{array}{l}\text { Autosomique } \\
\text { domi- } \\
\text { nant/récessif liée } \\
\text { à l'X }\end{array}$ & $\begin{array}{l}\text { Mutations } \\
{[291-294]}\end{array}$ \\
\hline $\begin{array}{l}\text { SFTPC- } \\
\text { SFTPA2/SFTPB- } \\
\text { ABCA3 }\end{array}$ & Surfactant & $\begin{array}{l}\text { Cancer du poumon, } \\
\text { syndrome emphysème } \\
\text { - fibrose }\end{array}$ & $\begin{array}{l}\text { Autosomique } \\
\text { domi- } \\
\text { nant/récessif }\end{array}$ & Mutations [54] \\
\hline ELMOD2 & $\begin{array}{l}\text { Réponse } \\
\text { antivirale }\end{array}$ & & Monogénique & $\begin{array}{l}\text { Pas de mutation } \\
\text { identifiée [295] }\end{array}$ \\
\hline$N F-1$ & $\begin{array}{l}\text { Suppresseur de } \\
\text { tumeur }\end{array}$ & Neurofibromatose & $\begin{array}{l}\text { Autosomique } \\
\text { dominant }\end{array}$ & Mutations [296] \\
\hline NKX-2 (TTF1) & $\begin{array}{l}\text { Facteur de } \\
\text { transcription }\end{array}$ & $\begin{array}{l}\text { Neuropathie, } \\
\text { hypothyroïdie }\end{array}$ & $\begin{array}{l}\text { Autosomique } \\
\text { dominant }\end{array}$ & $\begin{array}{l}\text { Mutations et } \\
\text { délétions [297] }\end{array}$ \\
\hline$H P S-1$ à $8 / A P-3 B 1$ & Lysosomes & Hermansky-Pudlak & $\begin{array}{l}\text { Autosomique } \\
\text { récessif }\end{array}$ & Mutations [298] \\
\hline FAM111B & Inconnu & $\begin{array}{l}\text { Myopathie, } \\
\text { poïkilodermie }\end{array}$ & $\begin{array}{l}\text { Autosomique } \\
\text { dominant }\end{array}$ & Mutations [299] \\
\hline
\end{tabular}

accru de cytopénie sous immunosuppresseurs [53]. Devant toute fibrose pulmonaire associée à une mutation de la télomérase, on conseille aux patients d'éviter les toxiques respiratoires, hépatiques et médullaires, que ce soit le tabac, les toxiques environnementaux ou les cytotoxiques médicamenteux par exemple.

\section{Autres anomalies génétiques}

Les PID familiales de l'adulte peuvent aussi être dues à des mutations des gènes codant pour les protéines du surfactant, le gène le plus souvent concerné étant SFTPC, dont la transmission est autosomique dominante (avec des néomutations fréquentes). Les mutations peuvent également porter sur SFTPA1, SFTPA2 (risque de cancer associé), SFTPB et ABCA3. L'aspect radiologique le plus fréquent associe verre dépoli prédominant, épaississements septaux, kystes, puis plus tardivement lésions en rayon de miel [54]. Ces mutations sont évoquées plutôt chez un patient jeune.

Des fibroses pulmonaires ont été décrites au cours de certains syndromes familiaux rares, comme le syndrome d'Hermansky-Pudlak, les neurofibromatoses et les mutations hétérozygotes de NKX-2 (TTF1) (PID, hypothyroïdie, anomalies neurologiques et poïkilodermie). Par ailleurs, on a incriminé plusieurs polymorphismes génétiques au cours des FPI, dont celui dans le promoteur de MUC5B, d'autres dans TOLLIP, TLR9, TERT, TR. Enfin, certaines formes de fibrose pulmonaire familiale pourraient être induites par des mécanismes de régulation épigénétique, comme des modifications de la méthylation de certains gènes.

\section{Enquête génétique chez un patient atteint ou suspect de FPI}

La recherche de mutation est proposée en cas de forme familiale de fibrose pulmonaire idiopathique ou non idiopathique, d'âge inférieur à 50 ans et/ou d'existence d'un élément d'orientation [50] : présence chez le patient (ou un apparenté au premier degré) d'une macrocytose, thrombocytopénie, anémie d'origine centrale, cirrhose hépatique de cause incertaine ou indéterminée, anomalies de la pigmentation cutanée, anomalies des muqueuses telles qu'une leucoplasie du bord de la langue, ou une canitie/leucotrichie (blanchissement prématuré massif des cheveux, avant l'âge de 30 ans).

Les mutations souvent recherchées sont TERT, TR pour le complexe télomérase (en cas de suspicion de fibrose pulmonaire entrant dans le cadre d'une téloméropathie) et SFTPA1, SFTPA2, SFTPC et ABCA3 pour le surfactant. En cas d'identification d'une mutation chez un cas index, on évalue les risques des apparentés en fonction du mode de transmission et on peut le préciser par l'exploration moléculaire des individus apparentés qui en font la demande.

L'attitude à adopter chez les sujets apparentés à un patient porteur d'une FPI génétique reste du domaine de la recherche clinique. Le risque de transmission de la mutation TERT ou TR pour un apparenté au premier degré est toujours inférieur à $50 \%$ (risque de transmission de $50 \%$ multiplié par la pénétrance de la maladie). Quand la mutation est avérée, le risque de développer une fibrose pulmonaire est de $60 \%$ chez les hommes et de $50 \%$ chez les femmes après 60 ans [55]. Le risque des manifestations extrapulmonaires associées est difficile à estimer.

La réalisation d'un test diagnostique n'est pas anodine, notamment sur le plan psychologique et médicojuridique et doit être effectuée dans le cadre d'une prise en charge globale, par une équipe pluridisciplinaire. En pratique, elle est réalisée dans les centres de compétence et de référence (Annexe 3). Le recueil d'un consentement écrit après information éclairée est obligatoire. Le rendu des résultats doit 
être réalisé en consultation et accompagné d'une proposition de conseil génétique. Une consultation spécialisée de génétique est proposée.

Le diagnostic génétique n'est pas utile chez les patients de plus de 50 ans présentant une FPI sporadique sans aucun signe évocateur de téloméropathie.

On ne connaît pas précisément les conséquences des anomalies génétiques sur la réponse au traitement des patients atteints de FPI, mais il est établi qu'une mutation du complexe télomérase augmente significativement le risque de mortalité après transplantation pulmonaire, notamment du fait de cytopénies sous immunosuppresseurs, en particulier l'azathioprine $[53,56,57]$.

\section{Recommandation 7}

Chez un patient suspecté de présenter une FPI, il est recommandé de rechercher à l'interrogatoire la présence d'autres cas de PID dans la famille, et de rechercher chez le patient la présence d'arguments cliniques et biologiques pour une cause génétique (âge $<50$ ans ; anomalies hématologiques, hépatiques, ou cutanéomuqueuses).

\section{Recommandation 8}

Chez un patient présentant une FPI dans un contexte familial ou s'il y a des arguments cliniques ou biologiques évoquant une cause génétique, il est proposé de réaliser un arbre généalogique et une analyse génétique moléculaire concernant à l'heure actuelle essentiellement les gènes du complexe de la télomérase et les gènes codant pour les protéines du surfactant, et d'adresser le patient en consultation spécialisée de génétique. dans un centre expérimenté dans les PID a été associé à une moindre survie [59].

\section{Concept de «Diagnostic provisoire de travail »}

Chez d'assez nombreux patients, on ne parvient pas à une certitude diagnostique selon les critères internationaux de 2011, alors même qu'une décision diagnostique et thérapeutique est nécessaire. Dans ce cas, il est proposé de parler de «Diagnostic provisoire de travail » de FPI, s'il n'y a pas de diagnostic différentiel plus probable [60]. Ce choix relève souvent d'une décision en discussion multidisciplinaire. Le concept pragmatique de diagnostic provisoire de travail peut être sujet à révision selon l'évolution ultérieure de la maladie (son « comportement ») [61,62].

\section{Recommandation 9}

Il est recommandé que le diagnostic définitif de FPI intègre l'ensemble des données disponibles au cours d'une discussion multidisciplinaire qui fait intervenir pneumologues, radiologues et pathologistes expérimentés dans le domaine des pneumopathies interstitielles diffuses.

\section{Recommandation 10}

Il est recommandé que les cas difficiles soient adressés, selon leur proximité, au centre de référence ou à un centre de compétences.

\section{Récapitulatif des examens complémentaires}

La liste des explorations qui doivent ou peuvent être réalisées pour le diagnostic de FPI et préparer le suivi ultérieur est indiquée au Tableau 8.

\section{Pronostic et suivi}

\section{Évaluation initiale du pronostic}

Les données disponibles suggèrent que les éléments suivants sont associés à une augmentation de la mortalité associée à la FPI [63] :

- facteurs démographiques : âge, sexe masculin ;

- signes et symptômes initiaux : importance de la dyspnée, DLco $<35-40 \%$ de la valeur théorique, saturation percutanée en oxygène $<88 \%$ au cours du test de marche de six minutes (TM6) en air ambiant, étendue de l'aspect en rayon de miel sur le scanner thoracique, HP précapillaire ;

- signes et symptômes apparaissant au cours de l'évolution : aggravation de la dyspnée, diminution de la CVF de plus de $5 \%$ en valeur absolue ou $10 \%$ en valeur absolue de la CVF théorique (exemple : diminution de $65 \%$ à $55 \%$ de la théorique) ou relative par rapport à la valeur absolue de la CVF (exemple : diminution de $2 \mathrm{~L}$ à $1,8 \mathrm{~L}$ ) en 6 mois [64], diminution de la DLco de plus de $15 \%$ en valeur absolue ou relative en 6 mois, diminution de la distance parcourue ficions et améliore l'evaluation pronostique des cas difficiles [58]. Dans une étude, un retard à la prise en charge 
Tableau 8 Principaux examens complémentaires utiles lors du diagnostic et au cours du suivi de la FPI.

\section{Au diagnostic de la} FPI

Systématiques

Parfois

Selon le contexte

Au cours du suivi

Tous les 3 à 6 mois

Tous les ans

Selon le contexte
Scanner thoracique de haute résolution

Capacité vitale forcée, capacité de transfert du monoxyde de carbone

Échographie cardiaque avec doppler

Anticorps antinucléaires

Anticorps antipeptides cycliques citrullinés

Facteur rhumatoïde

Numération formule sanguine

Protéine $\mathrm{C}$-réactive

Créatininémie

Transaminases, $\gamma$-glutamyltransférase, phosphatases alcalines

Biopsie pulmonaire vidéo-chirurgicale éventuelle (voir texte)

Formule cytologique sur lavage broncho-alvéolaire (voir texte)

Capacité pulmonaire totale, gazométrie artérielle en air au repos

Test de marche de 6 minutes avec mesure de saturation percutanée en oxygène

Analyse génétique (voir texte)

Anticorps anticytoplasme des polynucléaires neutrophiles

Anticorps anti-SSA, anti-SSB

Anticorps anticentromères, antitopoisomérase

Anticorps anti-ARNt-synthétases (notamment anti-Jo1, anti-PL7, anti-PL12)

Autres auto-anticorps des myosites : anti-Mi-2, -U3RNP, -MDA5, -NXP2, -TIF1 $\gamma$, -Ku, etc.

Créatine phosphokinase

Précipitines (selon exposition)

Recherche d'agents infectieux par lavage broncho-alvéolaire

Électrophorèse des protéines sanguines, immunoélectrophorèse des protéines, immunofixation urinaire, cryoglobulinémie

Recherche d'un reflux gastro-esophagien (endoscopie digestive haute, pH-métrie)

Recherche d'un syndrome d'apnées du sommeil (polygraphie ventilatoire, polysomnographie)

Capacité vitale forcée, capacité de transfert du monoxyde de carbone

Radiographie thoracique

Scanner thoracique (sans injection)

Scanner thoracique (sans ou avec injection selon l'indication)

Échographie cardiaque avec doppler

Capacité pulmonaire totale

Gazométrie artérielle en air

Test de marche de 6 minutes

Cathétérisme cardiaque droit (voir texte) au TM6 de plus de $50 \mathrm{~m}$ [65], aggravation de la fibrose sur le scanner thoracique ;

- l'estimation du pronostic vital à 1,2 et 3 ans peut être réalisée par le calculateur GAP ou le score GAP basés sur l'âge, le sexe et le retentissement sur la fonction respiratoire (http://www.acponline. org/journals/annals/extras/gap/) [66,67]. L'intégration dans le score GAP des antécédents d'hospitalisation respiratoire et de la variation de la CVF sur 24 semaines (score GAP longitudinal) améliore l'évaluation pronostique au cours du suivi $[68,69]$. Lorsqu'on ne dispose pas de la DLco pour calculer le score GAP, un score de fibrose au scanner peut apporter la même information pronostique [70] ;

- le score CPI (composite physiologic index) peut être utilisé pour évaluer la gravité de la fibrose indépendamment de l'existence éventuelle d'emphysème [71] ;
- une exacerbation aiguë est associée à une forte mortalité à court et moyen terme.

Ces différents éléments peuvent être utiles pour évaluer l'indication de la transplantation pulmonaire. Le handicap respiratoire doit également faire l'objet d'une évaluation.

Lorsque le diagnostic de FPI n'est pas formel (diagnostic provisoire de travail de FPI), une information pronostique importante est ajoutée par l'aggravation progressive irréversible de la maladie au cours du suivi (notion de «comportement clinique de la maladie »; Tableau 9) [61].

Le déclin fonctionnel respiratoire est variable dans le temps, même chez un patient donné, mais il prédit la mortalité [72]. La réévaluation des EFR en cours d'évolution a une valeur pronostique. 
Tableau 9 Pneumopathies interstitielles idiopathiques : classification selon la notion de « comportement clinique » de la maladie.

\begin{tabular}{|c|c|c|}
\hline $\begin{array}{l}\text { Comportement clinique de la } \\
\text { maladie }\end{array}$ & Objectif thérapeutique & Stratégie de suivi \\
\hline $\begin{array}{l}\text { Réversible et autolimitée (par } \\
\text { exemple, nombreux cas de RB-ILD) }\end{array}$ & $\begin{array}{l}\text { Supprimer la cause } \\
\text { potentielle }\end{array}$ & $\begin{array}{l}\text { Observation à court terme ( } 3 \text { à } \\
6 \text { mois) pour confirmer la } \\
\text { régression de la maladie }\end{array}$ \\
\hline $\begin{array}{l}\text { Réversible avec risque de } \\
\text { progression (par exemple, PINS } \\
\text { cellulaires et certaines PINS } \\
\text { fibreuses, DIP et POC) }\end{array}$ & $\begin{array}{l}\text { Induire une réponse initiale } \\
\text { puis ajuster le traitement au } \\
\text { long cours }\end{array}$ & $\begin{array}{l}\text { Observation à court terme pour } \\
\text { confirmer la réponse au traitement } \\
\text { Observation à long terme pour } \\
\text { vérifier le maintien du bénéfice } \\
\text { clinique }\end{array}$ \\
\hline $\begin{array}{l}\text { Stable avec maladie résiduelle (par } \\
\text { exemple, certaines PINS fibreuses) }\end{array}$ & Maintenir le statut & $\begin{array}{l}\text { Observation à long terme pour } \\
\text { évaluer l'évolution de la maladie }\end{array}$ \\
\hline $\begin{array}{l}\text { Progression irréversible, avec } \\
\text { possibilité de stabilisation (par } \\
\text { exemple, certaines PINS fibreuses) }\end{array}$ & Stabiliser & $\begin{array}{l}\text { Observation à long terme pour } \\
\text { évaluer l'évolution de la maladie }\end{array}$ \\
\hline $\begin{array}{l}\text { Progression irréversible en dépit du } \\
\text { traitement (par exemple, FPI, } \\
\text { certaines PINS fibreuses) }\end{array}$ & Ralentir la progression & $\begin{array}{l}\text { Observation à long terme pour } \\
\text { évaluer l'évolution de la maladie, } \\
\text { discuter une transplantation ou un } \\
\text { traitement palliatif }\end{array}$ \\
\hline
\end{tabular}

\section{Explorations fonctionnelles respiratoires}

Les explorations fonctionnelles respiratoires (EFR) de repos permettent d'évaluer la déficience fonctionnelle de la maladie et participent à l'évaluation pronostique. Elles montrent au repos:

- un trouble ventilatoire restrictif (diminution de la capacité pulmonaire totale, associée à une diminution de la capacité vitale lente) ;

- une diminution précoce de la DLco et du coefficient de transfert (DLco/VA) ; c'est souvent la seule anomalie détectée lors du diagnostic dans les formes précoces de FPI ;

- une mesure de la $\mathrm{PaO}_{2}$ au repos, assez longtemps normale ; les anomalies des échanges gazeux pulmonaires sont idéalement évalués par la détermination en air ambiant du gradient alvéolo-artériel de $\mathrm{PO}_{2}$.

En outre, les EFR à l'exercice montrent une réduction de l'aptitude à l'effort qui peut être évaluée par :

- la réduction de la capacité fonctionnelle de travail évaluée par la distance parcourue lors du TM6 ou sur cyclo-ergomètre (diminution de la consommation maximale d'oxygène et de la puissance maximale à l'exercice) ;

- la diminution de la saturation percutanée en oxygène à l'exercice (baisse de $\mathrm{SpO}_{2}>4 \%$ ) au cours d'un test d'exercice, standardisé ou non, notamment au TM6 ;

- la recherche d'une hypoxémie à l'exercice, souvent absente au repos, ou d'une élévation du gradient alvéoloartériel de $\mathrm{PO}_{2}$ au cours d'une exploration fonctionnelle sur cyclo-ergomètre et pouvant être la seule anomalie fonctionnelle respiratoire présente initialement.

Dans les essais thérapeutiques, comme lors du suivi des patients atteints de FPI, la CVF est fréquemment utilisée car sa mesure est reproductible et sa diminution est liée au pronostic [64,73-75]. L'exploration à l'exercice est utile notamment en cas de dyspnée mal expliquée (patients dyspnéiques ayant une déficience pulmonaire légère à modérée) ou si une réhabilitation respiratoire est envisagée $[76,77]$.

\section{Recommandation 11}

Il est recommandé d'évaluer la capacité vitale forcée et la capacité de diffusion du monoxyde de carbone chez un patient présentant une FPI au diagnostic.

\section{Recommandation 12}

Il est proposé d'évaluer également la capacité pulmonaire totale, la gazométrie artérielle en air au repos, la distance parcourue et la saturation percutanée en oxygène lors d'un test de marche de 6 minutes. 


\section{Examens de suivi et réévaluation du pronostic}

Le suivi des patients atteints de FPI permet d'identifier l'aggravation des symptômes, de suivre l'aggravation de la maladie par des EFR, de débuter le traitement, de prendre en compte les comorbidités et d'envisager une transplantation pulmonaire.

Les examens utiles pour assurer le suivi des patients atteints de FPI sont indiqués au Tableau 8. Il n'y a pas de donnée disponible permettant de recommander la fréquence de réalisation du scanner thoracique lors du suivi, mais un scanner annuel sans injection et basse dose est proposé, avec une attention particulière accordée à la recherche de cancer, qui survient fréquemment dans ce contexte, avec des conséquences majeures sur la prise en charge (dont la contre-indication de la transplantation). Il est légitime de le renouveler en cas de suspicion d'exacerbation aiguë de FPI (sans puis avec injection de produit de contraste) car il participe au diagnostic de cette complication, en cas de modification clinique inexpliquée, de suspicion clinique ou radiologique de cancer bronchique et lors de l'évaluation pour transplantation pulmonaire. L'espacement des visites de suivi peut être de trois à six mois. Ces visites doivent être effectuées en centre spécialisé (centre de référence, centre de compétences ou service hospitalier spécialisé dans les pneumopathies interstitielles diffuses) au moins annuellement, ou de façon plus rapprochée en cas de détérioration. Des visites tous les trois mois doivent être effectuées par le pneumologue traitant en alternance avec un centre spécialisé, préférentiellement dans le cadre d'un réseau de soins formel ou informel impliquant le médecin traitant.

\section{Recommandation 13}

Il est proposé d'évaluer le pronostic d'un patient atteint de FPI :

- au diagnostic, en fonction de l'importance de la dyspnée, de l'exploration fonctionnelle respiratoire (CVF, DLCo), de la saturation percutanée en oxygène en fin de test de marche de 6 minutes, de l'étendue de l'aspect en rayon de miel sur le scanner thoracique de haute résolution, de l'existence de signes d'hypertension pulmonaire à l'échocardiographie et à l'aide d'un score tel que le score GAP ;

- au cours du suivi, en fonction de l'évolution des symptômes, de la CVF, de la DLco et éventuellement de l'existence de signes d'hypertension pulmonaire à l'échocardiographie, et de la fibrose sur le scanner thoracique.

\section{Recommandation 14}

Il est recommandé d'effectuer au minimum un examen clinique et une exploration fonctionnelle respiratoire comportant une mesure de la CVF tous les 3 à 6 mois chez les patients ayant un diagnostic confirmé de FPI.

\section{Recommandation 15}

Il est proposé de réaliser une mesure de DLco tous les 3 à 6 mois chez les patients ayant un diagnostic confirmé de FPI.

\section{Recommandation 16}

Il est recommandé de réaliser un scanner thoracique en cas de suspicion d'exacerbation aiguë de FPI, de modification clinique inexpliquée, de suspicion de cancer bronchique, et en cas d'évaluation pour transplantation pulmonaire.

\section{Recommandation 17}

Il est recommandé d'accorder une attention particulière à la recherche de cancer bronchopulmonaire lorsqu'un scanner thoracique est réalisé.

\section{Traitements médicaux de la FPI à visée antifibrosante}

\section{Pirfénidone}

La pirfénidone ${ }^{4}$ (dérivé synthétique de la pyridine ou 5-méthyl-1-phényl-2-[1H]-pyridone) est une molécule de petite taille dont l'effet antifibrosant a été démontré in vitro et in vivo sur des modèles animaux. Elle agit par l'inhibition de la synthèse du transforming growth factor beta (TGF- $\beta$ ) en limitant l'expression, la synthèse et/ou l'accumulation du collagène et en inhibant le recrutement et/ou l'expression des fibroblastes. Elle présente en outre des propriétés anti-inflammatoires et anti-oxydantes [78].

Son développement clinique a débuté en 1999 par une étude pilote de phase II chez des patients atteints de FPI évoluée [79], puis s'est poursuivi par une série d'essais contrôlés randomisés (ECR) contre placebo [80-83].

\section{Efficacité}

Deux études japonaises versus placebo ont testé les effets de la pirfénidone à la dose de $1800 \mathrm{mg} / \mathrm{j}$ : le premier, un ECR de phase II (107 patients), a suggéré qu'elle diminue l'incidence des exacerbations aiguës et ralentit la dégradation de la capacité vitale à 36 semaines [80]. Le second, un ECR de phase III (275 patients), a montré sous pirfénidone une réduction significative du déclin de la capacité vitale et une amélioration significative de la survie sans progression (SSP) à la $52^{\mathrm{e}}$ semaine [81].

\section{Études Capacity 1 et Capacity 2}

L'efficacité de la pirfénidone a ensuite été évaluée par deux études pivot de phase III en double insu, CAPACITY1 (344 patients) et Capacity-2 (435 patients) [82], menées

\footnotetext{
${ }^{4}$ Esbriet $^{\odot}$ : laboratoire Roche -30 , cours de l'île Seguin, 92650 Boulogne-Billancourt.
} 
dans 110 centres de 13 pays, répartis sur trois continents. Dans Capacity-2, la pirfénidone a été administrée à la dose de $2403 \mathrm{mg} / \mathrm{j}$ (174 patients) ou $1197 \mathrm{mg} / \mathrm{j}$ (87 patients) comparativement au placebo (174 patients ; randomisation 2:1:2). Capacity-1 a comparé l'effet de la pirfénidone à $2403 \mathrm{mg} / \mathrm{j}(n=171)$ au placebo $(n=173$; randomisation $1: 1)$. Les patients éligibles étaient atteints de FPI légère à modérée (définie par une $C V F \geq 50 \%$ et une DLCo $\geq 35 \%$ de la valeur théorique) et parcouraient au moins $150 \mathrm{~m}$ au TM6. Le critère de jugement principal était la différence absolue du pourcentage de la CVF théorique à la $72^{\mathrm{e}}$ semaine.

L'analyse en intention de traiter a montré des résultats discordants sur le critère principal : la différence était significative à la $72^{\mathrm{e}}$ semaine entre pirfénidone $2403 \mathrm{mg} / \mathrm{j}$ et placebo dans Capacity-2 (réduction de la CVF de $-8 \%$ vs. $-12,4 \% ; p=0,001)$ mais non significative dans Capacity-1 $(-9,0 \%$ vs. $-9,6 \%)$, bien que dans cette dernière un effet significatif ait été observé jusqu'à la $48^{\mathrm{e}}$ semaine et à toutes les évaluations intermédiaires. En outre, Capacity-2 a montré une amélioration significative de la SSP (définie par la baisse confirmée $\geq 10 \%$ du pourcentage de CVF théorique, la baisse $\geq 15 \%$ du pourcentage de la DLco théorique, ou le décès) (hazard ratio [HR] 0,64; intervalle de confiance à $95 \%$ [IC 95] 0,44-0,95; $p=0,023$ ).

\section{Analyses groupées du programme Capacity}

L'analyse groupée des études Capacity-1 et Capacity-2 a montré la supériorité statistiquement significative de la pirfénidone à $2403 \mathrm{mg} / \mathrm{j}$ sur le placebo en termes [82] :

- de déclin de la CVF après 72 semaines de traitement $(-8,5 \%$ vs. $11 \% ; p=0,005)$;

- de pourcentage de patients ayant une dégradation de la CVF $\geq 10 \%$ (21\% vs. $31 \% ; p=0,003)$;

- de distance moyenne parcourue au TM6 (-52,8 m vs. $-76,8 \mathrm{~m} ; p<0,001)$;

- et de durée de la SSP (HR 0,74; IC 95 : 0,57-0,96 ; $p=0,025)$.

Ces différences sont cliniquement pertinentes $[64,65,84]$. Il n'y avait pas de différence significative du temps jusqu'à l'aggravation de la FPI (délai jusqu'à exacerbation aiguë, décès, transplantation pulmonaire, ou hospitalisation pour cause respiratoire) [82].

Une méta-analyse de la Cochrane Collaboration des deux essais du programme Capacity [82] et de l'essai japonais de phase III [81] (1046 patients au total) a confirmé l'amélioration significative de la SSP sous pirfénidone (HR 0,70 ; IC $95: 0,56-0,88 ; p=0,002$ ) [85].

\section{Étude ASCEND}

Un autre ECR de phase III en double insu contre placebo, l'étude ASCEND, a comparé l'effet de la pirfénidone $(2403 \mathrm{mg} / \mathrm{j})$ à celui du placebo, administrés pendant 52 semaines, chez 555 patients [83]. Le critère de jugement principal était la modification de la CVF ou le décès à 52 semaines. Les critères secondaires étaient la distance parcourue au TM6, la SSP, la dyspnée, les décès de toute cause ou par FPI. Les critères d'éligibilité étaient proches de ceux du programme Capacity mais modifiés de façon à inclure une population plus homogène de patients ayant un diagnostic de FPI très probable, et à haut risque de progression, incluant une CVF comprise entre $50 \%$ et $90 \%$ de la théorique, une DLco comprise entre $30 \%$ et $90 \%$ de la théorique, un rapport volume expiratoire maximal seconde (VEMS) /CVF $\geq 0,8$ (permettant d'exclure la plupart des patients ayant un emphysème) et une revue centralisée des données de la spirométrie, du scanner, de la biopsie pulmonaire (si pratiquée) et des causes de décès.

À l'inclusion, la CVF moyenne était de 67,8 $\pm 11,2 \%$ de la théorique et la DLco de $42 \%$ de la théorique environ. De façon notable, $95 \%$ des patients présentaient un aspect de PIC au scanner et environ $30 \%$ avaient eu une biopsie pulmonaire vidéochirurgicale.

Les résultats à 52 semaines ont montré, sous pirfénidone comparativement au placebo, une réduction de $47,9 \%$ de la proportion de patients ayant une diminution $\geq 10 \%$ de la CVF ou qui étaient décédés et une augmentation relative de $132,5 \%$ de la proportion de patients sans baisse de la CVF $(p<0,001)$. De plus, il existait une réduction du déclin de la distance parcourue au TM6 $(p=0,04)$, et une amélioration significative de la SSP $(p<0,001)$ sous pirfénidone. Il n'y avait pas de différence significative en termes de scores de dyspnée, de mortalité de toutes causes, ou de mortalité par FPI [83].

Une analyse de sensibilité a confirmé la robustesse de la différence statistique entre pirfénidone et placebo en termes d'évolution de la CVF [86].

\section{Analyses complémentaires}

Une analyse groupée des essais Capacity et Ascend a montré que, comparativement au placebo, la pirfénidone diminue significativement de $48 \%$ le risque de décès (HR 0,52; IC 95 : $0,31-0,87 ; p=0,01)$, tant en termes de décès de toute cause $(p=0,01)$ que de décès par FPI $(p=0,006)$ [83].

L'analyse groupée de la mortalité à 52 semaines dans les essais Ascend et Capacity (1247 patients) a montré que la pirfénidone diminue de 43,8 \% (IC 95 : 29,3-55,4\%) la proportion de patients décédés ou ayant une baisse $\geq 10 \%$ de la CVF théorique et augmente de 59,3\% (IC 95 : 29,0-96,8 \%) la proportion de patients indemnes de baisse de la CVF [87]. Un bénéfice a également été noté en termes de SSP, TM6 et de dyspnée. La qualité de vie n'a pas été étudiée dans ces études.

L'effet de la pirfénidone en termes de ralentissement du déclin de la fonction pulmonaire constaté dans les essais randomisés a été reproduit par plusieurs études observationnelles réalisées dans les conditions de la pratique hospitalo-universitaire courante, le bénéfice semblant être particulièrement prononcé chez les patients ayant la plus forte dégradation de la CVF initiale [88-93].

Les effets de la pirfénidone à long terme sont en cours d'évaluation par l'étude RECAP (suivi prolongé en ouvert des patients ayant terminé les essais Capacity) : celle-ci semble confirmer le maintien du bénéfice en termes de proportion de patients ayant une baisse $\geq 10 \%$ de la CVF [94].

\section{Sécurité d'emploi, tolérance}

La tolérance de la pirfénidone a été évaluée dans les études individuelles et par une analyse groupée des données de quatre ECR où 789 patients ont été exposés à la pirfénidone pendant une durée médiane de 2,6 ans (exposition cumulée de 2059 patients-années) [95]. Les effets indésirables (EI) digestifs et cutanés étaient les plus fréquents, presque toujours d'intensité faible à modérée et rarement cause d'arrêt du traitement. L'élévation des transaminases $(>3$ fois la 
limite supérieure de la normale) concernait 2,7 \% patients, avec une incidence ajustée de 1,7 pour 100 patients-années d'exposition. Une méta-analyse de 6 ECR (1073 patients) a montré que les arrêts du traitement sont significativement plus fréquents sous pirfénidone que sous placebo [96]. L'étude a également confirmé l'incidence accrue des El digestifs (nausées, dyspepsie, diarrhée, anorexie), neurologiques (fatigue, vertiges) et cutanés (photosensibilité, éruptions) sous pirfénidone, comparativement au placebo. Une étude prospective multicentrique observationnelle allemande a inclus 502 patients atteints de FPI, dont $44,2 \%$ ont reçu la pirfénidone (en monothérapie le plus souvent) et n'a pas observé d'El émergent [97].

\section{Modalités d'utilisation}

La pirfénidone bénéficie actuellement d'une autorisation de mise sur le marché ( $A M M)$ au Japon, en Europe (FPI légère à modérée), au Canada et aux États-Unis, à la dose maximale conseillée de $2403 \mathrm{mg} / \mathrm{j}$ ( 3 gélules de $267 \mathrm{mg} \times 3$ par jour, administrées conjointement à un aliment). Il faut éviter les inhibiteurs du CYP1A2 (fluvoxamine, jus de pamplemousse) ainsi que les inducteurs enzymatiques (tabac, oméprazole).

L'expérience clinique d'utilisation à long terme de la pirfénidone a confirmé les résultats des ECR de phase III en termes de sécurité d'emploi et de tolérance, avec un taux d'arrêts du traitement de $15 \%$ environ en raison d'El digestifs ou cutanés. Des conseils pratiques issus de cette expérience clinique cumulée facilitent beaucoup l'acceptation, la tolérance et l'observance du traitement (Tableau 10) [98]. La prise en charge des El digestifs et cutanés associe une combinaison ou une succession de mesures à type de réduction des doses, arrêt temporaire du traitement et utilisation de traitements symptomatiques. La tolérance hépatobiliaire doit être appréciée par un bilan hépatique réalisé avant puis périodiquement au cours du traitement ; l'élévation des enzymes hépatiques justifie la réduction des doses, voire un arrêt du traitement.

\section{Recommandation 18}

Il est recommandé de traiter par la pirfénidone les patients présentant un diagnostic confirmé de FPI légère à modérée (définie par une $\mathrm{CVF} \geq 50 \%$ de la valeur théorique et une $\mathrm{DLCo} \geq 30 \%$ ) ; ce traitement doit être instauré et surveillé par un pneumologue expérimenté dans le diagnostic et le traitement de la FPI et nécessite une surveillance régulière de la tolérance clinique et des taux des enzymes hépatiques ; le patient ne doit pas fumer pendant le traitement.

\section{Nintédanib}

Le nintédanib ésilate ${ }^{5}$ est un inhibiteur de plusieurs tyrosinekinases (ITK) impliquées dans la fibrose pulmonaire, ciblant en particulier les tyrosine-kinases associées aux récepteurs

\footnotetext{
5 Ofev $^{\odot}$ : laboratoire Boehringer Ingelheim, France, 14, rue Jean-
} Antoine-De-Baï, 75644 Paris cedex 13.
Tableau 10 Conseils pour la prévention et la prise en charge des effets indésirables associés au traitement par la pirfénidone.

\section{Administration et adaptations posologiques}

Absorber les gélules ( $267 \mathrm{mg}$ ) avec des aliments, en adaptant les prises aux habitudes alimentaires; en cas de nausées associées, la prise du matin peut être diminuée ou retardée

Le repas principal de la journée peut être associé à la prise de 3 gélules au maximum $(801 \mathrm{mg})$, les autres prises ( 1 à 2 gélules [267-534 mg]) étant associées à des collations secondaires (la prise sera si possible de 6 gélules par jour au minimum) La mise en route du traitement comprend une phase d'augmentation progressive des doses par paliers successifs (jusqu'à la dose d'entretien quotidienne recommandée de 9 gélules) sur 14 jours, voire 4 semaines si nécessaire Envisager un arrêt temporaire du traitement si les symptômes ne s'amendent pas après la réduction des doses

La ré-augmentation des doses après un arrêt temporaire peut être plus progressive qu'au départ Toutes les décisions relatives au traitement doivent être prises en concertation avec le patient et dans l'optique d'un équilibre entre les objectifs d'efficacité et de qualité de vie

Mesures complémentaires visant à prendre en charge les El digestifs

Les agents prokinétiques et peut-être les inhibiteurs de la pompe à protons peuvent être utiles

Mesures complémentaires visant à prévenir et à prendre en charge les El cutanés

Prévention des photosensibilisations

Éviter/limiter l'exposition solaire autant que possible, notamment en milieu de journée, fin d'après-midi et durant les périodes très ensoleillées; ne pas oublier que les UVA peuvent traverser la couche nuageuse et le vitrage des voitures

Éviter l'exposition solaire pendant quelques heures après le repas au cours duquel la pirfénidone a été prise

Se protéger du soleil par le port de vêtements couvrants, chapeaux à larges bords, lunettes de soleil, chemises à manches longues et pantalons longs, de gants pour les activités de plein air et la conduite automobile

Appliquer fréquemment et soigneusement sur les zones exposées des écrans solaires à indice de protection élevé contre les UVA et UVB

Prise en charge des éruptions cutanées En cas d'éruption cutanée, diminuer la dose de pirfénidone ; en cas de persistance de l'éruption après 7 jours, interrompre le traitement pendant 15 jours, puis le réintroduire très progressivement après la disparition des symptômes

Si les éruptions sont en rapport avec un mécanisme allergique, le traitement par la pirfénidone doit être définitivement arrêté

D’après Costabel et al. [98].

EI : effet indésirable ; UV : ultra-violets. 
du platelet-derived growth factor, du vascular endothelial growth factor (VEGF) et du fibroblast growth factor [99]. Il modifie le métabolisme des fibroblastes de patients atteints de FPI (prolifération, migration, différenciation en myofibroblastes, sécrétion de la matrice extracellulaire) et interfère avec la voie du TGF- $\beta$ [100-103].

\section{Efficacité}

L'essai randomisé en double insu de phase II Tomorrow a inclus 432 patients atteints de FPI et a permis de sélectionner la dose de $150 \mathrm{mg} \times 2 / \mathrm{j}$. À cette posologie, le nintédanib était associé, après 12 mois de traitement et comparativement au placebo, à un ralentissement du déclin de la fonction pulmonaire (CVF), à une diminution de l'incidence des exacerbations aiguës et une stabilisation de la qualité de vie évaluée par le score respiratoire de Saint-George [104].

\section{Essais Inpulsis ${ }^{\circledR}$}

Les études pivot Inpulsis $^{\odot}-1$ et Inpulsis $^{\odot}-2$ sont deux ECR similaires de phase III en double insu, ayant inclus 1066 patients au total et comparé le nintédanib $(150 \mathrm{mg} \times 2 / \mathrm{j})$ au placebo dans le cadre d'un traitement de 52 semaines $[105,106]$.

Les critères d'éligibilité associaient : CVF $\geq 50 \%$ de la théorique et DLco comprise entre $30 \%$ et $79 \%$ de la théorique ; aspect radiologique au minimum compatible avec le diagnostic de FPI selon une relecture centralisée ; rapport VEMS/CVF $\geq 0,7$ (sans exclusion des sujets ayant un aspect d'emphysème au scanner). N'étaient pas éligibles les patients à haut risque hémorragique (antécédents hémorragique, double anti-agrégation plaquettaire, traitement anticoagulant) et ceux ayant des antécédents récents d'infarctus du myocarde ou d'angor instable. L'administration concomitante d'une corticothérapie à dose stable (prednisone $\leq 15 \mathrm{mg} / \mathrm{j}$ ou équivalent) était autorisée.

À l'inclusion, les patients avaient en moyenne une CVF de $80 \%$ de la théorique et une DLco de $47 \%$ de la théorique. De façon notable, une proportion significative (environ $30 \%$ ) de participants avait un aspect radiologique de PIC possible avec bronchectasies par traction sans confirmation par biopsie pulmonaire, empêchant de poser formellement le diagnostic de FPI selon les critères internationaux, mais réalisant une situation fréquente en pratique quotidienne. Environ $40 \%$ des sujets avaient un emphysème associé à la FPI.

Le critère principal d'évaluation, représenté par la pente du taux de déclin annuel de la CVF (calculée par analyse de régression), était significativement moins important avec le nintédanib qu'avec le placebo dans les deux essais, avec une différence moyenne de $109,9 \mathrm{~mL} / \mathrm{an}$ (IC 95 : 75,9-144,0 mL/an ; $p<0,001$ ) dans l'analyse groupée des deux études [106]. Cet effet bénéfique sur la fonction respiratoire était retrouvé par l'analyse des critères secondaires pertinents (variation absolue du pourcentage de CVF théorique, proportion de patients « répondeurs » n'ayant pas de déclin $>5 \%$ ou $>10 \%$ de la CVF théorique). Les deux critères secondaires principaux - délai jusqu'à la première exacerbation aiguë de FPI diagnostiquée par les investigateurs et score respiratoire de Saint-George - étaient statistiquement significatifs dans l'essai Inpulsis ${ }^{\odot}-2$, mais pas dans l'essai Inpulsis ${ }^{\odot}-1$, ni dans l'analyse groupée des deux essais. En revanche, l'analyse groupée des deux essais en ce qui concerne les exacerbations aiguës suspectées ou confirmées par un comité d'adjudication a montré une réduction significative des évènements sous nintédanib (HR : 0,32 ; IC 95 : $0,16-0,65 ; p=0,001)$. En termes de mortalité, l'analyse a suggéré une tendance non significative en faveur du nintédanib (HR : 0,70; IC $95: 0,43-1,12 ; p=0,14$ ), mais l'essai n'était pas doté d'une puissance suffisante pour évaluer ce critère.

\section{Analyses complémentaires}

Une analyse prévue au protocole des données groupées d’Inpulsis $^{\odot}-1$ et -2 n'a pas montré de variations significatives de l'efficacité du nintedanib sur le critère principal (déclin de la CVF) et les critères secondaires clés (délai jusqu'à la première exacerbation aiguë, score de Saint-George) dans les sous-groupes définis par l'âge (< ou $\geq 65$ ans), l'origine ethnique (Blanc, Asiatique), le score de Saint-George initial ( $\leq$ ou $>40$ ), le niveau de CVF ( $\leq$ ou $>70 \%$ ou $90 \%$ ), le statut tabagique (fumeur actuel/passé ou jamais), l'utilisation d'une corticothérapie générale (oui/non) et de bronchodilatateurs (oui/non) à l'entrée dans l'étude [107,108].

Une analyse post-hoc a montré que l'effet du nintedanib est indépendant de la présence ou de l'absence d'emphysème et que le traitement ralentit le déclin fonctionnel aussi bien chez les patients ayant un rapport VEMS/CVF > 0,8 que ceux ayant VEMS/CVF $\leq 0,8$ [109]. Des données préliminaires et méthodologiquement faibles provenant de l'étude d'extension Inpulsis- $\mathrm{ON}^{\circledR}$ suggèrent que l'effet sur le déclin de la fonction serait également observé chez les patients ayant une CVF $<50 \%$ [110].

L'analyse groupée des données des essais Tomorrow et Inpulsis ${ }^{\odot}$ a montré une tendance non significative à la réduction de la mortalité de toute cause (HR : 0,70 ; IC 95 : $0,46-1,08 ; p=0,095)$ et de la mortalité d'origine respiratoire (HR : 0,62; IC $95: 0,37-1,06 ; p=0,078)$ [111].

\section{Sécurité d'emploi, tolérance}

L'essai de phase II Tomorrow a montré que les principaux El du nintédanib sont de nature digestive et dose-dépendants : diarrhée, nausées et vomissements, élévation des transaminases [104]. Ce profil d'El a été confirmé par les essais Inpulsis ${ }^{\odot}$ au cours desquels les diarrhées (> $60 \%$ ) et les nausées (> $20 \%$ ) étaient les $\mathrm{El}$ plus fréquents dans le groupe nintédanib [106]. La plupart de ces El étaient d'intensité légère ou modérée et n'ont conduit à un arrêt définitif du traitement que dans moins de $5 \%$ des cas.

Les études de suivi prolongé en ouvert des patients inclus dans les essais Tomorrow et Inpulsis ${ }^{\odot}$, actuellement en cours, suggèrent que ce profil de tolérance reste stable à long terme.

\section{Modalités d'utilisation}

Le nintédanib bénéficie actuellement d'une AMM dans le traitement de la FPI en Europe et aux États-Unis. La dose recommandée est de $150 \mathrm{mg}$ deux fois par jour, en deux prises espacées de $12 \mathrm{~h}$, associées à l'alimentation.

Le problème des El digestifs, notamment des diarrhées, est gérable en pratique par une stratégie associant réduction des doses, voire arrêt temporaire du nintedanib, et traitement symptomatique (réhydratation, traitement antidiarrhéique, antiémétique). Sauf intolérance grave, après la 
résolution des symptômes, le traitement peut être repris à une dose réduite de $100 \mathrm{mg} 2 \mathrm{fois} / \mathrm{j}$ ou à la dose maximale recommandée de $150 \mathrm{mg} 2$ fois/j. Les enzymes hépatiques doivent être dosées avant le début du traitement, puis périodiquement pendant son administration. En raison de son mode d'action (inhibition du récepteur du VEGF), le nintédanib doit être utilisé avec prudence chez les patients à risque accru d'hémorragie (antécédents hémorragiques, double antiagrégation plaquettaire, traitement anticoagulant) ou de perforation gastro-intestinale. Il ne doit pas être utilisé en cas d'allergie à l'arachide ou au soja. L'administration conjointe de kétoconazole augmente sensiblement l'exposition au nintédanib, alors que celle de la rifampicine la diminue.

\section{Recommandation 19}

Il est recommandé de traiter par le nintédanib les patients présentant un diagnostic confirmé de FPI légère à modérée (définie par une $\mathrm{CVF} \geq 50 \%$ de la valeur théorique et une $\mathrm{DLCO} \geq 30 \%$ ) ; ce traitement doit être instauré et surveillé par un pneumologue expérimenté dans le diagnostic et le traitement de la FPI et nécessite une surveillance régulière de la tolérance clinique et des taux des enzymes hépatiques.

\section{En pratique}

La comparaison des principales caractéristiques pratiques de la pirfénidone et du nintédanib apparaît au Tableau 11.

En l'absence de données suffisantes, l'association pirfénidone-nintédanib n'est pas recommandée en dehors d'un contexte de recherche clinique. Cependant, d'assez nombreux médicaments nouveaux sont actuellement en cours d'évaluation : à cet égard, en situation d'échec ou d'intolérance des médicaments approuvés, ou dans les circonstances autres que l'AMM des médicaments approuvés, il est important d'adresser les patients aux centres investigateurs (centre de référence, centres de compétence) pour envisager une inclusion dans ces études.

Il n'existe pas d'étude permettant de savoir si la pirfénidone ou le nintédanib peuvent causer des problèmes de cicatrisation en cas d'intervention chirurgicale. Le risque hémorragique lié à l'activité anti-angiogénique du nintédanib est mal connu en cas d'intervention. En pratique, la plupart des équipes arrêtent temporairement le traitement antifibrosant - environ trois semaines avant - en cas d'intervention chirurgicale majeure programmée ; la pratique varie selon les équipes de transplantation pulmonaire (dans une étude, les traitements étaient maintenus jusqu'à la transplantation sans complication particulière [112]).

\section{Quand débuter le traitement ?}

Il n'existe actuellement pas de recommandation précise sur le moment où il faut commencer le traitement antifibrosant. Cependant, la plupart des experts le débutent dès que le diagnostic de FPI est confirmé. Chez les patients asymptomatiques ou dont la fonction respiratoire est préservée au diagnostic, un temps d'observation initial avant le démarrage du traitement est proposé parfois car, à ce stade, les El des traitements peuvent dépasser leurs bénéfices cliniques. Cependant, il a été montré que même chez les patients ayant une fonction pulmonaire préservée, la maladie s'aggrave irrémédiablement, à la même vitesse, et les traitements ont le même bénéfice sur le déclin de la CVF $[107,113]$. Dans l'analyse post-hoc des essais Capacity et Ascend, l'effet de pirfénidone sur le score de dyspnée était significatif par rapport au placebo dans le sous-groupe des patients ayant à la randomisation une $\mathrm{CVF} \leq 80 \%$ ou un score GAP II-III, mais pas chez les patients ayant une CVF $>80 \%$ ou un score GAP I [113]. Dans l'analyse post-hoc des essais Inpulsis ${ }^{\odot}$, le nintedanib était associé à une moindre augmentation du score Saint-George de qualité de vie dans le groupe traité par rapport au placebo chez les patients ayant à la randomisation une CVF $\leq 70 \%$, mais il n'y avait pas de différence entre les deux groupes chez ceux dont la CVF était $>70 \%$ [107]. Ces observations suggèrent que l'effet du traitement sur la détérioration de la qualité de vie et l'aggravation de la dyspnée survient chez les patients dont la maladie s'accompagne d'une restriction fonctionnelle et peuvent participer à la décision thérapeutique. Il n'y a pas de donnée suffisante pour justifier le démarrage d'un traitement chez les patients dont la CVF est $<50 \%$ de la théorique et/ou la DLco $<30 \%$ de la théorique.

Le choix du traitement de première intention (pirfénidone ou nintédanib) tient compte des éléments figurant au Tableau 11, notamment en ce qui concerne les données démontrées pour les différents critères d'évaluation, la tolérance, les interactions médicamenteuses et les comorbidités. L'expérience du clinicien et la préférence du patient informé du bénéfice attendu (y compris pour la dyspnée et la qualité de vie) et des effets indésirables éventuels des traitements interviennent également dans la décision. Des études sont en cours pour mieux évaluer le bénéfice et la tolérance du traitement à différents stades de la maladie.

\section{Recommandation 20}

Il est proposé de traiter la FPI dès que le diagnostic est établi, en tenant compte de l'évaluation individuelle du bénéfice escompté et des risques du traitement.

\section{Traitements à visée antifibrosante non recommandés}

\section{Trithérapie associant prednisone-azathioprine - $\mathrm{N}$-acétylcystéine}

L'essai Ifigenia, un ECR publié en 2005 [114], avait suggéré un bénéfice fonctionnel respiratoire associé à l'administration de la $\mathrm{N}$-acétylcystéine (NAC) à posologie antioxydante $(1,8 \mathrm{~g} / \mathrm{j})$ chez les patients atteints de FPI et recevant, par ailleurs, une association de prednisone et d'azathioprine. Cependant, cette étude ne permettait pas de comparer directement au placebo le traitement triple combiné, ni le NAC en monothérapie.

L'essai randomisé à trois bras Panther a comparé les effets de la trithérapie azathioprine - prednisone - NAC 
Tableau 11 Pirfénidone et nintédanib : synthèse pour la pratique.

\begin{tabular}{|c|c|c|}
\hline & Pirfénidone $^{a}$ & Nintédanib \\
\hline Indication & $\begin{array}{l}\text { FPI confirmée avec CVF } \geq 50 \% \text { et } \\
\text { DLco } \geq 30 \%\end{array}$ & $\begin{array}{l}\text { FPI confirmée avec CVF } \geq 50 \% \text { et } \\
\text { DLco } \geq 30 \%\end{array}$ \\
\hline $\begin{array}{l}\text { Critères diagnostiques de FPI } \\
\text { dans les essais }\end{array}$ & Stricts & $\begin{array}{l}\text { Inclusion de patients ayant des critères } \\
\text { de PIC possible, avec bronchectasies par } \\
\text { traction sans rayon de miel et sans } \\
\text { confirmation histologique }\end{array}$ \\
\hline Critère de jugement principal & Déclin de la CVF & Pente de déclin de la CVF \\
\hline \multirow[t]{2}{*}{ Critères secondaires } & TM6 & Exacerbations aiguës (adjudiquées) \\
\hline & $\begin{array}{l}\text { Mortalité de toute cause à } 1 \text { an (analyse } \\
\text { groupée) }\end{array}$ & Qualité de vie $(C V F<70 \%)$ \\
\hline \multirow[t]{3}{*}{ Tolérance } & Nausées, troubles digestifs & Diarrhée \\
\hline & Photosensibilité & Nausées \\
\hline & $\begin{array}{l}\text { Fatigue, troubles du sommeil } \\
\text { Amaigrissement }\end{array}$ & Amaigrissement \\
\hline Dose maximale recommandée & 9 gélules à $267 \mathrm{mg} / \mathrm{j}$ en cours de repas & 2 gélules à $150 \mathrm{mg} / \mathrm{j}$ en cours de repas \\
\hline Surveillance & Bilan hépatique & Bilan hépatique \\
\hline \multirow[t]{2}{*}{ Prescription } & Pneumologue hospitalier & Pneumologue hospitalier \\
\hline & Médicament d'exception & Médicament d'exception \\
\hline SMR & Modéré & Modéré \\
\hline ASMR & Mineure (ASMR IV) & Mineure (ASMR IV) \\
\hline Commercialisation & 2012 & 2016 \\
\hline Interactions principales & $\begin{array}{l}\text { Inhibiteurs du CYP1A2 fluvoxamine } \\
\text { (contre-indiquée), jus de pamplemousse, } \\
\text { ciprofloxacine, amiodarone, propafénone } \\
\text { Autres inhibiteurs du CYP : fluoxétine, } \\
\text { paroxétine, chlormaphénicol } \\
\text { Inducteurs du CYP1A2 (ou autres CYP) : } \\
\text { tabac, oméprazole }{ }^{b} \text {, rifampicine }\end{array}$ & $\begin{array}{l}\text { Inhibiteurs de la P-gp : kétoconazole, } \\
\text { érythromycine, ciclosporine } \\
\text { Inducteurs de la P-gp : rifampicine, } \\
\text { carbamazépine, phénytoïne } \\
\text { Pirfénidone }\end{array}$ \\
\hline Contre-indications & $\begin{array}{l}\text { Hypersensibilité/angio-œdème à la } \\
\text { pirfénidone } \\
\text { Traitement par fluvoxamine } \\
\text { Insuffisance hépatique ou rénale sévère } \\
\text { Tabac fortement déconseillé }\end{array}$ & $\begin{array}{l}\text { Hypersensibilité au nintédanib ou au soja } \\
\text { Éviter si traitement anticoagulant, } \\
\text { traitement antiagrégant plaquettaire à } \\
\text { forte posologie, risque hémorragique, ou } \\
\text { cardiopathie ischémique }\end{array}$ \\
\hline
\end{tabular}

ASMR : amélioration du service médical rendu ; CVF : capacité vitale forcée ; DLco : capacité de diffusion du monoxyde de carbone ; FPI : fibrose pulmonaire idiopathique ; P-gp : p-glycoprotéine ; SMR : service médical rendu ; TM6 : test de marche de 6 minutes.

a Pour une information plus complète, voir le résumé des caractéristiques du produit.

b Les autres inhibiteurs de la pompe à protons peuvent être utilisés.

à ceux de la NAC en monothérapie et du placebo, en termes de déclin de la CVF à 60 semaines [115]. Le bras trithérapie a été arrêté prématurément en raison d'une augmentation significative de la mortalité globale $(p=0,01)$ et des hospitalisations non programmées $(p<0,001)$ comparativement au placebo, sans différence significative en termes de fonction respiratoire mesurée par la CVF.

\section{Recommandation 21}

Il est recommandé de ne pas débuter une trithérapie associant prednisone-azathioprine- $\mathrm{N}$-acétylcystéine chez les patients ayant un diagnostic confirmé de FPI.

\section{$\mathrm{N}$-acétylcystéine}

L'essai Panther (cf. ci-dessus) n'a pas montré de différence significative entre NAC et placebo en termes d'évolution de la CVF à la $60^{\circ}$ semaine de traitement (critère principal) [115].

Une analyse pharmacogénomique post-hoc de l'essai Panther a suggéré que le traitement par NAC pourrait être bénéfique chez certains patients porteurs d'un polymorphisme du gène TOLLIP présent dans environ $25 \%$ de la population ; inversement, il serait délétère chez $25 \%$ et sans effet chez $50 \%$ des sujets [116]. Ces données restent à confirmer avant d'être appliquées à la clinique. Une étude récente indique que l'association de la NAC à la pirfénidone pourrait avoir un effet délétère sur les effets de la pirfénidone, selon des mécanismes non définis [117]. 


\section{Recommandation 22}

Il n'est pas recommandé de débuter une monothérapie par $\mathrm{N}$-acétylcystéine chez les patients ayant un diagnostic confirmé de FPI.

\section{Recommandation 23 \\ Il n'est pas recommandé d'associer $\mathrm{N}$-acétylcystéine et pirfénidone.}

\section{Corticothérapie}

Les études (non contrôlées, anciennes et de faible effectif) n'ont pas montré d'amélioration de la survie des patients traités par corticothérapie $[10,118]$. La corticothérapie est associée à une morbidité importante à long terme [119]. Les biais méthodologiques [120-122] ou les résultats contradictoires $[123,124]$ des études ayant évalué l'effet de la corticothérapie associée à un traitement immunomodulateur (par exemple, azathioprine ou cyclophosphamide) sur la survie des patients ne permettent pas de recommander cette association dans le traitement de la FPI.

Une corticothérapie orale ne dépassant pas $10 \mathrm{mg} / \mathrm{j}$ de prednisone est parfois proposée pour son effet sur la toux lorsqu'elle est invalidante (cf. ci-dessous) [125]. La corticothérapie à posologie élevée est proposée en cas d'exacerbation aiguë (cf. ci-dessous) [3].

Il est à noter que dans les essais thérapeutiques ayant validé l'utilisation de la pirfénidone et du nintédanib (cf. ci-dessus) l'utilisation de faibles doses de prednisone $(<15 \mathrm{mg} / \mathrm{j})$ était possible, en association à ces médicaments ; les analyses a posteriori n'ont pas montré d'interaction avec l'effet bénéfique de ces agents et n'ont pas suggéré l'existence d'un bénéfice associé à la corticothérapie elle-même. En revanche, des données issues de ces analyses a posteriori suggèrent que les corticoïdes utilisés seuls, même à ces doses faibles, pourraient favoriser la survenue d'exacerbations [107].

\section{Recommandation 24}

Il n'est pas recommandé de prescrire une corticothérapie (avec ou sans immunosuppresseur) chez les patients ayant un diagnostic confirmé de FPI en dehors d'une exacerbation aiguë de fibrose.

\section{Traitement anticoagulant}

Un essai caractérisé par des limites méthodologiques importantes avait suggéré l'existence d'une amélioration de la survie associée à un traitement anticoagulant (warfarine au long cours ; héparine non fractionnée ou de bas poids moléculaire [HBPM] lors d'une hospitalisation) [126]. Un autre essai plus récent et de meilleure qualité méthodologique, ayant comparé la warfarine au placebo, a été arrêté prématurément en raison d'un excès de mortalité $(p=0,005)$ dans le groupe warfarine et d'une prévalence élevée des $\mathrm{EI}$, sans bénéfice apparent sur la progression de la maladie [127].
L'effet défavorable des anticoagulants n'était pas lié à une augmentation des évènements hémorragiques. Une étude observationnelle a suggéré que l'effet délétère des antivitaminiques $\mathrm{K}$ sur la survie s'observe également lorsqu'ils sont utilisés dans une autre indication que la FPI [128]. Il n'y a pas de donnée disponible sur l'effet des anticoagulants oraux directs au cours de la FPI.

\section{Recommandation 25}

Il est recommandé de ne pas prescrire un traitement anticoagulant par la warfarine pour le traitement de la fibrose chez les patients ayant un diagnostic confirmé de FPI. Les antivitaminiques K oraux ne sont pas contreindiqués au cours de la FPI lorsqu'ils sont indiqués par ailleurs (indication cardiovasculaire notamment), mais ils pourraient avoir un effet délétère. Il n'y a pas de donnée disponible concernant les anticoagulants oraux directs au cours de la FPI.

\section{Colchicine}

Plusieurs essais prospectifs n'ont pas montré de bénéfice clinique associé à la colchicine dans le traitement de la FPI [129-131]. Une étude rétrospective n'a montré aucun effet de la colchicine sur la survie [10].

\section{Recommandation 26}

Il n'est pas recommandé de prescrire un traitement par colchicine chez les patients ayant un diagnostic confirmé de FPI.

\section{Ciclosporine}

Deux études ayant inclus des effectifs limités de patients atteints de FPI, receveurs de greffe pulmonaire et dont le traitement immunosuppresseur comprenait de la ciclosporine, ont montré une progression de la maladie au niveau du poumon non transplanté $[132,133]$.

\section{Recommandation 27}

Il n'est pas recommandé de prescrire un traitement par ciclosporine A chez les patients ayant un diagnostic confirmé de FPI.

\section{Interféron-gamma-1b}

Deux ECR, dont l'un a inclus plus de 800 patients atteints d'une forme non avancée de FPI, ont montré l'absence d'effet de l'interféron- $\gamma$ - $1 \mathrm{~b}$ sur la progression de la maladie [134] et sur la survie globale [135].

\section{Antagonistes des récepteurs de l'endothéline-1}

Un ECR de phase II du bosentan, un antagoniste des récepteurs $A$ et $B$ de l'endothéline-1, n'a pas montré 


\section{Recommandation 28}

Il n'est pas recommandé de prescrire un traitement par l'interféron-gamma-1b chez les patients ayant un diagnostic confirmé de FPI. d'amélioration du critère principal d'évaluation (TM6 modifié) [136]. Un ECR pivot ultérieur chez des patients ayant une FPI confirmée par biopsie pulmonaire n'a pas montré d'effet du bosentan sur le critère principal d'évaluation (délai jusqu'à l'aggravation de la FPI ou le décès), ni sur la qualité de vie ou la dyspnée [137].

L'essai contrôlé randomisé Music n'a pas montré de bénéfice du macitentan, un autre antagoniste des récepteurs $A$ et $B$ de l'endothéline-1, sur le critère principal d'évaluation (variation de la CVF par rapport à la valeur initiale) [138].

L'essai contrôlé randomisé ARTEMIS-IPF [139] a montré un effet défavorable de l'ambrisentan, antagoniste des récepteurs $A$ de l'endothéline-1, sur le critère principal d'évaluation (délai jusqu'au décès ou l'aggravation fonctionnelle respiratoire) et un taux plus élevé d'hospitalisations pour complications respiratoires ; l'ambrisentan est maintenant contre-indiqué au cours de la FPI (y compris la FPI avec HP sévère).

\section{Recommandation 29}

Il n'est pas recommandé de prescrire un traitement par le bosentan ou le macitentan chez les patients ayant un diagnostic confirmé de FPI.

\section{Recommandation 30}

Il est recommandé de ne pas prescrire un traitement par l'ambrisentan chez les patients ayant un diagnostic confirmé de FPI.

\section{Étanercept}

Un ECR de l'étanercept, un récepteur recombinant du tumour necrosis factor- $\alpha$ humain, n'a pas montré de différence comparativement au placebo en termes de changement de la CVF sur 48 semaines [140].

\section{Recommandation 31}

Il n'est pas recommandé de prescrire un traitement par l'étanercept chez les patients ayant un diagnostic confirmé de FPI.

\section{Carlumab}

Un ECR de phase II a évalué le carlumab, un anticorps monoclonal dirigé contre le $\mathrm{CC}$-chemokine ligand 2 , chez 126 patients atteints de FPI et n'a pas montré de bénéfice

\section{Recommandation 32}

Il n'est pas recommandé de prescrire un traitement par le carlumab chez les patients ayant un diagnostic confirmé de FPI.

comparativement au placebo, en termes d'évolution de la CVF à toutes les posologies testées [141].

\section{Simtuzumab}

Un ECR de phase II du simtuzumab, un anticorps monoclonal humanisé anti-lysil-oxydase-like 2 (LOXL2), a été arrêté prématurément début 2016 en raison d'une absence d'efficacité [142].

\section{Recommandation 33}

Il n'est pas recommandé de prescrire un traitement par le simtuzumab chez les patients ayant un diagnostic confirmé de FPI.

\section{Transplantation pulmonaire}

Les données disponibles indiquent que la transplantation pulmonaire améliore la survie des patients atteints de FPI à un stade avancé [143-145]. Cependant, comme le montrent les données du registre de l'International Society for Heart and Lung Transplantation (ISHLT), les résultats dans la FPI sont significativement moins bons que dans la mucoviscidose ou l'HP [146].

En termes d'indications, un consensus de l'ISHLT invite à scinder le problème en deux questions [147] (Tableau 12) :

- quand faut-il adresser le patient atteint de FPI à un centre de greffe pour évaluation?

- quand faut-il l'inscrire sur liste d'attente?

Schématiquement, ces préconisations invitent à réaliser l'évaluation en centre spécialisé de façon précoce et à inscrire le patient sur liste en cas d'aggravation objective de la maladie.

L'âge par lui-même ne constitue pas une contreindication à la transplantation [147]. La limite d'âge de 65 ans environ (âge physiologique) est relative et doit tenir compte des comorbidités. Au-delà de 65 ans, la transplantation peut s'envisager exceptionnellement en l'absence de comorbidités significatives. Le choix entre transplantation monopulmonaire ou bipulmonaire n'est pas tranché [148] et dépend en partie des équipes. Une étude récente conclut à l'absence de différence de survie actuarielle entre les deux techniques [149].

Il existe, en France, une procédure de transplantation en super urgence qui ouvre pendant 15 jours un accès prioritaire à un greffon en cas d'insuffisance respiratoire aiguë, c'est-à-dire en cas d'intubation ou d'hypoxémie mal corrigée sous oxygénothérapie à $12 \mathrm{~L} / \mathrm{min}$. Elle s'adresse à des patients déjà inscrits sur liste d'attente ou ayant finalisé un bilan prétransplantation éliminant des contre-indications à la greffe (ou des comorbidités qui compromettraient le 


$\begin{array}{ll}\begin{array}{l}\text { Tableau } 12 \text { Fibrose } \\ \text { thique/pneumopathies }\end{array} & \begin{array}{c}\text { pulmonaire } \\ \text { interstitielles diffuses }\end{array} \\ \text { indications de la transplantation pulmonaire. }\end{array}$

pronostic de la greffe). Une oxygénation extracorporelle (extracorporeal membrane oxygenation [ECMO]) peut être utilisée dans cette attente. Les résultats de la transplantation après ECMO sont presque comparables à ceux de la transplantation en conditions habituelles.

\section{Recommandation 34}

Il est recommandé d'envisager une transplantation pulmonaire dans les formes graves ou en cas d'aggravation de la maladie chez les patients ayant un diagnostic confirmé de FPI et âgés de moins de 65 ans. Au-delà de 65 ans, ce traitement peut être envisagé exceptionnellement.

\section{Transplantation pulmonaire et FPI génétique}

Une mutation du complexe télomérase (cf. ci-dessus) augmente significativement le risque de mortalité après transplantation pulmonaire : ce constat souligne l'intérêt

\section{Recommandation 35}

Il est recommandé d'informer précocement le patient de la possibilité de la transplantation pulmonaire, sauf contre-indication évidente à la transplantation.

\section{Recommandation 36}

Il est proposé d'évaluer précocement le patient dans un centre de transplantation pulmonaire.

de l'enquête génétique dans les fibroses pulmonaires familiales. La transplantation pulmonaire n'est pas contreindiquée dans cette situation, mais le surcroît de risque doit être communiqué au patient, discuté ensemble, évalué sur le plan hématologique (recherche d'une anomalie hématologique, avis hématologique spécialisé). L'azathioprine doit être évitée.

\section{Recommandation 37}

Il est proposé de rechercher des arguments cliniques et biologiques en faveur d'une fibrose pulmonaire familiale ou génétique lors du bilan prétransplantation pulmonaire pour FPI.

\section{Autres traitements médicaux}

\section{Vaccination antigrippale et antipneumococcique}

Il n'existe aucune étude spécifique concernant la pratique de ces vaccinations dans le contexte de la FPI. Il est toutefois hautement probable que, comme les autres patients présentant une pathologie respiratoire chronique, les patients atteints de FPI soient exposés à un risque élevé de décès s'ils développent une infection à pneumocoque ou une infection grippale. Malgré l'absence de preuve, la vaccination antipneumococcique peut être réalisée à l'aide du vaccin pneumococcique polyosidique conjugué 13-valent (Prévenar $13^{T M}$ ) complété deux mois plus tard du vaccin pneumococcique polyosidique 23-valent (Pneumo $23^{\mathrm{TM}}$ ).

\section{Recommandation 38}

Il est recommandé de réaliser la vaccination antigrippale annuelle et la vaccination antipneumococcique chez les patients ayant un diagnostic confirmé de FPI. 


\section{Traitements symptomatiques (toux, dyspnée)}

\section{Toux}

Des données limitées suggèrent que les corticoïdes oraux et la thalidomide peuvent atténuer la toux chronique associée à la FPI [125,150,151]. L'utilisation des corticoïdes oraux à posologie élevée et de la thalidomide est déconseillée du fait de leur mauvaise tolérance.

Bien que le reflux gastro-esophagien soit fréquent au cours de la FPI, une étude randomisée contre placebo sur 18 patients n'a pas montré d'effet bénéfique du traitement antireflux sur la toux [152]. Des études sont en cours pour évaluer l'effet de la pirfénidone sur la toux.

\section{Recommandation 39}

Il est proposé de prescrire transitoirement une corticothérapie orale à faible posologie chez les patients atteints de FPI et présentant une toux sèche invalidante non améliorée par la codéine, en évaluant son efficacité et sa tolérance.

\section{Dyspnée}

Lorsqu'elle est réalisable, la réhabilitation respiratoire est le traitement non médicamenteux le plus efficace pour améliorer la dyspnée d'effort [153-156]. L'efficacité de la réhabilitation est le plus souvent maintenue à six mois. Le maintien des acquis à plus long terme est discuté et non retrouvé dans la majorité des études.

Une étude ayant inclus un effectif limité a montré une amélioration de la capacité d'exercice chez les patients atteints de FPI et recevant une oxygénothérapie en raison d'une hypoxémie au repos [157]. Selon deux études rétrospectives, l'oxygénothérapie ambulatoire peut améliorer significativement les performances au TM6 et la dyspnée chez les patients atteints de FPI [158,159]. Dans ces deux études, le débit d'oxygène était augmenté par paliers successifs jusqu'à ce que la saturation percutanée en oxygène soit $\geq 88 \%$ ou $90 \%$. Les modalités optimales de l'oxygénothérapie chez ces patients restent toutefois à préciser. Cet effet bénéfique de l'oxygénothérapie de déambulation sur la dyspnée n'a pas été retrouvé dans une étude récente [160].

Les dérivés morphiniques à faible dose $(10$ à $30 \mathrm{mg} / \mathrm{j})$ $[161,162])$ peuvent être utilisés en cas de dyspnée importante en surveillant attentivement les effets indésirables de ce traitement [163]. La morphine inhalée n'est pas efficace.

\section{Recommandation 40}

Il est proposé de prescrire une oxygénothérapie de déambulation chez les patients ayant un diagnostic confirmé de FPI et présentant une dyspnée d'effort importante et une désaturation à l'effort (saturation percutanée en oxygène $<88 \%$ lors des activités quotidiennes ou d'un exercice standardisé comme un test de marche de 6 minutes).

\section{Recommandation 41}

Il est proposé de prescrire des dérivés morphiniques à faible dose chez les patients atteints de FPI et présentant une dyspnée de repos, en l'absence d'hypercapnie, en évaluant leur efficacité, et en surveillant leur tolérance.

\section{Oxygénothérapie}

Des preuves indirectes d'un effet bénéfique de l'oxygénothérapie sont suggérées par les études ayant inclus des patients atteints de maladies pulmonaires obstructives [164,165]. L'oxygénothérapie de longue durée est habituellement indiquée au cours de l'insuffisance respiratoire chronique grave : $\mathrm{PaO}_{2} \leq 55 \mathrm{mmHg}(7,3 \mathrm{kPa})$ (soit $\mathrm{SaO}_{2} \leq 88 \%$ ) mesurée au repos en état stable à deux reprises; ou $\mathrm{PaO}_{2}$ entre $55-60 \mathrm{mmHg}(7,3-8,0 \mathrm{kPa})$ en présence de l'un au moins des critères suivants : polyglobulie (hématocrite $>55 \%$ ), signes d'HP, signes documentés d'insuffisance cardiaque droite. Les indications optimales de l'oxygénothérapie de longue durée au cours de la FPI restent toutefois à préciser.

Le bénéfice de l'oxygénothérapie de déambulation dans la FPI est discuté. Selon un ECR en double insu vs. air ambiant, elle semble améliorer la capacité à l'exercice mais le bénéfice sur la dyspnée est incertain, variable d'un patient à l'autre [160] (cf. ci-dessus).

\section{Recommandation 42}

Il est recommandé d'utiliser l'oxygénothérapie de longue durée chez les patients ayant un diagnostic confirmé de FPI et présentant une insuffisance respiratoire chronique grave, définie par une $\mathrm{PaO}_{2}<55 \mathrm{mmHg}$.

\section{Réhabilitation respiratoire}

Deux ECR ont montré une amélioration de la distance de marche, des symptômes ou de la qualité de vie chez des patients atteints de FPI suivant un programme de réhabilitation respiratoire $[166,167]$. Ses effets positifs sur la dyspnée ont été évoqués ci-dessus.

Les effets bénéfiques de la réadaptation respiratoire seraient plus marqués chez les patients ayant une forme avancée de FPI [168]. Toutefois, dans une autre étude, les améliorations du TM6 ont été d'autant plus prononcées que la maladie était moins sévère [169]. Le bénéfice de la réhabilitation semble persister à six mois si le maintien de l'activité physique est supervisé [170]. Les effets bénéfiques de la réhabilitation respiratoire seraient moins prononcés qu'au cours de la bronchopneumopathie chronique obstructive [171]. Dans une cohorte de 402 patients atteints de PID (dont la FPI), la réhabilitation respiratoire a été suivie d'une amélioration moyenne du périmètre de marche de 6 minutes de $46 \pm 3 \mathrm{~m}$, et d'une amélioration d'un score de santé physique et mentale (SF-36), sans modification du score de dyspnée [172]. 
La réhabilitation respiratoire n'est pas possible chez tous les patients atteints de FPI. Ses modalités restent à préciser ; elle peut inclure un entraînement à l'effort, un sevrage tabagique, une aide psychosociale et des soins de support. Elle est réalisable à domicile et susceptible d'améliorer la qualité de vie dans ce contexte [173]. Les indications prennent en compte les déficiences fonctionnelles (respiratoire, cardiocirculatoire, et musculaire) mesurées par la consommation maximale d'oxygène et/ou le TM6, et le handicap lié à la dyspnée et la dégradation de la qualité de vie qui lui est associée (restriction de la diversité des activités de la vie quotidienne et diminution de la participation à ces activités, telles que la marche).

\section{Recommandation 43}

Il est proposé de prescrire un programme de réhabilitation respiratoire aux patients ayant un diagnostic confirmé de FPI et présentant une limitation de leur capacité à l'exercice avec un handicap significatif.

\section{Soins palliatifs}

Il est souhaitable que la prise en charge palliative des patients atteints de FPI se développe et se structure en France [174]. Par rapport aux patients atteints de cancer, les patients atteints de PID sont moins pris en charge dans des structures de soins palliatifs, et ont une dyspnée plus importante [175]. Une étude randomisée a montré que la discussion collégiale des soins palliatifs ou des soins de support est acceptable et bénéfique au plan symptomatique et psychologique [176]. Il est souhaitable aussi de recueillir les directives anticipées des patients atteints de FPI. L'oxygénation à haut débit pourrait être intéressante dans les situations de fin de vie, mais elle est souvent peu efficace sur la dyspnée [177].

\section{Complications et comorbidités}

\section{Exacerbations aiguës}

\section{Diagnostic}

La notion d'exacerbation aiguë de FPI a été récemment revue et modifiée par un groupe coopérateur international [178]. Une nouvelle notion, celle d'aggravation respiratoire aiguë a été introduite car elle est associée à un mauvais pronostic. La nouvelle définition identifie une détérioration respiratoire aiguë cliniquement manifeste durant moins de 1 mois qui, si elle correspond à une cause parenchymateuse avec à l'imagerie un aspect en verre dépoli bilatéral ou alvéolaire bilatéral, est appelée exacerbation aiguë de FPI (Tableau 13). Cette dernière peut être classée en exacerbation idiopathique ou exacerbation déclenchée (par une infection, une procédure diagnostique, une cause médicamenteuse, une inhalation). Dans de rares cas, l'exacerbation aiguë est révélatrice de la maladie. L'aggravation respiratoire aiguë est de mauvais pronostic, même quand elle admet une cause sous-jacente, si elle nécessite une
Tableau 13 Exacerbation aiguë de fibrose pulmonaire idiopathique : critères diagnostiques en 2016.

Diagnostic préalable ou concomitant de $\mathrm{FPI}^{\mathrm{a}}$ Aggravation aiguë ou apparition d'une dyspnée depuis moins d'un mois

Scanner thoracique montrant de nouvelles opacités en verre dépoli et/ou condensation superposées à un aspect sous-jacent compatible avec un aspect de PIC $^{\mathrm{b}}$

Aggravation non totalement expliquée par une insuffisance cardiaque ou une surcharge hydrosodée

D'après Collard et al. [178].

FPI : fibrose pulmonaire idiopathique ; PIC : pneumopathie interstitielle commune. Les évènements qui sont considérés cliniquement comme des exacerbations aiguës de FPI mais qui ne remplissent pas les 4 critères diagnostiques du fait de données manquantes (absence de scanner thoracique) doivent être appelés « suspicion d'exacerbation aiguë ».

a Si le diagnostic de FPI n'est pas établi au préalable, ce critère peut être rempli en cas de présence d'un aspect de PIC au scanner et/ou à la biopsie sur l'évaluation actuelle.

b S'il n'y a pas de scanner thoracique antérieur, le qualificatif « nouvelles » peut être omis.

hospitalisation [179]. Le pronostic des exacerbations aiguës est sombre, le taux de mortalité à 3 ou 4 mois étant de $50 \%$ environ [178].

Les facteurs de risque établis comprennent une maladie respiratoire avancée (DLco basse, périmètre de marche diminué, HP, mauvaise oxygénation, dyspnée importante, diminution récente de la CVF) et d'autres facteurs (âge jeune, coronaropathie, index de masse corporelle élevé et antécédent d'exacerbation aiguë) [180]. Le risque d'exacerbation est augmenté aux pics de pollution d'ozone et de dioxyde d'azote [181].

Un angioscanner est indispensable pour éliminer une embolie pulmonaire. Le scanner permet également d'éliminer un pneumothorax ou une pneumopathie. L'angioscanner ne permet pas toujours une étude optimale de la pneumopathie infiltrante et l'identification du verre dépoli, parce qu'il est généralement réalisé en respiration libre et que l'injection de produit de contraste ou le risque de manœuvre de Valsalva peuvent modifier légèrement la densité du parenchyme pulmonaire ; une acquisition complémentaire de haute résolution en coupes fines et en inspiration profonde doit être réalisée de manière complémentaire en cas d'étude parenchymateuse insuffisante pour analyser les opacités surajoutées aux anomalies antérieures, en particulier des opacités en verre dépoli.

Les investigations complémentaires à la recherche d'une cause d'aggravation respiratoire peuvent donc comporter : un scanner thoracique (en inspiration avec coupes millimétriques sans injection pour évaluation des opacités en verre dépoli ; et, si les $D$-dimères sont positifs, un angioscanner à la recherche d'une embolie pulmonaire), une gazométrie artérielle au repos, une échographie cardiaque, un examen cytobactériologique des expectorations, un dosage de 
pro-brain natriuretic peptide, de protéine C-réactive, de D-dimères, éventuellement de procalcitonine, des recherches de virus respiratoires sur sécrétions nasopharyngées, des antigènes urinaires pneumococcique et de légionelle, des anticorps antinucléaires (si non recherchés antérieurement) et, si l'état clinique du patient l'autorise, un prélèvement endobronchique (analyse microbiologique ; éventuelle formule cytologique) et éventuellement une spirométrie. Une aggravation de l'hypoxémie (diminution de $10 \mathrm{mmHg}$ de la $\mathrm{PaO}_{2}$ ) est habituelle. Il n'est habituellement pas réalisé de biopsie pulmonaire vidéochirurgicale, qui comporte dans ce contexte un risque très élevé ; elle montrerait un aspect de dommage alvéolaire diffus associé à un aspect de PIC (parfois associé à des lésions de pneumopathie organisée) [182].

\section{Recommandation 44}

Il est recommandé de diagnostiquer une exacerbation aiguë de $\mathrm{FPI}$ en cas d'aggravation récente de la dyspnée depuis moins d'un mois environ, non liée à une cause extraparenchymateuse (exemple : pneumothorax, pleurésie, embolie pulmonaire), associée à de nouvelles opacités en verre dépoli et/ou alvéolaires à l'imagerie, non totalement expliquée par une insuffisance cardiaque ou une surcharge hydrosodée. Un facteur déclenchant doit être recherché (infection, procédure diagnostique, cause médicamenteuse, inhalation). le nintédanib administré en traitement de fond diminue l'incidence des exacerbations dans les essais Inpulsis ${ }^{\circledR}$ (analyse groupée) $[106,186]$.

Une oxygénothérapie extracorporelle par membrane (ECMO) permet parfois de passer le cap de l'insuffisance respiratoire aiguë jusqu'à la transplantation pulmonaire [187].

En termes pratiques, on peut citer à titre indicatif le schéma suivant utilisé dans l'essai EXAFIP :

- méthylprednisolone i.v., $10 \mathrm{mg} / \mathrm{kg} / \mathrm{j}$ (1000 mg au maximum) de $\mathrm{j} 1$ à $\mathrm{j} 3$, puis prednisone $1 \mathrm{mg} / \mathrm{kg} / \mathrm{j} \times 1$ semaine, $0,75 \mathrm{mg} / \mathrm{kg} / \mathrm{j} \times 1$ semaine, $0,5 \mathrm{mg} / \mathrm{kg} / \mathrm{j} \times 1$ semaine, $0,25 \mathrm{mg} / \mathrm{kg} / \mathrm{j} \times 1$ semaine, puis $0,125 \mathrm{mg} / \mathrm{kg} / \mathrm{j}$ jusqu'à 6 mois ;

- HBPM à doses prophylactique pendant la durée de l'hospitalisation;

- prophylaxie de la pneumopathie à Pneumocystis jirovecii par cotrimoxazole ;

- antibiothérapie à large spectre pendant l'hospitalisation ;

- lorsque l'on envisage de recourir au cyclophosphamide intraveineux (i.v.), il peut être utilisé à la posologie $600 \mathrm{mg} / \mathrm{m}^{2}$ adaptée à l'âge et à la fonction rénale sans dépasser $1,2 \mathrm{~g}$ dose totale à $\mathrm{j0}, \mathrm{j} 15, \mathrm{~m} 1, \mathrm{~m} 2$, en association à l'uromitexan $\left(\mathrm{H} 0,200 \mathrm{mg} / \mathrm{m}^{2}\right.$ i.v. ; $\mathrm{H} 4$, $200 \mathrm{mg} / \mathrm{m}^{2}$ i.v.) lors de chaque administration de cyclophosphamide, en prévention de la cystite hémorragique.

\section{Recommandation 45}

Il est proposé d'inclure les malades dans les essais en cas d'exacerbations aiguës.

\section{Traitement}

L'exacerbation aiguë de la FPI est une urgence thérapeutique en raison de son mauvais pronostic. Néanmoins, les traitements utilisés sont fondés sur de faibles niveaux de preuve, faute d'études adéquates de bonne qualité.

Les corticoïdes à posologie élevée sont couramment prescrits et cités par les recommandations internationales bien qu'aucun essai contrôlé ne permette d'affirmer leur efficacité [183].

Des observations isolées ont suggéré un bénéfice des immunosuppresseurs. La ciclosporine $\mathrm{A}$ a également été utilisée, sans résultats concluants. Après qu'un effet a été suggéré par quelques observations [184], le cyclophosphamide intraveineux (ajouté à la corticothérapie) est actuellement évalué par un ECR de phase III (EXAFIP ${ }^{6}$ ) [185].

Les limites méthodologiques [126] et les résultats défavorables [127] des essais japonais ayant évalué l'effet des anticoagulants (warfarine notamment) dans la FPI ont déjà été mentionnés (cf. ci-dessus). Il n'y a pas de bénéfice démontré des HBPM au cours des exacerbations aiguës de FPI, mais ce traitement est parfois utilisé transitoirement. Un traitement anticoagulant peut être prescrit en cas d'aggravation aiguë des symptômes et de suspicion de maladie veineuse thrombo-embolique.

Il n'existe pas de données sur l'utilisation de la pirfénidone et du nintédanib dans le traitement curatif des exacerbations aiguës. Néanmoins, on peut rappeler que

\footnotetext{
${ }^{6}$ ClinicalTrials.gov, Identifier: NCT02460588.
}

Recommandation 46

Il est proposé d'utiliser les corticoïdes à posologie élevée pour traiter les exacerbations aiguës de la FPI.

\section{Ventilation invasive et non invasive, oxygénothérapie à haut débit}

Plusieurs études ayant inclus des effectifs faibles ont évalué la ventilation mécanique chez des patients atteints de $\mathrm{FPI}$ en insuffisance respiratoire aiguë et ont montré un taux de mortalité hospitalière très élevé [188-197]. Les critères d'inclusion étaient variables ; deux de ces études ont inclus des patients présentant une insuffisance respiratoire aiguë d'étiologie inconnue [182,191]. Une étude représentative de 23 patients atteints de FPI et présentant une insuffisance respiratoire aiguë nécessitant une ventilation mécanique a montré un taux de mortalité hospitalière de $96 \%$ [190]. Une revue systématique de la ventilation mécanique chez 
135 patients atteints de FPI et présentant une insuffisance respiratoire aiguë (liée ou non à une exacerbation aiguë de FPI) a décrit un taux de mortalité hospitalière de $87 \%$ [198]. Néanmoins, le pronostic semble un peu moins sombre dans les publications plus récentes $[199,200]$.

Il existe très peu de données concernant la ventilation non invasive au cours de la FPI. Une étude rétrospective ayant inclus quelques patients présentant une exacerbation aiguë de FPI a suggéré que, dans ce contexte, la ventilation non invasive peut être préférée à la ventilation invasive sans accroître la mortalité [201]. Il est à noter que les techniques de prise en charge peu invasive se sont améliorées (oxygénation à fort débit).

\section{Indications du transfert en réanimation}

Compte tenu de la forte mortalité associée à la ventilation mécanique dans la FPI, ce traitement ne devrait être utilisé qu'après avoir été discuté avec les patients et leurs aidants (idéalement à l'avance) des objectifs thérapeutiques, concernant notamment la réduction des souffrances inutiles.

Les mesures de réanimation chez un patient en exacerbation aiguë de FPI apparaissent justifiées lorsqu'existe un projet de transplantation pulmonaire ou qu'une cause réversible d'aggravation a été identifiée, voire si la recherche étiologique n'a pas été effectuée. A contrario, ce transfert apparaît souvent déraisonnable si le projet de transplantation pulmonaire a été récusé et/ou si aucune cause d'aggravation aiguë n'a été identifiée par un bilan complet [202]. L'appréciation du clinicien est ici essentielle.

\section{Recommandation 48}

Il est proposé de n'utiliser la ventilation invasive ou non invasive que chez une minorité de patients atteints de FPI et en état d'insuffisance respiratoire aiguë, notamment si le patient répond aux critères de transplantation pulmonaire selon la procédure de super-urgence, s'il s'agit d'une exacerbation inaugurale de FPI, ou s'il existe une cause potentiellement réversible, ou que le diagnostic étiologique n'a pas encore été réalisé.

\section{Hypertension pulmonaire}

\section{Épidémiologie, diagnostic}

L'hypertension pulmonaire (HP) précapillaire est définie par une pression artérielle pulmonaire moyenne $\geq 25 \mathrm{mmHg}$ et une pression artérielle pulmonaire d'occlusion $\leq 15 \mathrm{mmHg}$ mesurée par cathétérisme cardiaque droit. Une HP précapillaire est présente chez $10 \%$ environ des patients atteints de FPI au moment du diagnostic et chez $30-45 \%$ lors du bilan prétransplantation pulmonaire [203]. L'HP est sévère (pression artérielle pulmonaire moyenne $\geq 40 \mathrm{mmHg}$ ) chez 2-9\% des patients atteints de FPI [204,205]. Lorsqu'elle est présente, l'HP est associée à une augmentation de la mortalité [205], de la dyspnée, de l'incapacité à l'exercice, à une altération de la DLco, une hypoxémie plus marquée et à un risque d'exacerbation aiguë de la FPI [206].
La survenue d'une HP au cours de la FPI doit faire rechercher une autre cause que la FPI : maladie veineuse thromboembolique, syndrome d'apnées obstructives du sommeil et/ou insuffisance cardiaque gauche, dont la prévalence est augmentée au cours de la FPI.

L'échographie cardiaque est l'examen non invasif de première intention pour détecter l'HP ; néanmoins, l'échographie cardiaque avec Doppler ne permet d'évaluer la pression artérielle pulmonaire systolique que chez la moitié environ des patients [207], peut sous-estimer ou surestimer la pression pulmonaire [207,208], et les valeurs prédictives positives et négatives pour le diagnostic d'HP précapillaire sont faibles [209]. D'autres approches ont été proposées, mais elles peuvent aussi être prises en défaut : scanner thoracique [210], dosage de BNP [211], score prédictif [212].

Le cathétérisme cardiaque droit permet de distinguer l'HP précapillaire d'une HP post-capillaire, notamment liée à une insuffisance cardiaque à fonction systolique préservée. Le cathétérisme cardiaque droit n'est pas recommandé en cas de suspicion d'HP au cours de la FPI sauf s'il admet des conséquences thérapeutiques concrètes (transplantation pulmonaire, autre diagnostic comme une HP du groupe 1 ou 4, inclusion dans un essai) [213]. S'il est réalisé, le cathétérisme doit comporter une épreuve de remplissage en cas de doute sur une insuffisance cardiaque gauche (notamment à fonction systolique préservée).

\section{Recommandation 49}

Il est proposé de pratiquer une échographie cardiaque au diagnostic de FPI.

\section{Recommandation 50}

Il est recommandé d'adresser à un centre spécialisé les patients avec FPI ayant à l'échographie cardiaque des signes d'hypertension pulmonaire sévère et/ou de dysfonction ventriculaire droite.

\section{Recommandation $\mathbf{5 1}$}

Il est proposé de réaliser un cathétérisme cardiaque droit pour diagnostiquer une hypertension pulmonaire chez les patients ayant un diagnostic confirmé de FPI dans les situations suivantes :

- évaluation prétransplantation ;

- doute sur un autre diagnostic (hypertension artérielle pulmonaire du groupe 1, hypertension pulmonaire thromboembolique chronique, cardiopathie gauche à fonction systolique préservée) ;

- si une évaluation précise du pronostic est jugée essentielle ;

- possibilité d'inclusion dans un essai thérapeutique. 


\section{Traitement}

Il est nécessaire de corriger une éventuelle hypoxémie de repos en cas d'HP. La transplantation pulmonaire ou cardiopulmonaire doit être envisagée selon l'âge et les comorbidités.

Le traitement spécifique de l'HP au cours de la FPI n'est pas recommandé $[213,214]$. Plusieurs séries de cas et essais thérapeutiques ont été publiés qui testaient divers médicaments (ambrisentan, bosentan, époprosténol, iloprost, sildenafil, trépostinil) avec des résultats globalement décevants [215].

Une étude rétrospective du traitement par l'époprosténol intraveineux ou le bosentan oral chez quelques patients atteints d'HP et de FPI avait suggéré une amélioration de la qualité de vie et du TM6 sur une période de 6 mois [216]. Cependant, un ECR en double insu ayant comparé le bosentan au placebo chez 60 patients a été totalement négatif à 16 semaines de traitement [217].

Suite aux résultats défavorables de l'essai ARTEMIS-IPF [139] (cf. ci-dessus), et en conséquence de l'arrêt prématuré de l'essai ARTEMIS-PH chez les patients ayant une HP, l'ambrisentan est maintenant contre-indiqué au cours de la FPI (y compris avec HP sévère). Dans une analyse posthoc de l'essai ARTEMIS-IPF, l'ambrisentan n'a pas montré de bénéfice à 12 mois chez des patients ayant une FPI légère à modérée [218].

Des études ouvertes réalisées sur de petits effectifs ayant suggéré un effet positif en termes d'hémodynamique pulmonaire et de TM6 avec le sildénafil [219-221], ce dernier a été formellement évalué contre placebo par un ECR ayant inclus 180 patients atteints de FPI avec DLCo $\leq 40 \%$ (la proportion de ceux ayant une HP n'étant pas clairement indiquée). Cet essai n'a pas montré de différence significative à 12 semaines en faveur du sildénafil en termes d'amélioration du TM6 (critère principal) [222]. Le sildénafil a toutefois amélioré significativement l'oxygénation artérielle, la DLco, la dyspnée et la qualité de vie. Une analyse a posteriori a suggéré une amélioration du TM6 chez les patients ayant une dysfonction ventriculaire droite à l'échographie cardiaque [223]. Les données du registre international Compera suggèrent une amélioration fonctionnelle à court terme chez certains patients traités par vasodilatateurs pulmonaires, essentiellement des inhibiteurs de la phosphodiestérase de type 5 [224].

Une étude pilote ouverte non contrôlée a évalué le riociguat, stimulateur soluble de la guanylate-cyclase, chez des patients atteints de pneumopathie interstitielle et d'HP précapillaire et a montré une amélioration du débit cardiaque sans modification des pressions pulmonaires, au prix d'une moins bonne saturation [225]. Une étude de phase 2 testant le riociguat dans les PID idiopathiques avec HP symptomatique a été interrompue de façon précoce sur les recommandations du comité indépendant de suivi de l'essai en raison d'une augmentation de la mortalité et des évènements indésirables graves dans le groupe recevant le riociguat ${ }^{7}$. À la suite des résultats de cet essai, l'agence nationale de la sécurité du médicament et des produits de santé a alerté les professionnels de santé sur la

\footnotetext{
7 https://clinicaltrials.gov/ct2/show/NCT02138825.
}

contre-indication du riociguat chez les patients ayant une HP associée à une pneumopathie interstitielle idiopathique ${ }^{8}$.

\section{Recommandation $\mathbf{5 2}$}

Chez les patients atteints de FPI et présentant une hypertension pulmonaire, il est recommandé de rechercher et de corriger une hypoxémie de repos, une maladie veineuse thromboembolique, une insuffisance cardiaque gauche et d'évaluer la possibilité d'une transplantation pulmonaire.

\section{Recommandation 53}

Chez les patients atteints de FPI et présentant une hypertension pulmonaire précapillaire, il n'est pas recommandé de prescrire un traitement spécifique de l'hypertension pulmonaire.

\section{Recommandation 54}

Chez les patients atteints de FPI, il est recommandé de ne pas prescrire l'ambrisentan ou le riociguat.

\section{Reflux gastro-esophagien}

La fréquence et l'importance du reflux gastro-esophagien (RGO) acide et non acide sont augmentées au cours de la FPI [226], notamment en raison d'une forte prévalence des hernies hiatales dans cette population [227,228]. Asymptomatique dans la moitié des cas $[9,229,230]$, le RGO est particulièrement fréquent lorsque la fibrose est radiologiquement asymétrique [231]. Le RGO est un facteur de risque d'inhalation, cause connue de pneumopathie pouvant contribuer, notamment lorsqu'il s'agit de micro-inhalations asymptomatiques mais itératives, à l'inflammation chronique des voies respiratoires et à la fibrose [232].

\section{Traitement}

Deux séries rétrospectives ont décrit une stabilisation de la fonction pulmonaire et des besoins en oxygène associés au traitement médical ou chirurgical du RGO [131,233]. Selon une autre étude rétrospective, le traitement médical par inhibiteurs de la pompe à protons (IPP) ou antagonistes des récepteurs $\mathrm{H} 2$ (anti-H2) serait associé de façon indépendante à une augmentation de la survie chez les patients atteints de FPI [234]. Les faiblesses méthodologiques de cette étude, mais aussi l'intérêt de cet axe de recherche ont été soulignés [183,235]. L'analyse rétrospective du groupe

\footnotetext{
8 http://ansm.sante.fr/S-informer/Informations-de-securiteLettres-aux-professionnels-de-sante/Riociguat-Adempas-contreindication-chez-les-patients-avec-hypertension-pulmonaireassociee-a-une-pneumopathie-interstitielle-idiopathique-Lettreaux-professionnels-de-sante.
} 
placebo de trois essais thérapeutiques a montré une moindre diminution de la CVF à 30 semaines chez les patients ayant reçu un traitement anti-acide (IPP ou anti-H2), mais ces résultats sont à interpréter avec prudence en raison des limites méthodologiques de cette étude [236]. Enfin, une étude post-hoc de la population des essais Capacity-1 et -2 et Ascend (624 patients dont 291 recevaient un traitement anti-acide à l'entrée dans l'étude) n'a pas confirmé le bénéfice du traitement anti-acide sur l'évolution fonctionnelle de la maladie et a suggéré une augmentation du risque d'infections respiratoires chez les patients dont la CVF était $\leq 70 \%$ [237].

Il convient de tenir compte du risque accru de pneumonie et d'ostéoporose lié à la suppression de l'acidité gastrique par les IPP [238]. Les données disponibles ne permettent pas de recommander une prise en charge différente du RGO chez les patients atteints de FPI par rapport à la population générale [238], mais incitent à une vigilance particulière vis-à-vis d'un possible reflux et une prise en charge active. La place éventuelle de la prise en charge du reflux non acide n'est pas connue. Un essai randomisé en cours vise à préciser la place de la chirurgie du RGO dans la FPI ${ }^{9}$. La présence d'une hernie hiatale peut être recherchée au scanner thoracique [228].

L'association pirfénidone - oméprazole doit être évitée en raison du risque d'interaction médicamenteuse mais d'autres IPP peuvent être utilisés si nécessaire (Tableau 11). Une étude japonaise suggère que l'utilisation d'antisécrétoires gastriques améliore la tolérance digestive de la pirfénidone [239].

\section{Recommandation 55}

Il est proposé de rechercher à l'interrogatoire un antécédent ou des symptômes de RGO chez les patients ayant un diagnostic confirmé de FPI. Lorsqu'existe une suspicion de RGO, il est proposé de l'explorer et de le traiter.

\section{Emphysème}

L'existence d'un emphysème associé à la FPI modifie la présentation clinique (aggravation de la dyspnée) et l'EFR (volumes pulmonaires préservés, DLco plus basse contrastant avec le respect des volumes, besoins en oxygène majorés). Cette présentation constitue une entité radioclinique maintenant bien individualisée : le syndrome d'emphysème et fibrose (SEF) pulmonaires combinés. Un seuil d'emphysème représentant plus de $15 \%$ des poumons au scanner influence l'évolution fonctionnelle de la FPI et serait considéré comme un critère diagnostique du SEF. Ce syndrome a été associé à la plupart des anomalies génétiques décrites au cours de la FPI. L'existence d'un emphysème complique le diagnostic scannographique de PIC car il rend difficile la distinction entre rayon de miel, emphysème avec réticulation et fibrose avec élargissement des espaces aériens dans la périphérie des pyramides basales.

Des données rétrospectives suggèrent que l'évolution des patients atteints de SEF est plus défavorable que celle des patients atteints de FPI seule $[240,241]$ mais il n'existe pas de données ajustées pour les différents facteurs pronostiques permettant d'affirmer que l'emphysème modifie la survie. Le diagnostic de SEF permet de ne pas attribuer à tort la conservation des volumes et débits pulmonaires à une forme légère de FPI. L'HP précapillaire est particulièrement fréquente chez les patients atteints de SEF et représente le principal facteur prédictif de mortalité [242]. Les analyses avec ajustement sur la présence ou l'absence d'une $\mathrm{HP}$ n'ont pas montré d'effet significatif de l'emphysème sur la survie [242]. Des données limitées suggèrent que l'oxygénothérapie au long cours peut être utile chez les patients atteints de SEF [243]. Les patients présentant un SEF ont des variations longitudinales de CVF et de DLCo plus faibles que les patients atteints de FPI sans emphysème [244] ; le suivi individuel de la CVF et de la DLco ne permet pas d'évaluer précisément le pronostic [245].

Il n'y a actuellement pas de données permettant de recommander une prise en charge particulière de l'emphysème au cours de la FPI, ni de la fibrose au cours du SEF. La composante de fibrose du SEF peut être traitée par antifibrosants si les critères sont remplis pour le diagnostic de FPI (avec emphysème) et notamment si la fibrose semble prédominante sur l'emphysème au plan radiologique, fonctionnel respiratoire, et/ou évolutif. Une analyse des sous-groupes de patients inclus dans les essais Inpulsis ${ }^{\odot}$ (cf. ci-dessus) a suggéré une efficacité comparable du nintedanib avec ou sans emphysème à l'inclusion [246]. Le traitement médical éventuel (pirfénidone, nintédanib) doit être évalué individuellement en tenant compte des effets indésirables, de l'absence de donnée spécifique concernant le bénéfice potentiel du traitement dans cette indication et de la difficulté de juger de l'évolution de la maladie (peu de variation de la CVF).

\section{Recommandation 56}

Il est recommandé de rechercher des signes d'emphysème sur le scanner thoracique pratiqué pour le diagnostic de FPI, pour ne pas sous-estimer la sévérité du syndrome emphysème - fibrose pulmonaire lorsque les volumes sont préservés.

\section{Recommandation 57}

Lorsqu'existe un emphysème, il est proposé de le prendre en charge comme au cours de la bronchopneumopathie chronique obstructive, y compris la recherche d'un déficit en $\alpha$-1-antitrypsine et la prescription de bronchodilatateurs inhalés s'ils améliorent la dyspnée.

\footnotetext{
${ }^{9}$ https://clinicaltrials.gov/ct2/show/NCT01982968.
} 


\section{Recommandation 58}

Il est proposé de ne pas prendre en compte la présence de l'emphysème dans les choix des thérapeutiques antifibrosantes chez les patients ayant un diagnostic confirmé de FPI.

\section{Recommandation 59}

Il est proposé de surveiller plus particulièrement le risque d'hypertension pulmonaire sévère lorsqu'il existe un syndrome emphysème - fibrose.

\section{Syndrome d'apnées obstructives du sommeil}

Plusieurs études conduites sur de petites séries ont montré une fréquence élevée du syndrome d'apnées obstructives du sommeil (SAOS) chez les patients atteints de FPI [247-249]. Une étude ayant inclus 50 patients atteints de FPI a montré que $88 \%$ d'entre eux présentaient un SAOS [250]. L'interrogatoire s'est révélé beaucoup moins sensible que la polysomnographie pour établir ce diagnostic. Une obésité n'est pas toujours présente. Néanmoins, l'importance clinique de la recherche et du traitement d'un SAOS n'est pas démontrée dans ce contexte, en particulier chez les patients ne présentant pas de symptômes de SAOS.

Il n'existe pas de donnée permettant de formuler une recommandation relative au traitement du SAOS chez les patients atteints de FPI. Le traitement par pression positive continue semble efficace dans le contexte de la FPI et pourrait améliorer la qualité de vie [251]. Les données concernant l'utilisation de dispositifs extrathoraciques à pression négative chez ces patients sont trop limitées pour pouvoir les recommander en routine $[252,253]$. Les données disponibles ne permettent pas de recommander une prise en charge différente du SAOS chez les patients atteints de FPI par rapport à la population générale [254].

\section{Recommandation 60}

Il est recommandé de pratiquer une polygraphie ventilatoire ou une polysomnographie pour rechercher un SAOS chez les patients ayant un diagnostic confirmé de FPI s'il existe des signes cliniques évocateurs de syndrome d'apnées du sommeil. Il n'y a pas de données spécifiques concernant la prise en charge du syndrome d'apnées du sommeil au cours de la FPI par rapport aux patients sans FPI.

\section{Recommandation 61}

Lorsqu'il est présent chez les patients ayant un diagnostic confirmé de FPI, il est proposé de traiter un SAOS selon les recommandations habituelles en vigueur en dehors de la FPI.

\section{Cancer bronchopulmonaire}

Plusieurs études ont montré la fréquence élevée et le mauvais pronostic du cancer bronchopulmonaire (CBP) au cours de la FPI : comparativement à la population générale, le risque relatif de CBP au cours de la FPI a été estimé à 7,31 (IC 95 : 4,47-11,93) [255]. La prévalence du CBP au cours de la FPI serait située entre 4,4 et 9,8\% [255-257]. Dans une étude rétrospective de cohorte (103 patients atteints de $\mathrm{FPI}$ ), le risque cumulé de développer un CBP a atteint $55 \%$ à 10 ans [258]. Dans une récente étude rétrospective de cohortes, la prévalence du CBP histologiquement prouvé chez les patients atteints de FPI était de $13 \%$ et l'incidence cumulée a atteint $41 \%$ à un an et $82 \%$ à trois ans ; la survenue du cancer était de mauvais pronostic en termes de survie [259]. Les données disponibles ne permettent pas de proposer un dépistage du CBP au cours de la FPI, mais le médecin en charge du suivi doit être informé de sa fréquence afin d'en tenir compte en cas de modification clinique ou radiologique évocatrice. Le CBP est fortement associé à une augmentation du risque de décès au cours de la FPI (HR 2,9 $[1,6-5,2], p<0,0001)[260]$.

Le diagnostic de CBP sur FPI ou SEF est souvent problématique car ces patients fragiles sont difficiles à explorer en raison de l'insuffisance respiratoire sous-jacente [261]. Les petites tumeurs survenant sur poumon fibreux sont souvent difficiles à détecter et apparaissent comme de petits nodules solides de forme ronde ou ovalaire, développés le plus souvent en zone de fibrose [262]. Il s'agit le plus souvent de carcinomes bronchiques non à petites cellules (CBNPC).

Les données disponibles ne permettent pas de recommander une prise en charge spécifique du CBNPC au cours de la FPI. La prise en charge est rendue plus difficile par le risque d'insuffisance respiratoire aiguë et/ou d'exacerbation aiguë de FPI lors des traitements du cancer (exérèse chirurgicale, radiothérapie, chimiothérapie) [263]. Cependant, la prise en charge de ces malades doit se rapprocher le plus possible des recommandations de prise en charge en population normale. Dans les cancers localisés, le bilan d'opérabilité doit être mené jusqu'à la réalisation d'une $\mathrm{VO}_{2}$ max. Chez les malades dont l'opérabilité est retenue, la lobectomie permettrait d'obtenir une meilleure survie, mais le risque d'exacerbation serait moindre en cas de résection limitée [264]. Une étude rétrospective cas ( $n=12)$ /témoins $(n=16)$ suggère que l'utilisation d'un antifibrosant comme la pirfénidone pourrait réduire le risque d'exacerbation postopératoire chez des malades atteints de FPI [265]. Chez les malades inopérables, une étude rétrospective a suggéré la faisabilité de la radiothérapie stéréotaxique avec un risque accru de pneumopathie radique de grade 3 et 4 , mais avec un contrôle de la maladie équivalent et une survie similaire [266]. Dans les cancers localement avancés, il n'y a pas de données disponibles, mais la radiothérapie conventionnelle est déconseillée [267] ; ces malades sont pris en charge comme des cancers étendus. Dans les cancers étendus, la recherche d'une addiction oncogénique (mutation d'EGFR et réarrangement de $A L K)$ doit être réalisée, mais la fréquence du tabagisme chez les malades atteints de FPI rend rare la fréquence de détection de ces anomalies [268-271]. Par ailleurs, la présence d'une PID est associée à un risque multiplié par 2 ou 
3 de pneumopathie secondaire aux inhibiteurs de la tyrosine kinase de l'EGFR [272], avec un risque particulier associé au gefitinib (OR 2,20 [1,03-4,70]) [273]. En l'absence d'addiction oncogénique et chez les malades éligibles à une chimiothérapie, un doublet à base de platine peut être proposé. Cette proposition repose sur des données issues d'études de cohortes rétrospectives et reposant pour la plupart sur l'association carboplatine/paclitaxel [274-279] ; l'utilisation du bevacizumab chez quelques malades n'a pas posé de problème particulier [278]. Il existe très peu de données concernant le risque d'exacerbations en fonction des traitements utilisés [280], les résultats de chimiothérapies de deuxième ligne [279] et l'immunothérapie en cas de FPI. Tous ces éléments soulignent l'importance de l'orientation des malades atteints de FPI et de cancer bronchique vers des centres experts. La prise en charge palliative est souvent le seul recours possible.

La prise en charge des cancers bronchiques à petites cellules repose sur l'association carboplatine/étoposide, y compris dans les formes localisées au thorax, qui en cas de FPI ne peuvent pas bénéficier d'une radiothérapie thoracique [281-285].

\section{Recommandation 62}

Il est proposé d'informer le médecin en charge du suivi de la fréquence du cancer bronchopulmonaire chez les patients ayant un diagnostic confirmé de FPI.

\section{Recommandation 63}

Il est recommandé de conseiller au patient de cesser de fumer s'il est fumeur et de l'informer sur les moyens d'aide au sevrage tabagique.

\section{Recommandation 64}

Il est proposé de réaliser une TDM annuelle. Lorsqu'une TDM est réalisée, elle permet aussi de rechercher un cancer bronchique, en particulier chez les malades chez lesquels les données fonctionnelles respiratoires permettraient une exérèse chirurgicale en cas de cancer bronchopulmonaire localisé.

\section{Recommandation 65}

Chez les patients ayant un diagnostic confirmé de FPI et présentant un cancer bronchopulmonaire, il est recommandé de prendre en compte la FPI dans les choix thérapeutiques.

\section{Autres comorbidités}

La fréquence élevée des autres comorbidités associées à la FPI a été récemment confirmée par une revue systématique de la littérature [286]. Les maladies cardiovasculaires sont les comorbidités les plus fréquentes : leur incidence augmente avec l'ancienneté de la FPI et elles sont associées à un risque accru de mortalité $[287,288]$. Par exemple, dans le registre allemand INSIGHTS, on retrouvait à l'inclusion une hypertension artérielle, une coronaropathie et une sténose carotidienne et/ou un accident vasculaire cérébral dans environ $54 \%, 25 \%$ et $8 \%$ des cas, respectivement [97]. Le diabète est présent chez $10 \%$ à $20 \%$ des patients environ et il est de mauvais pronostic [288]. Le risque thromboembolique est significativement augmenté et semble plutôt associé à une FPI évoluée à pronostic défavorable [289]. Selon une étude observationnelle ayant comparé près de 9300 patients atteints de FPI à des témoins appariés pour l'âge et le sexe, le risque relatif est de 15,5 en ce qui concerne l'HP, 7 environ pour l'embolie pulmonaire et l'emphysème, 5,2 pour la bronchopneumopathie chronique, 3,8 pour l'insuffisance cardiaque, 3,6 pour le SAOS, 2,4 pour le RGO, 2,1 pour l'infarctus du myocarde et 1,7 pour la thrombose veineuse profonde [290].

Les données disponibles ne permettent pas de recommander de dépistage systématique de ces comorbidités, mais il est important d'en informer le médecin en charge du suivi (médecin généraliste ou pneumologue suivant l'organisation des soins). Le scanner thoracique réalisé pour le suivi de la FPI peut détecter certaines des comorbidités (athérome, calcifications coronariennes, séquelle d'infarctus du myocarde).

Enfin, il faut conseiller une ventilation protective dans toute chirurgie sous anesthésie générale, pour limiter le risque de barotraumatisme.

\section{Recommandation 66}

Il est proposé de rechercher des comorbidités (pathologies cardiovasculaires, maladie veineuse thromboembolique, diabète, dépression) chez les patients ayant un diagnostic confirmé de FPI et d'en informer le médecin traitant en charge du suivi.

\section{Remerciements}

Les auteurs remercient $M$. Benoît Bouquillon (Opened Mind Health, Lille) pour son aide à la coordination et l'établissement des recommandations ; M. le Pr Philippe Delaval, Rennes ; l'association pour l'amélioration de la prise en charge des maladies pulmonaires rares.

\section{Déclaration de liens d'intérêts}

Vincent Cottin : au cours des 5 dernières années, V. Cottin a perçu des honoraires ou financements pour des participations à des congrès, actions de formation, groupes d'experts, de la part des laboratoires Actélion, Bayer, Biogen Idec, Boehringer Ingelheim, Gilead, GSK, Novartis, Pfizer, Promédior, Roche et Sanofi. Son ex-épouse est employée par Sanofi. 
Bruno Crestani : au cours des 5 dernières années, B. Crestani a perçu des honoraires ou financements pour des communications, des participations à des congrès, à des groupes d'experts, des travaux de recherche, des actions de formation de la part des laboratoires Boehringer Ingelheim, MedImmune, Intermune, Roche et Sanofi.

Jacques Cadranel : au cours des 5 dernières années, J. Cadranel a été investigateur principal/coordonnateur/responsable scientifique d'études cliniques promues par les laboratoires Roche, Boehringer Ingelheim et Intermune; il a perçu des honoraires pour des actions de formation des laboratoires Roche et Intermune.

Jean-François Cordier : au cours des 5 dernières années, J.-F. Cordier a perçu des honoraires ou financements pour des participations à des congrès, actions de formation, communications, conseil, travaux de recherche, participation à des groupes d'experts, rôle d'investigateur principal/coordonnateur/responsable scientifique d'études cliniques de la part des laboratoires Actélion, Boehringer Ingelheim et Roche.

Sylvain Marchand-Adam : au cours des 5 dernières années, S. Marchand-Adam a perçu des honoraires ou financements pour des communications, du conseil, des participations à des congrès, groupes d'experts de la part des laboratoires Roche et Boehringer-Ingelheim ; S. Marchand-Adam a été investigateur principal ou coordonnateur d'études cliniques promues par les laboratoires Roche et Boehringer-Ingelheim.

Grégoire Prévot : au cours des 5 dernières années, G. Prévot a perçu des honoraires ou financements pour des participations à des congrès, communications, actions de formation, groupes d'experts, travaux de recherche, de la part des laboratoires Boehringer-Ingelheim, Roche, Actelion et GSK.

Emmanuel Bergot : au cours des 5 dernières années, E. Bergot a perçu des honoraires ou financements pour des participations à des congrès, missions de conseil, actions de formation, participation à des groupes d'experts, rôle d'investigateur principal/coordonnateur/responsable scientifique d'études cliniques de la part des laboratoires Boehringer Ingelheim et Roche.

Philippe Camus : au cours des 5 dernières années, P. Camus a perçu des honoraires ou financements pour des participations à des congrès, groupes d'experts, rôle d'investigateur principal d'études cliniques de la part des laboratoires Boehringer Ingelheim ; P. Camus possède des actions de Roche.

Jean-Charles Dalphin : au cours des 5 dernières années, J.-C. Dalphin a perçu des honoraires ou financements pour des participations à des congrès, actions de formation, conseil et participation à des groupes d'experts de la part des laboratoires Boehringer Ingelheim et Roche.

Claire Dromer : au cours des 5 dernières années, C. Dromer a perçu des honoraires ou financements pour des participations à des congrès et actions de formation de la part des laboratoires Roche et Boehringer Ingelheim.

Emmanuel Gomez : au cours des 5 dernières années, E. Gomez a perçu des financements pour des participations à des congrès de la part des laboratoires Boehringer Ingelheim.
Dominique Israel-Biet : au cours des 5 dernières années, D. Israel-Biet a perçu des honoraires ou financements pour des participations à des congrès, communications, actions de formation, des groupes d'experts, rôle d'investigateur principal/coordonnateur/responsable scientifique d'études cliniques de la part des laboratoires Boehringer Ingelheim, Intermune et Roche.

Stéphane Jouneau : au cours des 5 dernières années, S. Jouneau a perçu des honoraires ou financements pour des participations à des congrès, communications, actions de formation, groupes d'experts, travaux de recherche de la part des laboratoires Actelion, AIRB, Astra Zeneca, BMS, Boehringer, Chiesi, Gilead, GSK, Mundipharma, Novartis, Pfizer, Roche et Savara-Serendex.

Romain Kessler : au cours des 5 dernières années, R. Kessler a perçu des honoraires ou financements pour des participations à des congrès, communications, actions de formation, travaux de recherche, rôle d'investigateur principal/coordonnateur/responsable scientifique d'études cliniques de la part des laboratoires Intermune et Boehringer Ingelheim.

Charles-Hugo Marquette : au cours des 5 dernières années, C.-H. Marquette a perçu des financements ou des honoraires pour des participations à des congrès, actions de formation, groupes d'experts de la part des laboratoires Boehringer Ingelheim.

Martine Reynaud-Gaubert : au cours des 5 dernières années, M. Raynaud-Gaubert a perçu des honoraires ou financements pour des participations à des congrès, communications, actions de formation, groupes d'experts, rôle d'investigateur principal/coordonnateur/responsable scientifique d'études cliniques de la part des laboratoires Boehringer Ingelheim et Roche.

Bernard Aguilaniu : au cours des 5 dernières années, B. Aguilaniu a perçu des honoraires ou financements pour des participations à des congrès, communications, actions de formation, conseil, groupes d'experts, travaux de recherche de la part des laboratoires Intermune, Roche et Boehringer Ingelheim.

Daniel Bonnet : au cours des 5 dernières années, D. Bonnet a perçu des honoraires ou financements pour des participations à des congrès, actions de formation, groupes d'experts de la part des laboratoires Roche et Boehringer Ingelheim.

Philippe Carré : au cours des 5 dernières années, P. Carré a perçu des honoraires pour des actions de formation de la part des laboratoires Roche.

Claire Danel : au cours des 5 dernières années, C. Danel a participé à des sessions de formation pour les internes organisées avec les laboratoires Boehringer Ingelheim.

Jean-Baptiste Faivre : au cours des 5 dernières années, J.-B. Faivre a perçu des honoraires ou financements pour des participations à un groupe d'experts de la part des laboratoires Boehringer Ingelheim.

Gilbert Ferretti : au cours des 5 dernières années, G. Ferretti a perçu des honoraires ou financements pour des participations à des congrès, actions de formation, conseil, groupes d'experts de la part des laboratoires Boehringer Ingelheim et Roche. 
Nicolas Just : au cours des 5 dernières années, N. Just a perçu des financements pour des participations à des congrès de la part des laboratoires Roche.

François Lebargy : au cours des 5 dernières années, F. Lebargy a perçu des honoraires ou financements pour des participations à des congrès, actions de formation, travaux de recherche, participation à des essais thérapeutiques en tant qu'investigateur principal, de la part des laboratoires Boehringer Ingelheim et Roche.

Philippe Terrioux : au cours des 5 dernières années, P. Terrioux a perçu des financements pour participation à des congrès de la part des laboratoires Boehringer Ingelheim.

Françoise Thivolet-Béjui : au cours des 5 dernières années, F. Thivolet a perçu des honoraires ou financements pour des participations à des actions de formation et à des groupes d'experts de la part des laboratoires Boehringer Ingelheim, / agence Relmagine.

Dominique Valeyre : au cours des 5 dernières années, D. Valeyre a perçu des honoraires ou financements pour des communications, participations à des congrès, actions de formation, conseil, travaux de recherche, groupes d'experts, rôle d'investigateur principal/coordonnateur/responsable scientifique d'études cliniques de la part des laboratoires Intermune, Boehringer Ingelheim, Roche et Astra.

Benoît Wallaert, Bruno Philippe et Bruno Trumbic déclarent ne pas avoir de liens d'intérêts.

\section{Annexe A. Matériel complémentaire}

Le matériel complémentaire (annexes 1-3) accompagnant la version en ligne de cet article est disponible sur http://www.sciencedirect.com et http://dx.doi.org/10.1016/j.rmr.2017.07.018.

\section{Références}

[1] Nalysnyk L, Cid-Ruzafa J, Rotella P, et al. Incidence and prevalence of idiopathic pulmonary fibrosis: review of the literature. Eur Respir Rev 2012;21:355-61.

[2] Hopkins RB, Burke N, Fell C, et al. Epidemiology and survival of idiopathic pulmonary fibrosis from national data in Canada. Eur Respir J 2016.

[3] Raghu G, Collard HR, Egan JJ, et al. An official ATS/ERS/JRS/ALAT statement: idiopathic pulmonary fibrosis: evidence-based guidelines for diagnosis and management. Am J Respir Crit Care Med 2011;183:788-824.

[4] Cottin V, Crestani B, Valeyre D, et al. Recommandations pratiques pour le diagnostic et la prise en charge de la fibrose pulmonaire idiopathique. Élaborées par le centre national de référence et les centres de compétence pour les maladies pulmonaires rares sous l'égide de la Société de pneumologie de langue française. Rev Mal Respir 2013;30:879-902.

[5] Haute Autorité de santé. Méthode «Recommandations pour la pratique clinique ». Saint-Denis: HAS; 2010.

[6] Gribbin J, Hubbard RB, Le Jeune I, et al. Incidence and mortality of idiopathic pulmonary fibrosis and sarcoidosis in the UK. Thorax 2006;61:980-5.

[7] Scott J, Johnston I, Britton J. What causes cryptogenic fibrosing alveolitis? A case-control study of environmental exposure to dust. Br Med J 1990;301:1015-7.
[8] Mannino DM, Etzel RA, Parrish RG. Pulmonary fibrosis deaths in the United States, 1979-1991. An analysis of multiplecause mortality data. Am J Respir Crit Care Med 1996;153: $1548-52$.

[9] Raghu G, Freudenberger TD, Yang S, et al. High prevalence of abnormal acid gastro-esophageal reflux in idiopathic pulmonary fibrosis. Eur Respir J 2006;27:136-42.

[10] Douglas WW, Ryu JH, Schroeder DR. Idiopathic pulmonary fibrosis: impact of oxygen and colchicine, prednisone, or no therapy on survival. Am J Respir Crit Care Med 2000;161:1172-8.

[11] King Jr TE, Tooze JA, Schwarz MI, et al. Predicting survival in idiopathic pulmonary fibrosis: scoring system and survival model. Am J Respir Crit Care Med 2001;164:1171-81.

[12] Cottin V, Cordier JF. Velcro crackles: the key for early diagnosis of idiopathic pulmonary fibrosis? Eur Respir J 2012;40:519-21.

[13] Sellares J, Hernandez-Gonzalez F, Lucena CM, et al. Auscultation of velcro crackles is associated with usual interstitial pneumonia. Medicine (Baltimore) 2016;95:e2573.

[14] Watadani T, Sakai F, Johkoh T, et al. Interobserver variability in the CT assessment of honeycombing in the lungs. Radiology 2013;266:936-44.

[15] Walsh SL, Calandriello L, Sverzellati N, et al. Interobserver agreement for the ATS/ERS/JRS/ALAT criteria for a UIP pattern on CT. Thorax 2016;71:45-51.

[16] Raghu G, Lynch D, Godwin JD, et al. Diagnosis of idiopathic pulmonary fibrosis with high-resolution CT in patients with little or no radiological evidence of honeycombing: secondary analysis of a randomised, controlled trial. Lancet Respir Med 2014;2:277-84.

[17] Raghu G, Wells AU, Nicholson AG, et al. Effect of nintedanib in subgroups of idiopathic pulmonary fibrosis by diagnostic criteria. Am J Respir Crit Care Med 2016.

[18] Cottin V, Capron F, Grenier P, et al. Pneumopathies interstitielles diffuses idiopathiques. Classification de Consensus international multidisciplinaire de l'American thoracic society et de l'European respiratory society, principales entités anatomocliniques et conduite du diagnostic. Rev Mal Respir 2004;21:299-318.

[19] Chung JH, Chawla A, Peljto AL, et al. CT scan findings of probable usual interstitial pneumonitis have a high predictive value for histologic usual interstitial pneumonitis. Chest 2015;147:450-9.

[20] Gruden JF. CT in idiopathic pulmonary fibrosis: diagnosis and beyond. AJR Am J Roentgenol 2016;206:495-507.

[21] Hutchinson JP, Fogarty AW, McKeever TM, et al. In-hospital mortality after surgical lung biopsy for interstitial lung disease in the United States, 2000 to 2011. Am J Respir Crit Care Med 2016;193:1161-7.

[22] Hutchinson JP, McKeever TM, Fogarty AW, et al. Surgical lung biopsy for the diagnosis of interstitial lung disease in England: 1997-2008. Eur Respir J 2016.

[23] Babiak A, Hetzel J, Krishna G, et al. Transbronchial cryobiopsy: a new tool for lung biopsies. Respiration 2009;78:203-8.

[24] Johannson KA, Marcoux VS, Ronksley PE, et al. Diagnostic yield and complications of transbronchial lung cryobiopsy for interstitial lung disease: a systematic review and metaanalysis. Ann Am Thorac Soc 2016.

[25] Ganganah O, Guo SL, Chiniah M, et al. Efficacy and safety of cryobiopsy versus forceps biopsy for interstitial lung diseases and lung tumours: a systematic review and meta-analysis. Respirology 2016.

[26] Poletti V, Benzaquen S. Transbronchial cryobiopsy in diffuse parenchymal lung disease. A new star in the horizon. Sarcoidosis Vasc Diffuse Lung Dis 2014;31:178-81. 
[27] Gershman E, Fruchter O, Benjamin F, et al. Safety of cryotransbronchial biopsy in diffuse lung diseases: analysis of three hundred cases. Respiration 2015;90:40-6.

[28] Poletti V, Casoni GL, Gurioli C, et al. Lung cryobiopsies: a paradigm shift in diagnostic bronchoscopy? Respirology 2014;19:645-54.

[29] Tomassetti S, Wells AU, Costabel U, et al. Bronchoscopic lung cryobiopsy increases diagnostic confidence in the multidisciplinary diagnosis of idiopathic pulmonary fibrosis. Am J Respir Crit Care Med 2015.

[30] American thoracic society, European respiratory society. American thoracic society/European respiratory society international multidisciplinary consensus classification of the idiopathic interstitial pneumonias. This joint statement of the American thoracic society (ATS), and the European respiratory society (ERS) was adopted by the ATS board of directors, June 2001 and by the ERS Executive Committee, June 2001. Am J Respir Crit Care Med 2002;165: 277-304.

[31] Morell F, Villar A, Montero MA, et al. Chronic hypersensitivity pneumonitis in patients diagnosed with idiopathic pulmonary fibrosis: a prospective case-cohort study. Lancet Respir Med 2013;1:685-94.

[32] Jeong YJ, Lee KS, Chung MP, et al. Chronic hypersensitivity pneumonitis and pulmonary sarcoidosis: differentiation from usual interstitial pneumonia using high-resolution computed tomography. Semin Ultrasound CT MR 2014;35:47-58.

[33] Wuyts WA, Cavazza A, Rossi G, et al. Differential diagnosis of usual interstitial pneumonia: when is it truly idiopathic? Eur Respir Rev 2014;23:308-19.

[34] Park JH, Kim DS, Park IN, et al. Prognosis of fibrotic interstitial pneumonia: idiopathic versus collagen vascular disease-related subtypes. Am J Respir Crit Care Med 2007; 175:705-11.

[35] Cottin V. Interstitial lung disease: are we missing formes frustes of connective tissue disease? Eur Respir J 2006;28:893-6.

[36] Lega JC, Reynaud Q, Belot A, et al. Idiopathic inflammatory myopathies and the lung. Eur Respir Rev 2015;24:216-38.

[37] Foulon G, Delaval P, Valeyre D, et al. Anca-associated lung fibrosis: analysis of 17 patients. Respir Med 2008;102:1392-8.

[38] Kang BH, Park JK, Roh JH, et al. Clinical significance of serum autoantibodies in idiopathic interstitial pneumonia. J Korean Med Sci 2013;28:731-7.

[39] Kono M, Nakamura Y, Enomoto N, et al. Usual interstitial pneumonia preceding collagen vascular disease: a retrospective case control study of patients initially diagnosed with idiopathic pulmonary fibrosis. Plos One 2014;9:e94775.

[40] Bonella F, Costabel U. Biomarkers in connective tissue disease-associated interstitial lung disease. Semin Respir Crit Care Med 2014;35:181-200.

[41] Ley B, Brown KK, Collard HR. Molecular biomarkers in idiopathic pulmonary fibrosis. Am J Physiol Lung Cell Mol Physiol 2014;307:L681-91.

[42] Jenkins RG, Simpson JK, Saini G, et al. Longitudinal change in collagen degradation biomarkers in idiopathic pulmonary fibrosis: an analysis from the prospective, multicentre Profile study. Lancet Respir Med 2015;3:462-72.

[43] Meyer KC, Raghu G, Baughman RP, et al. An official American thoracic society clinical practice guideline: the clinical utility of bronchoalveolar lavage cellular analysis in interstitial lung disease. Am J Respir Crit Care Med 2012;185:1004-14.

[44] Ohshimo S, Bonella F, Cui A, et al. Significance of bronchoalveolar lavage for the diagnosis of idiopathic pulmonary fibrosis. Am J Respir Crit Care Med 2009;179:1043-7.

[45] Borie R, Kannengiesser C, Nathan N, et al. Fibroses pulmonaires familiales. Rev Mal Respir 2015;32:413-34.
[46] Steele MP, Speer MC, Loyd JE, et al. Clinical and pathologic features of familial interstitial pneumonia. Am J Respir Crit Care Med 2005;172:1146-52.

[47] Lee HY, Seo JB, Steele MP, et al. High-resolution CT scan findings in familial interstitial pneumonia do not conform to those of idiopathic interstitial pneumonia. Chest 2012;142:1577-83.

[48] Lee HL, Ryu JH, Wittmer MH, et al. Familial idiopathic pulmonary fibrosis: clinical features and outcome. Chest 2005; 127:2034-41.

[49] Newton CA, Batra K, Torrealba J, et al. Telomere-related lung fibrosis is diagnostically heterogeneous but uniformly progressive. Eur Respir J 2016;48:1710-20.

[50] Borie R, Tabeze L, Thabut G, et al. Prevalence and characteristics of TERT and TERC mutations in suspected genetic pulmonary fibrosis. Eur Respir J 2016;48:1721-31.

[51] Diaz de Leon A, Cronkhite JT, Katzenstein AL, et al. Telomere lengths, pulmonary fibrosis and telomerase (TERT) mutations. Plos One 2010;5:e10680.

[52] Cronkhite JT, Xing C, Raghu G, et al. Telomere shortening in familial and sporadic pulmonary fibrosis. Am J Respir Crit Care Med 2008;178:729-37.

[53] Borie R, Kannengiesser C, Hirschi S, et al. Severe hematologic complications after lung transplantation in patients with telomerase complex mutations. J Heart Lung Transplant 2015;34:538-46.

[54] van Moorsel CH, van Oosterhout MF, Barlo NP, et al. Surfactant protein $\mathrm{C}$ mutations are the basis of a significant portion of adult familial pulmonary fibrosis in a dutch cohort. Am J Respir Crit Care Med 2010;182:1419-25.

[55] Diaz de Leon A, Cronkhite JT, Yilmaz C, et al. Subclinical lung disease, macrocytosis, and premature graying in kindreds with telomerase (TERT) mutations. Chest 2011;140:753-63.

[56] Stuart BD, Lee JS, Kozlitina J, et al. Effect of telomere length on survival in patients with idiopathic pulmonary fibrosis: an observational cohort study with independent validation. Lancet Respir Med 2014;2:557-65.

[57] Garcia CK. Running short on time: lung transplant evaluation for telomere-related pulmonary fibrosis. Chest 2015;147:1450-2.

[58] Walsh SL, Wells AU, Desai SR, et al. Multicentre evaluation of multidisciplinary team meeting agreement on diagnosis in diffuse parenchymal lung disease: a case-cohort study. Lancet Respir Med 2016.

[59] Lamas DJ, Kawut SM, Bagiella E, et al. Delayed access and survival in idiopathic pulmonary fibrosis: a cohort study. Am J Respir Crit Care Med 2011;184:842-7.

[60] Wells AU. Any fool can make a rule and any fool will mind it"'. BMC Med 2016;14:23.

[61] Travis WD, Costabel U, Hansell DM, et al. An official american thoracic society/european respiratory society statement: update of the international multidisciplinary classification of the idiopathic interstitial pneumonias. Am J Respir Crit Care Med 2013;188:733-48.

[62] Skolnik K, Ryerson CJ. Unclassifiable interstitial lung disease: a review. Respirology 2016;21:51-6.

[63] Ley B, Collard HR, King Jr TE. Clinical course and prediction of survival in idiopathic pulmonary fibrosis. Am J Respir Crit Care Med 2011;183:431-40.

[64] du Bois RM, Weycker D, Albera C, et al. Forced vital capacity in patients with idiopathic pulmonary fibrosis: test properties and minimal clinically important difference. Am J Respir Crit Care Med 2011;184:1382-9.

[65] du Bois RM, Weycker D, Albera C, et al. Six-minute-walk test in idiopathic pulmonary fibrosis: test validation and minimal clinically important difference. Am J Respir Crit Care Med 2011;183:1231-7. 
[66] du Bois RM, Weycker D, Albera C, et al. Ascertainment of individual risk of mortality for patients with idiopathic pulmonary fibrosis. Am J Respir Crit Care Med 2011;184:459-66.

[67] Ley B, Ryerson CJ, Vittinghoff E, et al. A multidimensional index and staging system for idiopathic pulmonary fibrosis. Ann Intern Med 2012;156:684-91.

[68] Ley B, Bradford WZ, Weycker D, et al. Unified baseline and longitudinal mortality prediction in idiopathic pulmonary fibrosis. Eur Respir J 2015;45:1374-81.

[69] Salisbury ML, Xia M, Zhou Y, et al. Idiopathic pulmonary fibrosis: gender-age-physiology index stage for predicting future lung function decline. Chest 2015.

[70] Ley B, Elicker BM, Hartman TE, et al. Idiopathic pulmonary fibrosis: CT and risk of death. Radiology 2014;273:570-9.

[71] Wells AU, Desai SR, Rubens MB, et al. Idiopathic pulmonary fibrosis: a composite physiologic index derived from disease extent observed by computed tomography. Am J Respir Crit Care Med 2003;167:962-9.

[72] Schmidt SL, Tayob N, Han MK, et al. Predicting pulmonary fibrosis disease course from past trends in pulmonary function. Chest 2014;145:579-85.

[73] Zappala CJ, Latsi PI, Nicholson AG, et al. Marginal decline in forced vital capacity is associated with a poor outcome in idiopathic pulmonary fibrosis. Eur Respir J 2010;35:830-6.

[74] Richeldi L, Ryerson CJ, Lee JS, et al. Relative versus absolute change in forced vital capacity in idiopathic pulmonary fibrosis. Thorax 2012;67:407-11.

[75] Wells AU. Forced vital capacity as a primary end point in idiopathic pulmonary fibrosis treatment trials: making a silk purse from a sow's ear. Thorax 2012.

[76] Aguilaniu B. EFX et pneumopathies interstitielles diffuses : qu'en attendre et quelle place dans la prise en charge ? Lett Pneumol 2016;19:17-20.

[77] Holland AE. Exercise limitation in interstitial lung disease mechanisms, significance and therapeutic options. Chron Respir Dis 2010;7:101-11.

[78] Carter NJ. Pirfenidone: in idiopathic pulmonary fibrosis. Drugs 2011;71:1721-32.

[79] Raghu G, Johnson WC, Lockhart D, et al. Treatment of idiopathic pulmonary fibrosis with a new antifibrotic agent, pirfenidone: results of a prospective, open-label phase II study. Am J Respir Crit Care Med 1999;159:1061-9.

[80] Azuma A, Nukiwa T, Tsuboi E, et al. Double-blind, placebo-controlled trial of pirfenidone in patients with idiopathic pulmonary fibrosis. Am J Respir Crit Care Med 2005;171:1040-7.

[81] Taniguchi H, Ebina M, Kondoh Y, et al. Pirfenidone in idiopathic pulmonary fibrosis. Eur Respir J 2010;35:821-9.

[82] Noble PW, Albera C, Bradford WZ, et al. Pirfenidone in patients with idiopathic pulmonary fibrosis (Capacity): two randomised trials. Lancet 2011;377:1760-9.

[83] King Jr TE, Bradford WZ, Castro-Bernardini S, et al. A phase 3 trial of pirfenidone in patients with idiopathic pulmonary fibrosis. N Engl J Med 2014;370:2083-92.

[84] Vancheri C, du Bois RM. A progression-free end-point for idiopathic pulmonary fibrosis trials: lessons from cancer. Eur Respir J 2013;41:262-9.

[85] Spagnolo P, Del Giovane C, Luppi F, et al. Non-steroid agents for idiopathic pulmonary fibrosis. Cochrane Database Syst Rev 2010:CD003134.

[86] Lederer DJ, Bradford WZ, Fagan EA, et al. Sensitivity analyses of the change in FVC in a phase 3 trial of pirfenidone for idiopathic pulmonary fibrosis. Chest 2015;148:196-201.

[87] Noble PW, Albera C, Bradford WZ, et al. Pirfenidone for idiopathic pulmonary fibrosis: analysis of pooled data from three multinational phase 3 trials. Eur Respir J 2016;47:243-53.

[88] Sugino K, Ishida F, Kikuchi N, et al. Comparison of clinical characteristics and prognostic factors of combined pulmonary fibrosis and emphysema versus idiopathic pulmonary fibrosis alone. Respirology 2014;19:239-45.

[89] Iwasawa T, Ogura T, Sakai F, et al. CT analysis of the effect of pirfenidone in patients with idiopathic pulmonary fibrosis. Eur J Radiol 2014;83:32-8.

[90] Loeh B, Drakopanagiotakis F, Bandelli GP, et al. Intraindividual response to treatment with pirfenidone in idiopathic pulmonary fibrosis. Am J Respir Crit Care Med 2015;191:110-3.

[91] Harari S, Caminati A, Albera C, et al. Efficacy of pirfenidone for idiopathic pulmonary fibrosis: an Italian real life study. Respir Med 2015;109:904-13.

[92] Oltmanns U, Kahn N, Palmowski K, et al. Pirfenidone in idiopathic pulmonary fibrosis: real-life experience from a German tertiary referral center for interstitial lung diseases. Respiration 2014;88:199-207.

[93] Kreuter M. Pirfenidone: an update on clinical trial data and insights from everyday practice. Eur Respir Rev 2014;23:111-7.

[94] Costabel U, Albera C, Bradford WZ. Analysis of lung function and survival in RECAP: An open-label extension study of pirfenidone in patients with idiopathic pulmonary fibrosis. Sarcoid Vasc Diffuse Lung Dis 2014;31:198-205.

[95] Valeyre D, Albera C, Bradford WZ, et al. Comprehensive assessment of the long-term safety of pirfenidone in patients with idiopathic pulmonary fibrosis. Respirology 2014;19:740-7.

[96] Jiang C, Huang H, Liu J, et al. Adverse events of pirfenidone for the treatment of pulmonary fibrosis: a metaanalysis of randomized controlled trials. Plos One 2012;7: e47024.

[97] Behr J, Kreuter M, Hoeper MM, et al. Management of patients with idiopathic pulmonary fibrosis in clinical practice: the Insights-IPF registry. Eur Respir J 2015;46:186-96.

[98] Costabel U, Bendstrup E, Cottin V, et al. Pirfenidone in idiopathic pulmonary fibrosis: expert panel discussion on the management of drug-related adverse events. Adv Ther 2014;31:375-91.

[99] Grimminger F, Gunther A, Vancheri C. The role of tyrosine kinases in the pathogenesis of idiopathic pulmonary fibrosis. Eur Respir J 2015;45:1426-33.

[100] Wollin L, Maillet I, Quesniaux V, et al. Antifibrotic and anti-inflammatory activity of the tyrosine kinase inhibitor nintedanib in experimental models of lung fibrosis. J Pharmacol Exp Ther 2014;349:209-20.

[101] Wollin L, Wex E, Pautsch A, et al. Mode of action of nintedanib in the treatment of idiopathic pulmonary fibrosis. Eur Respir J 2015;45:1434-45.

[102] Hostettler KE, Zhong J, Papakonstantinou E, et al. Antifibrotic effects of nintedanib in lung fibroblasts derived from patients with idiopathic pulmonary fibrosis. Respir Res 2014;15:157.

[103] Rangarajan S, Kurundkar A, Kurundkar D, et al. Novel mechanisms for the antifibrotic action of nintedanib. Am J Respir Cell Mol Biol 2016;54:51-9.

[104] Richeldi L, Costabel U, Selman M, et al. Efficacy of a tyrosine kinase inhibitor in idiopathic pulmonary fibrosis. N Engl J Med 2011;365:1079-87.

[105] Richeldi L, Cottin V, Flaherty KR, et al. Design of the Inpulsis trials: two phase 3 trials of nintedanib in patients with idiopathic pulmonary fibrosis. Respir Med 2014;108:1023-30.

[106] Richeldi L, du Bois RM, Raghu G, et al. Efficacy and safety of nintedanib in idiopathic pulmonary fibrosis. N Engl J Med 2014;370:2071-82.

[107] Costabel U, Inoue Y, Richeldi L, et al. Efficacy of nintedanib in idiopathic pulmonary fibrosis across prespecified subgroups in Inpulsis. Am J Respir Crit Care Med 2016;193:178-85.

[108] Kolb M, Richeldi L, Behr J, et al. Nintedanib in patients with idiopathic pulmonary fibrosis and preserved lung volume. Tho$\operatorname{rax} 2016$ 
[109] Cottin V. Nintedanib: a new treatment for idiopathic pulmonary fibrosis. Clin Invest 2015;5:621-32.

[110] Wuyts WA, Kolb M, Stowasser S, et al. First data on efficacy and safety of nintedanib in patients with idiopathic pulmonary fibrosis and forced vital capacity of $\leq 50 \%$ of predicted value. Lung 2016;194:739-43.

[111] Richeldi L, Cottin V, du Bois RM, et al. Nintedanib in patients with idiopathic pulmonary fibrosis: combined evidence from the Tomorrow and Inpulsis trials. Respir Med 2016.

[112] Delanote I, Wuyts WA, Yserbyt J, et al. Safety and efficacy of bridging to lung transplantation with antifibrotic drugs in idiopathic pulmonary fibrosis: a case series. BMC Pulm Med 2016;16:156.

[113] Albera C, Costabel U, Fagan EA, et al. Efficacy of pirfenidone in patients with idiopathic pulmonary fibrosis with more preserved lung function. Eur Respir J 2016;48:843-51.

[114] Demedts M, Behr J, Buhl R, et al. High-dose acetylcysteine in idiopathic pulmonary fibrosis. N Engl J Med 2005;353:2229-42.

[115] Raghu G, Anstrom KJ, King Jr TE, et al. Prednisone, azathioprine, and $\mathrm{N}$-acetylcysteine for pulmonary fibrosis. N Engl J Med 2012;366:1968-77.

[116] Oldham JM, Ma SF, Martinez FJ, et al. TOLLIP, MUC5B, and the response to $\mathrm{N}$-acetylcysteine among individuals with idiopathic pulmonary fibrosis. Am J Respir Crit Care Med 2015; 192:1475-82.

[117] Behr J, Bendstrup E, Crestani B, et al. Safety and tolerability of acetylcysteine and pirfenidone combination therapy in idiopathic pulmonary fibrosis: a randomised, doubleblind, placebo-controlled, phase 2 trial. Lancet Respir Med 2016;4:445-53.

[118] Nagai S, Kitaichi M, Hamada K, et al. Hospital-based historical cohort study of 234 histologically proven Japanese patients with IPF. Sarcoid Vasc Diffuse Lung Dis 1999;16:209-14.

[119] Gay SE, Kazerooni EA, Toews GB, et al. Idiopathic pulmonary fibrosis: predicting response to therapy and survival. Am J Respir Crit Care Med 1998;157:1063-72.

[120] Winterbauer RH, Hammar SP, Hallman KO, et al. Diffuse interstitial pneumonitis. Clinicopathologic correlations in 20 patients treated with prednisone/azathioprine. Am J Med 1978;65:661-72.

[121] Raghu G, Depaso WJ, Cain K, et al. Azathioprine combined with prednisone in the treatment of idiopathic pulmonary fibrosis: a prospective double-blind, randomized, placebocontrolled clinical trial. Am Rev Respir Dis 1991;144:291-6.

[122] Johnson MA, Kwan S, Snell NJ, et al. Randomised controlled trial comparing prednisolone alone with cyclophosphamide and low dose prednisolone in combination in cryptogenic fibrosing alveolitis. Thorax 1989;44:280-8.

[123] Collard HR, Ryu JH, Douglas WW, et al. Combined corticosteroid and cyclophosphamide therapy does not alter survival in idiopathic pulmonary fibrosis. Chest 2004;125:2169-74.

[124] Pereira CA, Malheiros T, Coletta EM, et al. Survival in idiopathic pulmonary fibrosis-cytotoxic agents compared to corticosteroids. Respir Med 2006;100:340-7.

[125] Hope-Gill BD, Hilldrup S, Davies C, et al. A study of the cough reflex in idiopathic pulmonary fibrosis. Am J Respir Crit Care Med 2003;168:995-1002.

[126] Kubo H, Nakayama K, Yanai M, et al. Anticoagulant therapy for idiopathic pulmonary fibrosis. Chest 2005;128:1475-82.

[127] Noth I, Anstrom KJ, Calvert SB, et al. A placebo-controlled randomized trial of warfarin in idiopathic pulmonary fibrosis. Am J Respir Crit Care Med 2012;186:88-95.

[128] Kreuter M, Wijsenbeek MS, Vasakova M, et al. Unfavourable effects of medically indicated oral anticoagulants on survival in idiopathic pulmonary fibrosis. Eur Respir J 2016;47:1776-84.
[129] Fiorucci E, Lucantoni G, Paone G, et al. Colchicine, cyclophosphamide and prednisone in the treatment of mild-moderate idiopathic pulmonary fibrosis: comparison of three currently available therapeutic regimens. Eur Rev Med Pharmacol Sci 2008;12:105-11.

[130] Antoniou KM, Nicholson AG, Dimadi M, et al. Long-term clinical effects of interferon gamma-1b and colchicine in idiopathic pulmonary fibrosis. Eur Respir J 2006;28: 496-504.

[131] Douglas WW, Ryu JH, Swensen SJ, et al. Colchicine versus prednisone in the treatment of idiopathic pulmonary fibrosis. A randomized prospective study. Am J Respir Crit Care Med 1998;158:220-5.

[132] Grgic A, Lausberg H, Heinrich M, et al. Progression of fibrosis in usual interstitial pneumonia: serial evaluation of the native lung after single lung transplantation. Respiration 2008;76:139-45.

[133] Wahidi MM, Ravenel J, Palmer SM, et al. Progression of idiopathic pulmonary fibrosis in native lungs after single lung transplantation. Chest 2002;121:2072-6.

[134] Raghu G, Brown KK, Bradford WZ, et al. A placebo-controlled trial of interferon gamma-1b in patients with idiopathic pulmonary fibrosis. N Engl J Med 2004;350:125-33.

[135] King Jr TE, Albera C, Bradford WZ, et al. Effect of interferon gamma-1b on survival in patients with idiopathic pulmonary fibrosis (INSPIRE): a multicentre, randomised, placebo-controlled trial. Lancet 2009;374:222-8.

[136] King Jr TE, Behr J, Brown KK, et al. BUILD-1: a randomized placebo-controlled trial of bosentan in idiopathic pulmonary fibrosis. Am J Respir Crit Care Med 2008;177:75-81.

[137] King Jr TE, Brown KK, Raghu G, et al. BUILD-3: a randomized, controlled trial of bosentan in idiopathic pulmonary fibrosis. Am J Respir Crit Care Med 2011;184:92-9.

[138] Raghu G, Million-Rousseau R, Morganti A, et al. Efficacy and safety of macitentan in idiopathic pulmonary fibrosis: results of a prospective, randomized, double-blind, placebocontrolled trial. Am J Respir Crit Care Med 2012;185:A3631.

[139] Raghu G, Behr JB, Egan KKJ, et al. ARTEMIS-IPF: a placebocontrolled trial of ambrisentan in idiopathic pulmonary fibrosis. Am J Respir Crit Care Med 2012;185:A3632.

[140] Raghu G, Brown KK, Costabel U, et al. Treatment of idiopathic pulmonary fibrosis with etanercept: an exploratory, placebocontrolled trial. Am J Respir Crit Care Med 2008;178:948-55.

[141] Raghu G, Martinez FJ, Brown KK, et al. CC-chemokine ligand 2 inhibition in idiopathic pulmonary fibrosis: a phase 2 trial of carlumab. Eur Respir J 2015;46:1740-50.

[142] Raghu G, Brown KK, Collard HR, et al. Efficacy of simtuzumab versus placebo in patients with idiopathic pulmonary fibrosis: a randomised, double-blind, controlled, phase 2 trial. Lancet Respir Med 2017;5:22-32.

[143] Mason DP, Brizzio ME, Alster JM, et al. Lung transplantation for idiopathic pulmonary fibrosis. Ann Thorac Surg 2007;84:1121-8.

[144] Keating D, Levvey B, Kotsimbos T, et al. Lung transplantation in pulmonary fibrosis: challenging early outcomes counterbalanced by surprisingly good outcomes beyond 15 years. Transplant Proc 2009;41:289-91.

[145] Thabut G, Mal H, Castier Y, et al. Survival benefit of lung transplantation for patients with idiopathic pulmonary fibrosis. J Thorac Cardiovasc Surg 2003;126:469-75.

[146] The International society for heart and lung transplantation. Adult lung transplantation statistics; 2015 [26 mai 2016; available from: https://www.ishlt.org/registries/ slides. asp?slides=heartLungRegistry].

[147] Weill D, Benden C, Corris PA, et al. A consensus document for the selection of lung transplant candidates: 2014 - an update from the Pulmonary transplantation council of the 
International society for heart and lung transplantation. J Heart Lung Transplant 2015;34:1-15.

[148] Thabut G, Christie JD, Ravaud P, et al. Survival after bilateral versus single-lung transplantation for idiopathic pulmonary fibrosis. Ann Intern Med 2009;151:767-74.

[149] Chauhan D, Karanam AB, Merlo A, et al. Post-transplant survival in idiopathic pulmonary fibrosis patients concurrently listed for single and double lung transplantation. J Heart Lung Transplant 2016;35:657-60.

[150] Horton MR, Danoff SK, Lechtzin N. Thalidomide inhibits the intractable cough of idiopathic pulmonary fibrosis. Thorax 2008;63:749.

[151] Horton MR, Santopietro V, Mathew L, et al. Thalidomide for the treatment of cough in idiopathic pulmonary fibrosis: a randomized trial. Ann Intern Med 2012;157:398-406.

[152] Kilduff CE, Counter MJ, Thomas GA, et al. Effect of acid suppression therapy on gastroesophageal reflux and cough in idiopathic pulmonary fibrosis: an intervention study. Cough 2014; 10:4

[153] Vainshelboim B, Oliveira J, Fox BD, et al. Long-term effects of a 12-week exercise training program on clinical outcomes in idiopathic pulmonary fibrosis. Lung 2015;193:345-54.

[154] Vainshelboim B, Oliveira J, Yehoshua L, et al. Exercise training-based pulmonary rehabilitation program is clinically beneficial for idiopathic pulmonary fibrosis. Respiration 2014;88:378-88.

[155] Kenn K, Gloeckl R, Behr J. Pulmonary rehabilitation in patients with idiopathic pulmonary fibrosis - a review. Respiration 2013;86:89-99.

[156] Dowman L, Hill CJ, Holland AE. Pulmonary rehabilitation for interstitial lung disease. Cochrane Database Syst Rev 2014;10:CD006322.

[157] Morrison DA, Stovall JR. Increased exercise capacity in hypoxemic patients after long-term oxygen therapy. Chest 1992;102:542-50.

[158] Visca D, Montgomery A, de Lauretis A, et al. Ambulatory oxygen in interstitial lung disease. Eur Respir J 2011;38:987-90.

[159] Frank RC, Hicks S, Duck AM, et al. Ambulatory oxygen in idiopathic pulmonary fibrosis: of what benefit? Eur Respir J 2012;40:269-70.

[160] Nishiyama O, Miyajima H, Fukai Y, et al. Effect of ambulatory oxygen on exertional dyspnea in IPF patients without resting hypoxemia. Respir Med 2013;107:1241-6.

[161] Jennings AL, Davies AN, Higgins JP, et al. A systematic review of the use of opioids in the management of dyspnoea. Thorax 2002; 57:939-44.

[162] Kohberg C, Andersen CU, Bendstrup E. Opioids: an unexplored option for treatment of dyspnea in IPF. Eur Clin Respir J 2016;3:30629.

[163] Allen S, Raut S, Woollard J, et al. Low dose diamorphine reduces breathlessness without causing a fall in oxygen saturation in elderly patients with end-stage idiopathic pulmonary fibrosis. Palliat Med 2005;19:128-30.

[164] Nocturnal oxygen therapy trial group. Continuous or nocturnal oxygen therapy in hypoxemic chronic obstructive lung disease: a clinical trial. Ann Intern Med 1980;93:391-8.

[165] Medical research council working party. Long-term domiciliary oxygen therapy in chronic hypoxic cor pulmonale complicating chronic bronchitis and emphysema. Report of the Medical research council working party. Lancet 1981;1:681-6.

[166] Holland AE, Hill CJ, Conron M, et al. Short term improvement in exercise capacity and symptoms following exercise training in interstitial lung disease. Thorax 2008;63:549-54.

[167] Nishiyama O, Kondoh Y, Kimura T, et al. Effects of pulmonary rehabilitation in patients with idiopathic pulmonary fibrosis. Respirology 2008;13:394-9.
[168] Ferreira A, Garvey C, Connors GL, et al. Pulmonary rehabilitation in interstitial lung disease: benefits and predictors of response. Chest 2009;135:442-7.

[169] Holland AE, Hill CJ, Glaspole I, et al. Predictors of benefit following pulmonary rehabilitation for interstitial lung disease. Respir Med 2012;106:429-35.

[170] Ryerson CJ, Cayou C, Topp F, et al. Pulmonary rehabilitation improves long-term outcomes in interstitial lung disease: a prospective cohort study. Respir Med 2014;108: 203-10.

[171] Kozu R, Senjyu H, Jenkins SC, et al. Differences in response to pulmonary rehabilitation in idiopathic pulmonary fibrosis and chronic obstructive pulmonary disease. Respiration 2011;81:196-205.

[172] Huppmann P, Sczepanski B, Boensch M, et al. Effects of inpatient pulmonary rehabilitation in patients with interstitial lung disease. Eur Respir J 2012.

[173] Rammaert B, Leroy S, Cavestri B, et al. [Home-based pulmonary rehabilitation in idiopathic pulmonary fibrosis]. Rev Mal Respir 2009;26:275-82.

[174] Taillé C. Où meurent les patients atteints de fibrose pulmonaire idiopathique ? Info Respir 2015.

[175] Ahmadi Z, Wysham NG, Lundstrom S, et al. End-of-life care in oxygen-dependent ILD compared with lung cancer: a national population-based study. Thorax 2016;71:510-6.

[176] Bajwah S, Ross JR, Wells AU, et al. Palliative care for patients with advanced fibrotic lung disease: a randomised controlled phase II and feasibility trial of a community case conference intervention. Thorax 2015;70:830-9.

[177] Abernethy AP, McDonald CF, Frith PA, et al. Effect of palliative oxygen versus room air in relief of breathlessness in patients with refractory dyspnoea: a double-blind, randomised controlled trial. Lancet 2010;376:784-93.

[178] Collard HR, Ryerson CJ, Corte TJ, et al. Acute exacerbation of idiopathic pulmonary fibrosis: an International working grup report. Am J Respir Crit Care Med 2016;194:265-75.

[179] Brown AW, Fischer CP, Shlobin OA, et al. Outcomes after hospitalization in idiopathic pulmonary fibrosis: a cohort study. Chest 2015;147:173-9.

[180] Luppi F, Cerri S, Taddei S, et al. Acute exacerbation of idiopathic pulmonary fibrosis: a clinical review. Intern Emerg Med 2015;10:401-11.

[181] Johannson KA, Vittinghoff E, Lee K, et al. Acute exacerbation of idiopathic pulmonary fibrosis associated with air pollution exposure. Eur Respir J 2014;43:1124-31.

[182] Collard HR, Moore BB, Flaherty KR, et al. Acute exacerbations of idiopathic pulmonary fibrosis. Am J Respir Crit Care Med 2007; $176: 636-43$.

[183] Raghu G. Idiopathic pulmonary fibrosis: increased survival with "gastroesophageal reflux therapy": fact or fallacy? Am J Respir Crit Care Med 2011;184:1330-2.

[184] Morawiec E, Tillie-Leblond I, Pansini V, et al. Exacerbations of idiopathic pulmonary fibrosis treated with corticosteroids and cyclophosphamide pulses. Eur Respir J 2011;38:1487-9.

[185] Assistance publique - Hôpitaux de Paris. Cyclophosphamide for acute exacerbation of idiopathic pulmonary fibrosis (EXAFIP); 2016. Available from: https://clinicaltrials. gov/ct2/show/NCT02460588?term=exafip\&rank=1.

[186] Richeldi L. Time for prevention of idiopathic pulmonary fibrosis exacerbation. Ann Am Thorac Soc 2015;12:S181-5.

[187] Trudzinski FC, Kaestner F, Schafers HJ, et al. Outcome of patients with interstitial lung disease treated with extracorporeal membrane oxygenation for acute respiratory failure. Am J Respir Crit Care Med 2015.

[188] Blivet S, Philit F, Sab JM, et al. Outcome of patients with idiopathic pulmonary fibrosis admitted to the ICU for respiratory failure. Chest 2001;120:209-12. 
[189] Kim DS, Park JH, Park BK, et al. Acute exacerbation of idiopathic pulmonary fibrosis: frequency and clinical features. Eur Respir J 2006;27:143-50.

[190] Molina-Molina M, Badia JR, Marin-Arguedas A, et al. [Outcomes and clinical characteristics of patients with pulmonary fibrosis and respiratory failure admitted to an intensive care unit. A study of 20 cases]. Med Clin (Barc) 2003;121: 63-7.

[191] Saydain G, Islam A, Afessa B, et al. Outcome of patients with idiopathic pulmonary fibrosis admitted to the intensive care unit. Am J Respir Crit Care Med 2002;166:839-42.

[192] Nava S, Rubini F. Lung and chest wall mechanics in ventilated patients with end stage idiopathic pulmonary fibrosis. Thorax 1999;54:390-5.

[193] Stern JB, Mal H, Groussard O, et al. Prognosis of patients with advanced idiopathic pulmonary fibrosis requiring mechanical ventilation for acute respiratory failure. Chest 2001;120:213-9.

[194] Al-Hameed FM, Sharma S. Outcome of patients admitted to the intensive care unit for acute exacerbation of idiopathic pulmonary fibrosis. Can Respir J 2004;11:117-22.

[195] Fumeaux T, Rothmeier C, Jolliet P. Outcome of mechanical ventilation for acute respiratory failure in patients with pulmonary fibrosis. Intensive Care Med 2001;27: 1868-74.

[196] Mollica C, Paone G, Conti V, et al. Mechanical ventilation in patients with end-stage idiopathic pulmonary fibrosis. Respiration 2010;79:209-15.

[197] Rangappa P, Moran JL. Outcomes of patients admitted to the intensive care unit with idiopathic pulmonary fibrosis. Crit Care Resusc 2009;11:102-9.

[198] Mallick S. Outcome of patients with idiopathic pulmonary fibrosis (IPF) ventilated in intensive care unit. Respir Med 2008;102:1355-9.

[199] Rush B, Wiskar K, Berger L, et al. The use of mechanical ventilation in patients with idiopathic pulmonary fibrosis in the United States: a nationwide retrospective cohort analysis. Respir Med 2016;111:72-6.

[200] Gaudry S, Vincent F, Rabbat A, et al. Invasive mechanical ventilation in patients with fibrosing interstitial pneumonia. J Thorac Cardiovasc Surg 2014;147:47-53.

[201] Yokoyama T, Kondoh Y, Taniguchi H, et al. Noninvasive ventilation in acute exacerbation of idiopathic pulmonary fibrosis. Intern Med 2010;49:1509-14.

[202] Mullier A, Cottin V, Richard JC, et al. Fibrose pulmonaire : dans quels cas et sur quels critères envisager une admission en réanimation? Reanimation 2013:45-53.

[203] Nathan SD, Cottin V. Pulmonary hypertension in patients with idiopathic pulmonary fibrosis. Eur Respir Mon 2012;57:148-60.

[204] Shorr AF, Wainright JL, Cors CS, et al. Pulmonary hypertension in patients with pulmonary fibrosis awaiting lung transplant. Eur Respir J 2007;30:715-21.

[205] Lettieri CJ, Nathan SD, Barnett SD, et al. Prevalence and outcomes of pulmonary arterial hypertension in advanced idiopathic pulmonary fibrosis. Chest 2006;129:746-52.

[206] Judge EP, Fabre A, Adamali HI, et al. Acute exacerbations and pulmonary hypertension in advanced idiopathic pulmonary fibrosis. Eur Respir J 2012;40:93-100.

[207] Nathan SD, Shlobin OA, Barnett SD, et al. Right ventricular systolic pressure by echocardiography as a predictor of pulmonary hypertension in idiopathic pulmonary fibrosis. Respir Med 2008;102:1305-10.

[208] Swanson KL, Utz JP, Krowka MJ. Doppler echocardiographyright heart catheterization relationships in patients with idiopathic pulmonary fibrosis and suspected pulmonary hypertension. Med Sci Monit 2008;14:CR177-82.
[209] Arcasoy SM, Christie JD, Ferrari VA, et al. Echocardiographic assessment of pulmonary hypertension in patients with advanced lung disease. Am J Respir Crit Care Med 2003;167:735-40.

[210] Devaraj A, Wells AU, Meister MG, et al. The effect of diffuse pulmonary fibrosis on the reliability of $\mathrm{CT}$ signs of pulmonary hypertension. Radiology 2008;249:1042-9.

[211] Leuchte HH, Baumgartner RA, Nounou ME, et al. Brain natriuretic peptide is a prognostic parameter in chronic lung disease. Am J Respir Crit Care Med 2006;173:744-50.

[212] Zisman DA, Karlamangla AS, Kawut SM, et al. Validation of a method to screen for pulmonary hypertension in advanced idiopathic pulmonary fibrosis. Chest 2008;133:640-5.

[213] Galie N, Humbert M, Vachiery JL, et al. 2015 ESC/ERS Guidelines for the diagnosis and treatment of pulmonary hypertension: the Joint Task Force for the diagnosis and treatment of pulmonary hypertension of the European society of cardiology (ESC) and the European respiratory society (ERS): Endorsed by: Association for European paediatric and congenital cardiology (AEPC), International society for heart and lung transplantation (ISHLT). Eur Respir J 2015;46:903-75.

[214] Seeger W, Adir Y, Barbera JA, et al. Pulmonary hypertension in chronic lung diseases. J Am Coll Cardiol 2013;62:D109-16.

[215] Nathan SD, King CS. Treatment of pulmonary hypertension in idiopathic pulmonary fibrosis: shortfall in efficacy or trial design? Drug Des Devel Ther 2014;8:875-85.

[216] Minai OA, Sahoo D, Chapman JT, et al. Vaso-active therapy can improve 6-min walk distance in patients with pulmonary hypertension and fibrotic interstitial lung disease. Respir Med 2008;102:1015-20.

[217] Corte TJ, Keir GJ, Dimopoulos K, et al. Bosentan in pulmonary hypertension associated with fibrotic idiopathic interstitial pneumonia. Am J Respir Crit Care Med 2014;190:208-17.

[218] Raghu G, Nathan SD, Behr J, et al. Pulmonary hypertension in idiopathic pulmonary fibrosis with mild-to-moderate restriction. Eur Respir J 2015;46:1370-7.

[219] Ghofrani HA, Wiedemann R, Rose F, et al. Sildenafil for treatment of lung fibrosis and pulmonary hypertension: a randomised controlled trial. Lancet 2002;360:895-900.

[220] Madden BP, Allenby M, Loke TK, et al. A potential role for sildenafil in the management of pulmonary hypertension in patients with parenchymal lung disease. Vascul Pharmacol 2006;44:372-6.

[221] Collard HR, Anstrom KJ, Schwarz MI, et al. Sildenafil improves walk distance in idiopathic pulmonary fibrosis. Chest 2007;131:897-9.

[222] Zisman DA, Schwarz M, Anstrom KJ, et al. A controlled trial of sildenafil in advanced idiopathic pulmonary fibrosis. N Engl J Med 2010;363:620-8.

[223] Han MK, Bach DS, Hagan PG, et al. Sildenafil preserves exercise capacity in patients with idiopathic pulmonary fibrosis and right-sided ventricular dysfunction. Chest 2013;143:1699-708.

[224] Hoeper MM, Behr J, Held M, et al. Pulmonary hypertension in patients with chronic fibrosing idiopathic interstitial pneumonias. Plos One 2015;10:e0141911.

[225] Hoeper MM, Halank M, Wilkens H, et al. Riociguat for interstitial lung disease and pulmonary hypertension: a pilot trial. Eur Respir J 2013;41:853-60.

[226] Savarino E, Carbone R, Marabotto E, et al. Gastrooesophageal reflux and gastric aspiration in idiopathic pulmonary fibrosis patients. Eur Respir J 2013;42:1322-31.

[227] Noth I, Zangan SM, Soares RV, et al. Prevalence of hiatal hernia by blinded multidetector CT in patients with idiopathic pulmonary fibrosis. Eur Respir J 2012;39:344-51.

[228] Tossier C, Dupin C, Plantier L, et al. Hiatal hernia on thoracic computed tomography in pulmonary fibrosis. Eur Respir J 2016;48:833-42. 
[229] Tobin RW, Pope CE, Pellegrini CA, et al. Increased prevalence of gastroesophageal reflux in patients with idiopathic pulmonary fibrosis. Am J Respir Crit Care Med 1998;158: 1804-8.

[230] Sweet MP, Patti MG, Leard LE, et al. Gastroesophageal reflux in patients with idiopathic pulmonary fibrosis referred for lung transplantation. J Thorac Cardiovasc Surg 2007;133:1078-84.

[231] Tcherakian C, Cottin V, Brillet PY, et al. Progression of idiopathic pulmonary fibrosis: lessons from asymmetrical disease. Thorax 2011;66:226-31.

[232] Lee JS, Collard HR, Raghu G, et al. Does chronic microaspiration cause idiopathic pulmonary fibrosis? Am J Med 2010;123:304-11.

[233] Linden PA, Gilbert RJ, Yeap BY, et al. Laparoscopic fundoplication in patients with end-stage lung disease awaiting transplantation. J Thorac Cardiovasc Surg 2006;131: 438-46.

[234] Lee JS, Ryu JH, Elicker BM, et al. Gastroesophageal reflux therapy is associated with longer survival in patients with idiopathic pulmonary fibrosis. Am J Respir Crit Care Med 2011;184:1390-4.

[235] Raghu G, Meyer KC. Silent gastro-oesophageal reflux and microaspiration in IPF: mounting evidence for anti-reflux therapy? Eur Respir J 2012;39:242-5.

[236] Lee JS, Collard HR, Anstrom KJ, et al. Anti-acid treatment and disease progression in idiopathic pulmonary fibrosis: an analysis of data from three randomised controlled trials. Lancet Respir Med 2013;1:369-76.

[237] Kreuter M, Wuyts W, Renzoni E, et al. Antacid therapy and disease outcomes in idiopathic pulmonary fibrosis: a pooled analysis. Lancet Respir Med 2016.

[238] DeVault KR, Castell DO. Updated guidelines for the diagnosis and treatment of gastroesophageal reflux disease. Am J Gastroenterol 2005;100:190-200.

[239] Arai T, Inoue Y, Sasaki Y, et al. Predictors of the clinical effects of pirfenidone on idiopathic pulmonary fibrosis. Respir Investig 2014;52:136-43.

[240] Mejia M, Carrillo G, Rojas-Serrano J, et al. Idiopathic pulmonary fibrosis and emphysema: decreased survival associated with severe pulmonary arterial hypertension. Chest 2009;136:10-5.

[241] Cottin V, Nunes H, Brillet PY, et al. Combined pulmonary fibrosis and emphysema: a distinct underrecognised entity. Eur Respir J 2005;26:586-93.

[242] Cottin V, Le Pavec J, Prevot G, et al. Pulmonary hypertension in patients with combined pulmonary fibrosis and emphysema syndrome. Eur Respir J 2010;35:105-11.

[243] Cottin V, Cordier JF. Combined pulmonary fibrosis and emphysema: an experimental and clinically relevant phenotype. Am J Respir Crit Care Med 2005;172:1605, author reply - 6 .

[244] Akagi T, Matsumoto T, Harada T, et al. Coexistent emphysema delays the decrease of vital capacity in idiopathic pulmonary fibrosis. Respir Med 2009;103:1209-15.

[245] Schmidt SL, Nambiar AM, Tayob N, et al. Pulmonary function measures predict mortality differently in IPF versus combined pulmonary fibrosis and emphysema. Eur Respir J 2011;38:176-83.

[246] Cottin V, Taniguchi H, Richeldi L, et al. Effect of baseline emphysema on reduction in FVC decline with nintedanib in the Inpulsis(trials. In: 18th International colloquium on lung and airway fibrosis. 2014.

[247] Clark M, Cooper B, Singh S, et al. A survey of nocturnal hypoxaemia and health related quality of life in patients with cryptogenic fibrosing alveolitis. Thorax 2001;56:482-6.

[248] Aydogdu M, Ciftci B, Firat Guven S, et al. [Assessment of sleep with polysomnography in patients with interstitial lung disease]. Tuberk Toraks 2006;54:213-21.
[249] Mermigkis C, Chapman J, Golish J, et al. Sleep-related breathing disorders in patients with idiopathic pulmonary fibrosis. Lung 2007;185:173-8.

[250] Lancaster LH, Mason WR, Parnell JA, et al. Obstructive sleep apnea is common in idiopathic pulmonary fibrosis. Chest 2009;136:772-8.

[251] Mermigkis C, Bouloukaki I, Antoniou K, et al. Obstructive sleep apnea should be treated in patients with idiopathic pulmonary fibrosis. Sleep Breath 2015;19:385-91.

[252] Series F, Cormier Y, Lampron N, et al. Increasing the functional residual capacity may reverse obstructive sleep apnea. Sleep 1988;11:349-53.

[253] Heinzer RC, Stanchina ML, Malhotra A, et al. Lung volume and continuous positive airway pressure requirements in obstructive sleep apnea. Am J Respir Crit Care Med 2005;172:114-7.

[254] Société de pneumologie de langue française, Société française d'anesthésie réanimation, Société française de cardiologie SFdMdT, Société française d'ORL, Société de physiologie, Société française de recherche et de médecine du sommeil. Recommandations pour la pratique clinique. Syndrome d'apnées hypopnées obstructives du sommeil de l'adulte. Rev Mal Respir 2010;27:806-33.

[255] Hubbard R, Venn A, Lewis S, et al. Lung cancer and cryptogenic fibrosing alveolitis. A population-based cohort study. Am J Respir Crit Care Med 2000;161:5-8.

[256] Turner-Warwick ME, Burrows B, Johnson A. Cryptogenic fibrosing alveolitis: clinical features and their influence on survival. Thorax 1980;35:171-80.

[257] Harris JM, Johnston ID, Rudd R, et al. Cryptogenic fibrosing alveolitis and lung cancer: the BTS study. Thorax 2010;65:70-6.

[258] Ozawa Y, Suda T, Naito T, et al. Cumulative incidence of and predictive factors for lung cancer in IPF. Respirology 2009;14:723-8.

[259] Tomassetti S, Gurioli C, Ryu JH, et al. The impact of lung cancer on survival of idiopathic pulmonary fibrosis. Chest 2015;147:157-64.

[260] Kreuter M, Ehlers-Tenenbaum S, Palmowski K, et al. Impact of comorbidities on mortality in patients with idiopathic pulmonary fibrosis. Plos One 2016;11:e0151425.

[261] Girard N, Marchand-Adam S, Naccache JM, et al. Lung cancer in combined pulmonary fibrosis and emphysema: a series of 47 Western patients. J Thorac Oncol 2014;9:1162-70.

[262] Oh SY, Kim MY, Kim JE, et al. Evolving early lung cancers detected during follow-up of idiopathic interstitial pneumonia: serial CT features. AJR Am J Roentgenol 2015;204:1190-6.

[263] Fell CD. Idiopathic pulmonary fibrosis: phenotypes and comorbidities. Clin Chest Med 2012;33:51-7.

[264] Sato T, Teramukai S, Kondo H, et al. Impact and predictors of acute exacerbation of interstitial lung diseases after pulmonary resection for lung cancer. J Thorac Cardiovasc Surg 2014;147, 1604-11 e3.

[265] Iwata T, Yoshida S, Nagato K, et al. Experience with perioperative pirfenidone for lung cancer surgery in patients with idiopathic pulmonary fibrosis. Surg Today 2015;45:1263-70.

[266] Ueki N, Matsuo Y, Togashi Y, et al. Impact of pretreatment interstitial lung disease on radiation pneumonitis and survival after stereotactic body radiation therapy for lung cancer. $\mathrm{J}$ Thorac Oncol 2015;10:116-25.

[267] Yamaguchi S, Ohguri T, Ide S, et al. Stereotactic body radiotherapy for lung tumors in patients with subclinical interstitial lung disease: the potential risk of extensive radiation pneumonitis. Lung Cancer 2013;82:260-5.

[268] Sekine A, Tamura K, Satoh $\mathrm{H}$, et al. Prevalence of underlying lung disease in smokers with epidermal growth factor receptor-mutant lung cancer. Oncol Rep 2013;29: 2005-10. 
[269] Usui K, Ushijima T, Tanaka Y, et al. The frequency of epidermal growth factor receptor mutation of non small cell lung cancer according to the underlying pulmonary diseases. Pulm Med 2011;2011:290132.

[270] Fujimoto D, Tomii K, Otoshi T, et al. Preexisting interstitial lung disease is inversely correlated to tumor epidermal growth factor receptor mutation in patients with lung adenocarcinoma. Lung Cancer 2013;80:159-64.

[271] Primiani A, Dias-Santagata D, lafrate AJ, et al. Pulmonary adenocarcinoma mutation profile in smokers with smokingrelated interstitial fibrosis. Int J Chron Obstruct Pulmon Dis 2014;9:525-31.

[272] Qi WX, Sun YJ, Shen Z, et al. Risk of interstitial lung disease associated with EGFR-TKIs in advanced non-small-cell lung cancer: a meta-analysis of 24 phase III clinical trials. J Chemother 2015;27:40-51.

[273] Burotto M, Manasanch EE, Wilkerson J, et al. Gefitinib and erlotinib in metastatic non-small cell lung cancer: a metaanalysis of toxicity and efficacy of randomized clinical trials. Oncologist 2015;20:400-10.

[274] Shukuya T, Ishiwata T, Hara M, et al. Carboplatin plus weekly paclitaxel treatment in non-small cell lung cancer patients with interstitial lung disease. Anticancer Res 2010;30:4357-61.

[275] Minegishi Y, Sudoh J, Kuribayasi H, et al. The safety and efficacy of weekly paclitaxel in combination with carboplatin for advanced non-small cell lung cancer with idiopathic interstitial pneumonias. Lung Cancer 2011;71:70-4.

[276] Okuda K, Hirose T, Oki Y, et al. Evaluation of the safety and efficacy of combination chemotherapy with vinorelbine and platinum agents for patients with non-small cell lung cancer with interstitial lung disease. Anticancer Res 2012;32:5475-80.

[277] Watanabe N, Taniguchi H, Kondoh Y, et al. Efficacy of chemotherapy for advanced non-small cell lung cancer with idiopathic pulmonary fibrosis. Respiration 2013;85:326-31.

[278] Shimizu R, Fujimoto D, Kato R, et al. The safety and efficacy of paclitaxel and carboplatin with or without bevacizumab for treating patients with advanced nonsquamous non-small cell lung cancer with interstitial lung disease. Cancer Chemother Pharmacol 2014;74:1159-66.

[279] Choi MK, Hong JY, Chang W, et al. Safety and efficacy of gemcitabine or pemetrexed in combination with a platinum in patients with non-small-cell lung cancer and prior interstitial lung disease. Cancer Chemother Pharmacol 2014;73:1217-25.

[280] Kenmotsu H, Naito T, Kimura M, et al. The risk of cytotoxic chemotherapy-related exacerbation of interstitial lung disease with lung cancer. J Thorac Oncol 2011;6:1242-6.

[281] Minegishi $\mathrm{Y}$, Kuribayashi H, Kitamura K, et al. The feasibility study of carboplatin plus etoposide for advanced small cell lung cancer with idiopathic interstitial pneumonias. J Thorac Oncol 2011;6:801-7.

[282] Yoshida T, Yoh K, Goto K, et al. Safety and efficacy of platinum agents plus etoposide for patients with small cell lung cancer with interstitial lung disease. Anticancer Res 2013;33:1175-9.

[283] Watanabe N, Taniguchi H, Kondoh Y, et al. Chemotherapy for extensive-stage small-cell lung cancer with idiopathic pulmonary fibrosis. Int J Clin Oncol 2014;19:260-5.

[284] Miyazaki K, Satoh H, Kurishima K, et al. Interstitial lung disease in patients with small cell lung cancer. Med Oncol 2010;27:763-7.

[285] Togashi Y, Masago K, Handa T, et al. Prognostic significance of preexisting interstitial lung disease in Japanese patients with small-cell lung cancer. Clin Lung Cancer 2012;13:304-11.

[286] Raghu G, Amatto VC, Behr J, et al. Comorbidities in idiopathic pulmonary fibrosis patients: a systematic literature review. Eur Respir J 2015;46:1113-30.

[287] Vancheri C, Cottin V, Kreuter M, et al. IPF, comorbidities and management implications. Sarcoidosis Vasc Diffuse Lung Dis 2015;32:17-23.

[288] Hyldgaard C, Hilberg O, Bendstrup E. How does comorbidity influence survival in idiopathic pulmonary fibrosis? Respir Med 2014;108:647-53.

[289] Navaratnam V, Fogarty AW, McKeever T, et al. Presence of a prothrombotic state in people with idiopathic pulmonary fibrosis: a population-based case-control study. Thorax 2014;69:207-15.

[290] Collard HR, Ward AJ, Lanes S, et al. Burden of illness in idiopathic pulmonary fibrosis. J Med Econ 2012;15:829-35.

[291] Armanios M, Price C. Telomeres and disease: an overview. Mutat Res 2012;730:1-2.

[292] Stanley SE, Gable DL, Wagner CL, et al. Loss-of-function mutations in the RNA biogenesis factor NAF1 predispose to pulmonary fibrosis-emphysema. Sci Transl Med 2016;8:351ra107.

[293] Stuart BD, Choi J, Zaidi S, et al. Exome sequencing links mutations in PARN and RTEL1 with familial pulmonary fibrosis and telomere shortening. Nat Genet 2015;47:512-7.

[294] Kannengiesser C, Borie R, Menard C, et al. Heterozygous RTEL1 mutations are associated with familial pulmonary fibrosis. Eur Respir J 2015;46:474-85.

[295] Hodgson U, Pulkkinen V, Dixon M, et al. ELMOD2 is a candidate gene for familial idiopathic pulmonary fibrosis. Am J Hum Genet 2006;79:149-54.

[296] Zamora AC, Collard HR, Wolters PJ, et al. Neurofibromatosisassociated lung disease: a case series and literature review. Eur Respir J 2007;29:210-4.

[297] Hamvas A, Deterding RR, Wert SE, et al. Heterogeneous pulmonary phenotypes associated with mutations in the thyroid transcription factor gene NKX2-1. Chest 2013;144:794-804.

[298] Dell'Angelica EC, Shotelersuk V, Aguilar RC, et al. Altered trafficking of lysosomal proteins in Hermansky-Pudlak syndrome due to mutations in the beta $3 \mathrm{~A}$ subunit of the AP-3 adaptor. Mol Cell 1999;3:11-21.

[299] Mercier S, Kury S, Shaboodien G, et al. Mutations in FAM111B cause hereditary fibrosing poikiloderma with tendon contracture, myopathy, and pulmonary fibrosis. Am J Hum Genet 2013;93:1100-7. 